\title{
oroduction laitiere
}

\section{au canada}

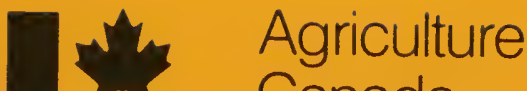

PUBLICATION 1439 1972
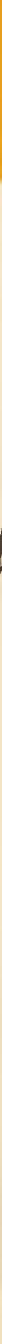


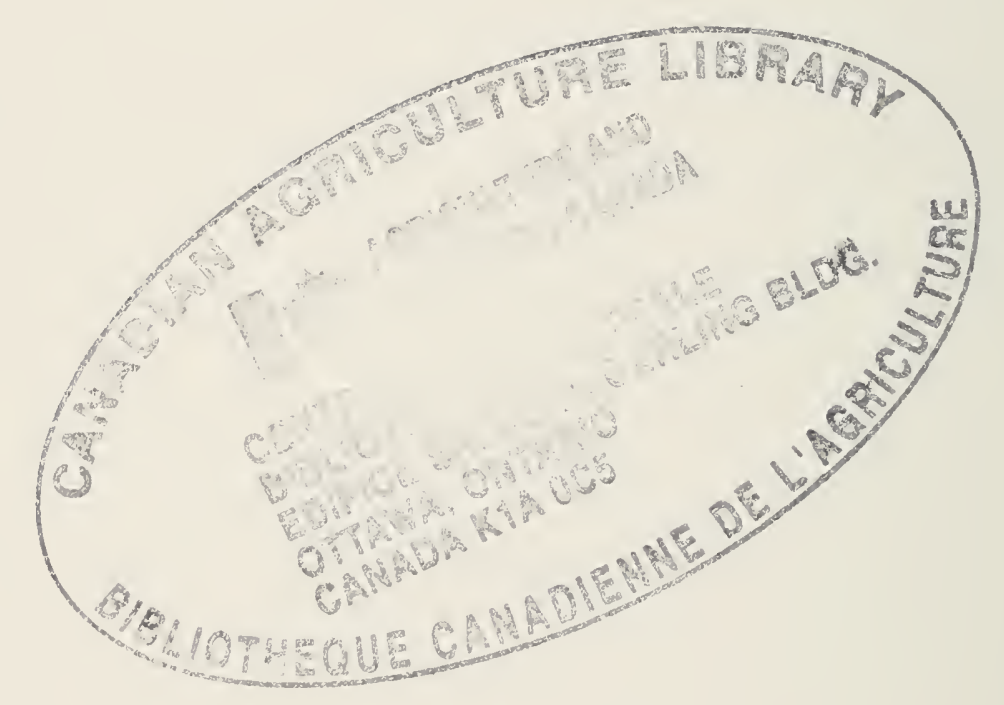


ADDENDA à la publication 1439 (Production laitière au Canada)

JUL 291976

Le tableau 1 (page 7) est remplacé par le suivant:

TABLEAU 1

Nombre d'enregistrements et nombre d'inscriptions au contrôle d'aptitudes de bovins laitiers par race au Canada - 1975

\begin{tabular}{lrrrr}
\hline Race & $\begin{array}{c}\text { Nombre } \\
\text { d'enregis- } \\
\text { trements }\end{array}$ & $\begin{array}{c}\text { Pourcentage } \\
\text { du total }\end{array}$ & $\begin{array}{c}\text { Nombre } \\
\text { d'inscriptions } \\
\text { su controle } \\
\text { d'aptitudes }\end{array}$ & $\begin{array}{c}\text { Pourcentage } \\
\text { du total } \\
\text { mis à } \\
\text { I'eprouve }\end{array}$ \\
\hline Ayrshire - - - & 8319 & 7.0 & 19100 & 9.4 \\
Suisse brune - - & 2162 & 1.8 & 620 & .3 \\
Guernsey - - & 2347 & 1.9 & 5860 & 2.7 \\
Holstein-Frisonne - & 101368 & 83.8 & 169500 & 81.3 \\
Jersey - - - - & 5951 & 4.9 & 10700 & 5.1 \\
Canadienne- - - & 779 & .6 & 2600 & 1.2 \\
\hline
\end{tabular}

Le tableau 2 (page 8) est remplacé par le suivant:

TABLEAU 2

Production des vaches inscrites au contrôle d'aptitudes au Canåda $-1975^{1}$

\begin{tabular}{|c|c|c|c|c|}
\hline \multirow[b]{2}{*}{ Race } & \multirow{2}{*}{$\begin{array}{c}\text { Nombre } \\
\text { de } \\
\text { releves }\end{array}$} & \multicolumn{3}{|c|}{ Production moyenne } \\
\hline & & Lait (Ib) & MG (\%) & MG (Ib) \\
\hline Ayrshire $---\cdots$ & 14318 & 10272 & 4.01 & 412 \\
\hline Suisse brune ---- & 443 & 10861 & 4.15 & 451 \\
\hline Guernsey - - - - - & 4335 & 9473 & 4.81 & 456 \\
\hline Holstein-Frisonne - - & 119931 & 12872 & 3.73 & 480 \\
\hline Jersey ------ & 7991 & 8086 & 5.21 & 421 \\
\hline Red Poll ----- & 23 & 8144 & 3.95 & 322 \\
\hline Shorthorn à deux fins - & 349 & 8315 & 3.82 & 318 \\
\hline Canadienne $\quad----$ & 1779 & 7413 & 4.34 & 322 \\
\hline
\end{tabular}

1 Production relle en 305 jours.

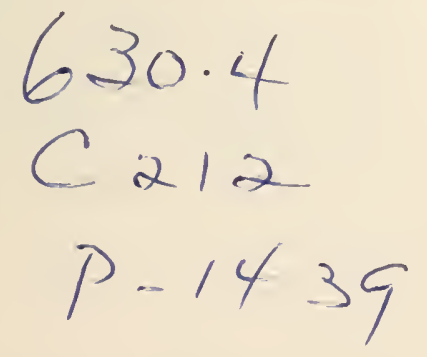





\section{ADDENDA à la publication 1439 (Production laitière au Canada)}

Le paragraphe suivant doit être ajouté à la page 9; il doit précéder immédiatement la rubrique "Contrôle d'aptitudes".

\section{Conseil canadien du contrôle laitier}

Le Conseil, créé en 1974, a pour tâche d'élaborer et de normaliser des méthodes de contrôle laitier. II se compose de représentants de chaque programme provincial de contrôle, de la Fédération des producteurs de lait du Canada, du Comité mixte des associations d'éleveurs de bovins laitiers de race, des principaux organismes d'éleveurs de bovins laitiers, du secteur de l'insémination artificielle et du ministère de l'Agriculture du Canada. En outre, il a à sa disposition un Comité technique, qui agit à titre de conseiller scientifique. 
Digitized by the Internet Archive in 2012 with funding from

Agriculture and Agri-Food Canada - Agriculture et Agroalimentaire Canada 



\section{$630.4 \mathrm{C} 212 \mathrm{P} 14391972 \mathrm{fr} . \mathrm{C.1}$}

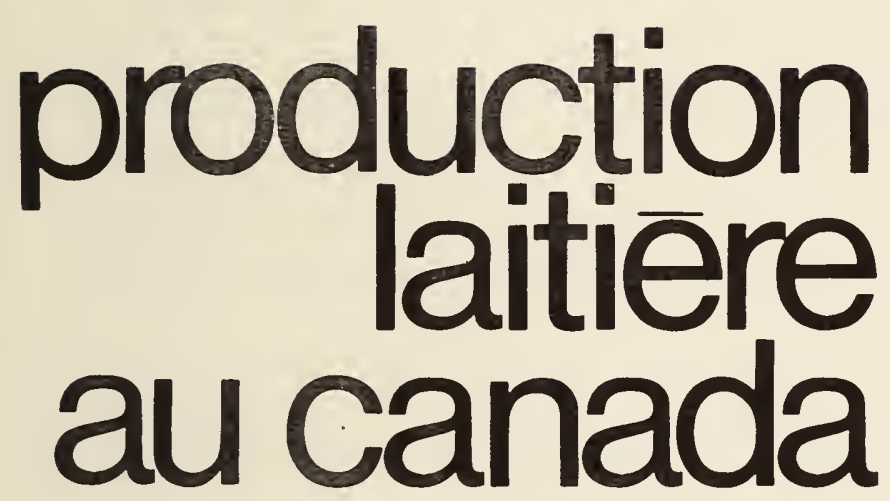

MINISTÈRE DE L'AGRICULTURE DU CANADA PUBLICATION 14391972

La brochure Dairy Husbandry in Ontario, publication $\mathrm{n}^{0} 519$ du ministère de l'Agriculture et de l'Alimentation de la province de l'Ontario, a été publiée pour la première fois en 1957, et, depuis lors, elle est en grande demande.

Le ministère fédéral de l'Agriculture avec la permission des auteurs, de l'Université de Guelph et du ministère de l'Agriculture et de l'Alimentation de l'Ontario en a fait la mise à jour, la traduction et la rédaction à l'intention $\mathrm{du}$ public de langue française. 
On peut obtenir des exemplaires de cette publication à la DIVISION DE L'INFORMATION

MINISTĖRE DE L'AGRICULTURE DU CANADA

OTTAWA

K1A 0C7

\section{INFORMATION CANADA, OTTAWA, 1972}

Imprimé 1972

Réimprimé 1975

$10 \mathrm{M}-37014-1: 75$

No. de cat.: A63-1439F

Kromar Printing (1969) Ltd. contract number OKT4-1685 
AVANT-PROPOS

SITUATION DE LA PRODUCTION LAITIERE AU CANADA …..... 5

AMELIORATION DES BOVINS LAITIERS _ _....................... 9

METHODES DE CONTROLE LAITIER ...................................... 10

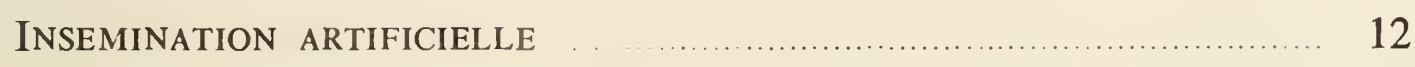

PROGRAMMES D'AMELIORATION DES RACES ……............................ 13

SELECTION DES BOVINS LAITIERS …....................................... 15

BESOINS ALIMENTAIRES DES BOVINS LAITIERS …............ 26

CARACTERISTIQUES DES ALIMENTS DU BETAIL ……......... 32

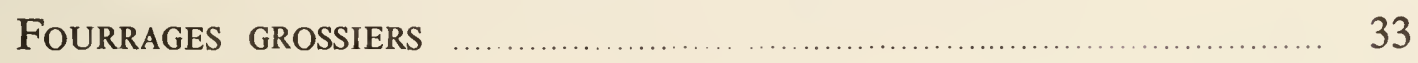

CONCENTRES

ALIMENTATION DES VACHES LAITIERES ….......................... 38

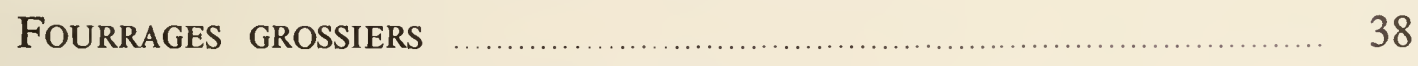

Programme D'AFFouragement EN ETE ……................................. 39

COMPLEMENTS DES FOURRAGES ……....................................... 43

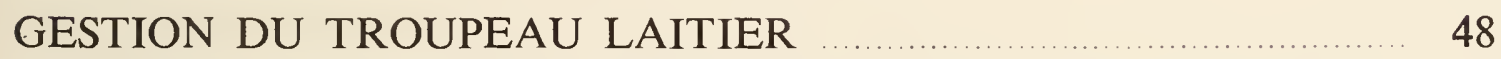

ALIMENTATION ET ENTRETIEN DES VACHES TARIES …....... 51

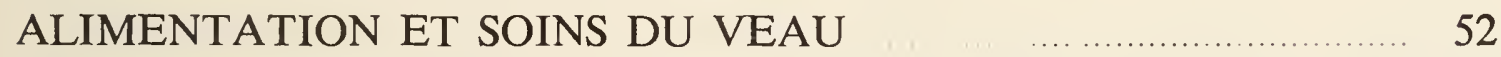

ALIMENTATION DES GENISSES _....................................... 57

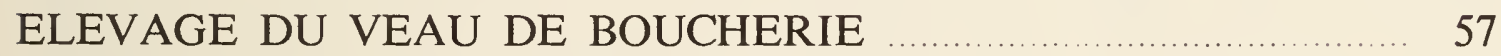

SANTE DU TROUPEAU

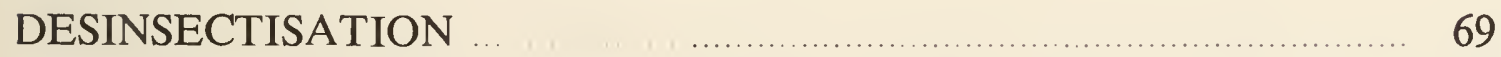

LOGEMENT DU TROUPEAU LAITIER …........................... 71

ORganisATION DE L'ETABLE A STALLES .................................... 73

STOCKAGE DES ALIMENTS ........................................................ 74

AERATION

STABULATION LIBRE A LOGETTES ……........................................ 76

LOGEMENT DES JEUNES ANIMAUX ET DES VACHES TARIES …............ 80

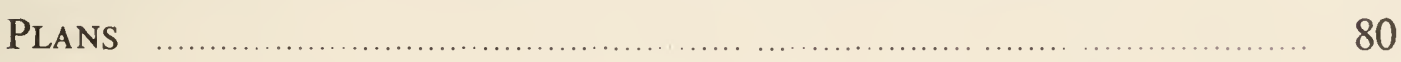

ANNEXES 



\section{AVANT-PROPOS}

$\mathrm{Vu}$ son apport au bien-être de l'homme, la vache laitière est dite assez justement la nourrice du genre humain. Créature docile, dont les dispositions à ruminer en feraient, aux yeux des profanes, le modèle de la simplicité, la vache, tout au contraire, est un être étonnamment complexe, apte à consommer des matières premières de qualité inférieure et à les transformer, par un processus secret, en l'un des aliments naturels les plus riches en valeur nutritive.

La vache contribue non seulement à assurer l'équilibre alimentaire de l'homme, mais encore à relever la situation financière des agriculteurs qui choisissent d'écouler leurs récoltes par cet intermédiaire. Néanmoins, son rendement varie avec les conditions de son exploitation. Pour produire abondamment, la vache demande une alimentation appropriée en plus d'un logement convenable, de soins suffisants et d'intervention compétente en cas de maladie ou d'infestation parasitaire. La présente publication a donc pour but de fournir aux personnes vouées à la production laitière, les informations de nature, si elles sont utilisés judicieusement, à accroître la rentabilité des exploitations.

La texte suivant a été rédigé en collaboration avec des membres du personnel du Collège d'agriculture de l'Ontario, du Collège de médecine vétérinaire de l'Ontario, Université de Guelph, ainsi que de la Direction des bestiaux, ministère de l'Agriculture et de l'Alimentation de l'Ontario, Toronto.

\section{SITUATION DE LA PRODUCTION LAITIERE AU CANADA}

Depuis plus d'un siècle, la production laitière tient une place importante dans l'économie du pays. Un peu plus de la moitié des fermes énumérées, lors du recensement de 1966, gardaient un troupeau laitier. En 1969, 44\% de tous les bovins d'élevage du Canada, âgés d'un an et plus, étaient exploités en vue de la production laitière. Il restait donc $56 \%$ des animaux d'élevage destinés à la production du boeuf. Ces chiffres ne comprennent pas les bouvillons à l'engraissement, lesquels proviennent pour un grand nombre des troupeaux laitiers.

La ferme familiale a toujours occupé une place prépondérante dans l'agriculture canadienne. La production laitière convient bien à ce mode l'exploitation. En effet, les bovins laitiers fournissent deux sources de revenus.

Bien que la vente du lait soit la principale, les recettes provenant de la vente des vaches laitières taries, des vaches excédentaires, des génisses et des veaux de lait constituent aussi un appoint appréciable.

La production laitière est une spéculation très importante. Elle contribue pour une grande partie au total des recettes agricoles. En 1968, les producteurs de lait du Canada ont reçu $\$ 643$ millions pour la vente de lait et de crème et $\$ 110$ millions en paiements d'appoint du gouvernement fédéral. Environ 30\% des bovins d'abattage et environ $90 \%$ des veaux abattus provenaient de 
troupeaux laitiers. La vente de vaches excédentaires et de génisses, d'exploitation laitière et d'élevage, a aussi fourni un supplément de revenu. Les exportations de bovins laitiers canadiens de race intéressent beaucoup de pays disséminés aux quatre coins du monde.

On estime que pour l'année 1968 les ventes de vaches et de veaux provenant des troupeaux laitiers canadiens s'établissent à environ \$248 millions. Le revenu total brut provenant de l'exploitation des troupeaux laitiers (lait, crème et bétail) se montait à un peu plus d'un milliard de dollars, soit $23 \%$ de l'ensemble des rentrées en espèces provenant de la vente des principaux produits agricoles. Ce montant est supérieur aux recettes totales provenant de la vente du blé, lesquelles s'établissaient à \$926 millions en 1968.

En ce qui regarde le revenu tiré de la production laitière, les provinces diffèrent grandement l'une et l'autre. Dans l'Est, la spéculation laitière constitue une partie importante de l'économie agricole, alors que dans les Prairies, elle est nettement secondaire, par rapport à la production des céréales et à l'élevage des bovins de boucherie. En Nouvelle-Ecosse, au Québec et en Colombie-Britannique, le revenu tiré des ventes de lait et de crème l'emporte sur celui provenant de toute autre activité agricole importante. Le revenu provenant de la production laitière est particulièrement important au Québec: en 1968, cette spéculation y rapportait plus de $44 \%$ des recettes agricoles. L'Ontario vient en tête quant à l'importance des recettes provenant de la vente de produits laitiers, les producteurs en 1968 ayant touché $\$ 285$ millions (y compris les subventions fédérales), soit $21 \%$ des recettes agricoles de la province.

\section{Evolution de la production laitière}

Malgré l'importance que prend la production laitière dans l'agriculture canadienne, le nombre des vaches laitières est à la baisse depuis plusieurs années. La diminution a été plutôt brusque depuis 1964. En effet, au premier juin, on comptait alors 2,845,000 vaches laitières dans les fermes, contre 2,584,000 à la même date en 1969. De 1959 à 1969, le nombre de vaches laitières a diminué d'environ $13 \%$, les baisses les plus considérables se produisant dans les provinces des Prairies et de l'Atlantique.

Bien que l'effectif des troupeaux laitiers soit en progression, moins de quatre fermes laitières sur dix ont déclaré avoir treize vaches ou plus, lors du recensement de 1966. La ventilation des données indiquent qu'en 1956, les troupeaux d'au moins treize vaches comprenaient environ $50 \%$ des effectifs, alors qu'en 1966, ce rapport s'établissait à environ $70 \%$.

Malgré la diminution progressive du nombre de vaches, la production laitière n'a guère varié au Canada durant la période de huit ans s'étendant de 1961 à 1968. La diminution numérique a été contrebalancée par l'augmentation du rendement annuel par vache. La production s'est établie en 1968, à 18.3 milliards de livres de lait. La plus grande partie du lait provient du Québec et de l'Ontario, qui ensemble fournissent près de $75 \%$ de la production canadienne. Les quantités de lait gardé par les agriculteurs pour leur propre consommation et pour l'alimentation du bétail sont allées en diminuant 
graduellement, de façon à ce que de plus grandes quantités aillent à la transformation industrielle.

En 1968, la production annuelle par vache s'établissait en moyenne à plus de 7,000 livres de lait, comparativement à environ 5,800 livres en 1958. Ces chiffres représentent des moyennes mais ils ne renseignent pas sur la situation dans son ensemble. Le grand nombre de vaches dans les exploitations qui comptent de une à sept têtes, sont généralement de médiocres productrices; elles ont pour effet d'altérer en profondeur le tableau d'ensemble. Certains éleveurs canadiens comptent dans leurs troupeaux des vaches dont le rendement rivalise avec celui des plus fortes productrices au monde. Plusieurs des plus importants producteurs possèdent des troupeaux dont le rendement annuel moyen par vache s'élève à 12,000 livres de lait, ou même davantage.

Parmi les facteurs de l'augmentation du rendement laitier par vache, le plus important a été la compétence de la gestion agricole. Signalons à ce sujet la tendance à remplacer les vaches de certaines races à aptitudes médiocres par d'autres appartenant à des races laitières spécialisées. D'autre part, on pratique l'insémination artificielle sur un plus fort pourcentage de vaches: ainsi, les agriculteurs font appel aux services des meilleurs taureaux disponibles pour la mise à exécution de leur programme d'élevage laitier. Le croisement des vaches avec ces taureaux a permis d'accroître de façon manifeste les aptitudes laitières naturelles, et dans la plupart des cas, les aptitudes beurrières des troupeaux. Un autre facteur important a contribué à améliorer le rendement par vache ces dernières années, savoir l'adoption de meilleurs programmes d'alimentation.

\section{Utilisation du lait}

La population du Canada est passée de 17.1 millions d'habitants en 1958 à 20.8 millions en 1968. Cette augmentation de $22 \%$ a donné de l'expansion au marché intérieur des produits laitiers. La consommation, par personne, des deux principaux produits laitiers, le lait nature et le beurre, a régressé durant cette période; aussi la consommation intérieure de lait et de produits laitiers n'a pas été aussi élevée qu'elle aurait pu l'être. Néanmoins la consommation globale de lait et de produits laitiers, exprimée en équivalent de lait entier, a augmenté d'environ $7 \%$.

De tout le lait produit au Canada en 1968, environ $63 \%$ a servi à la fabrication de produits laitiers, $28 \%$ a été vendu pour la consommation sous forme de lait ou de crème, et environ $9 \%$ a été utilisé dans les fermes. Dans le secteur industriel, la fabrication du beurre a pris environ $43 \%$ du lait de transformation, le fromage $12 \%$, les produits laitiers concentrés et la crème glacée, un peu plus de $8 \%$.

La consommation par personne de lait et de produits laitiers, exprimée en équivalent de lait entier a baissé de 963 livres en 1958 à 846 livres en 1968. Exprimé en équivalent de lait entier (3.5\% de graisse butyrique), la diminution par personne de la consommation de lait nature serait due à la préférence que 
manifestent les consommateurs pour le lait partiellement écrémé ( $2 \%$ de graisse butyrique). Ce changement d'habitudes chez les consommateurs tient à leur souci de réduire leur consommation de graisses d'origine animale. L'acceptation des produits de remplacement des produits laitiers tels que la poudre similicrème (à café), les garnitures de desserts et les crèmes d'imitation contenant des huiles végétales, ont contribué pour une grande part à la diminution de la demande de crème fraîche de consommation, et pour une part moins importante, à celle de lait entier concentré. Pareille disposition est attribuable beaucoup plus à l'avantage des prix et à la facilité d'utilisation des succédanés qu'à des préoccupations d'ordre diététique.

Il y a vingt-cinq ans, la plupart des expéditeurs de crème pratiquaient l'écrémage à la ferme et donnaient le petit lait au bétail. Depuis les dix dernières années, la pratique tend de plus en plus à expédier le lait entier, au lieu du produit de l'écrémage, de sorte que cette opération se fait maintenant à l'usine. Conséquemment des quantités beaucoup plus grandes de lait écrémé doivent s'écouler par les voies du commerce. La plus grande partie de ce lait est transformée en lait en poudre et en caséine. Ces dernières années, on a éprouvé beaucoup de difficultés à vendre le lait écrémé en poudre excédentaire sur les marchés mondiaux.

L'histoire de la production du fromage au Canada est longue et intéressante. A la fin de la Deuxième guerre mondiale, la quantité de lait utilisée pour la fabrication du fromage a diminué, mais depuis une dizaine d'années, elle est de nouveau à la hausse. Environ $94 \%$ de la production de fromage au Canada provient de l'Ontario et du Québec. La majeure partie des exportations se font vers le Royaume-Uni où le cheddar se vend comme spécialité.

Il est encourageant de constater que par personne, la consommation de fromage va en augmentant, ce qui en fait l'un des seuls produits laitiers pour lesquels la demande s'accroît. La situation serait peut-être attribuable au fait qu'une partie considérable de l'accroissement de la population résulte de l'immigration originaire de pays où le fromage forme régulièrement une partie importante de l'alimentation. Ces nouveaux canadiens ont naturellement conservé la plupart de leurs habitudes alimentaires. Aussi les fromagers s'appliquent à fabriquer de nouvelles variétés de fromage pour répondre à leur demande. Les canadiens d'origine commencent eux aussi, à prendre goût à ces fromages fins. 


\section{L'AMELIORATION DES BOVINS LAITIERS}

\section{Races}

La spéculation laitière au Canada intéresse principalement cinq races spécialisées-les races Ayrshire, Suisse brune, Guernsey, Holstein-Frisonne, et Jersey auxquelles se joignent deux races à deux fins, la Red Poll et la Shorthorn. Il n'existe pas de statistiques sur l'effectif de chaque race, mais l'inscription des animaux de race au Canada donne une idée du nombre relatif d'animaux appartenant à ces races.

\section{TABLEAU 1. Inscription et contrôle d'aptitudes des bovins laitiers par race au Canada - 1968}

\begin{tabular}{|c|c|c|c|c|}
\hline Race & $\begin{array}{c}\text { Nombre } \\
\text { d'enregistre- } \\
\text { ments }\end{array}$ & $\begin{array}{c}\text { Pourcentage } \\
\text { du total }\end{array}$ & $\begin{array}{l}\text { Nombre } \\
\text { d'inscriptions } \\
\text { au contrôle } \\
\text { d'aptitudes }\end{array}$ & $\begin{array}{c}\text { Pourcentage } \\
\text { du total }\end{array}$ \\
\hline Ayrshire & 10,475 & 9.1 & 16,170 & 11.1 \\
\hline Suisse brune & 606 & .5 & 402 & .3 \\
\hline Guernsey ..... & 4,681 & 4.1 & 8,365 & 5.8 \\
\hline Holstein-Frisonne & 90,698 & 78.8 & 106,352 & 73.3 \\
\hline Jersey & 8.668 & 7.5 & 13,791 & 9.5 \\
\hline
\end{tabular}

Pour ce qui intéresse l'amélioration de la race, le nombre de vaches de race pure inscrit à un programme de contrôle d'aptitudes reconnu est beaucoup plus important que le nombre d'animaux enregistrés chaque année, puisque les données de la production sont essentielles à la sélection judicieuse. Les deux dernières colonnes du tableau 1 indiquent le nombre de vaches de race pure inscrites au contrôle en 1968.

Comme leur désignation l'indique, les races à deux fins possèdent quelquesunes des aptitudes des races de boucherie; sans donner autant de lait que les principales races spécialisées, elles en produisent des quantités considérables. (Voir tableau 2.)

On se rend de plus en plus compte des aptitudes bouchères de l'animal laitier et les termes "type laitier" et "type de boucherie" n'ont plus le sens exclusif qu'ils avaient.

Les personnes qui projettent de former un troupeau laitier devraient premièrement se fixer sur la race de vaches à garder. Les considérations importantes aptes à influencer cette décision sont:

1. l'état du marché du lait;

2. les préférences personnelles;

3. l'état du marché, tant local qu'à l'étranger, des sujets d'élevage excédentaires;

4. les disponibilités en bovins de grande valeur génétique, femelles et mâles. 
TABLEAU 2. Production des vaches inscrites au contrôle d'aptitudes au Canada 1968 $^{1}$

\begin{tabular}{|c|c|c|c|c|}
\hline Race & $\begin{array}{l}\text { Nombre de } \\
\text { relevés }\end{array}$ & Lait (lb) & $\begin{array}{l}\text { Production } \\
\text { M.g. (\%) }\end{array}$ & $\begin{array}{l}\text { moyenne } \\
\text { M.g. (lb) }\end{array}$ \\
\hline Ayrshire & 12,736 & 9,397 & 4.02 & 377 \\
\hline Suisse brune & 322 & 10,311 & 4.17 & 430 \\
\hline Guernsey $\ldots$ & 6,364 & 8,765 & 4.85 & 425 \\
\hline Holstein-Frisonne & 87,113 & 12,243 & 3.73 & 457 \\
\hline Jersey & 10,521 & 7,675 & 5.27 & 404 \\
\hline Red Poll & 83 & 7,237 & 3.97 & 287 \\
\hline Shorthorn à deux fins & 489 & 7,515 & 3.85 & 290 \\
\hline
\end{tabular}

1. Production réelle en 305 jours.

Il n'est pas question ici de comparer les différentes races, chacune des races laitières prouvant, par son existence même, son aptitude à servir la spéculation laitière au Canada.

Pour plusieurs espèces, tels le porc, la volaille et le mouton, l'animal destiné au commerce résulte du croisement de deux ou plusieurs races ou lignées reconnues, mais en Amérique du Nord, les bovins laitiers sont en très grande partie des animaux de race pure ou des animaux de haute qualité issus de croisements d'amélioration. Il n'existe pas actuellement de preuves de la supériorité de la vache laitière de race croisée sur celle de race pure, et jusqu'à ce qu'on ait démontré que la vigueur hybride accroît le rendement laitier ou améliore d'autres caractères économiques, la vache laitière commerciale continuera d'être de race pure ou de croisement d'amélioration de haute qualité issue de l'une ou l'autre des races laitières reconnues.

\section{METHODES DE CONTROLE LAITIER}

Même pour la même race les aptitudes laitières et beurrières des vaches varient beaucoup de l'une à l'autre; cette différence est due en grande partie à la façon dont les vaches sont alimentées. L'hérédité est aussi un facteur qui influe sur les variations de la production de lait et de matière grasse, et si la médiocrité du rendement résulte de ce facteur, l'alimentation ne saurait la corriger.

Chaque producteur de lait devrait avoir une méthode lui permettant de mesurer le rendement de chaque vache. S'il ne s'intéresse pas particulièrement à la teneur en matière grasse, il peut mettre au point sa propre méthode d'évaluation en pesant tout simplement la quantité de lait donnée par traite par chaque vache, et en additionnant les pesées individuelles à la fin de chaque lactation. Cependant, la plupart des producteurs de lait tiennent autant à connaître la teneur en graisse butyrique que la quantité de lait, et pour ce, ils peuvent faire inscrire leurs troupeaux à un programme de contrôle laitier qui leur fournira les renseignements détaillés qui les intéressent. 


\section{Contrôle d'aptitudes}

Le Contrôle d'aptitudes (R.O.P.) programme que patronne le ministère de l'Agriculture du Canada a pour objet de fournir un service d'essai du lait des vaches de race pure. Les éleveurs ont le choix entre deux plans. Le plan A comporte la pesée quotidienne par l'éleveur de la production de lait de chaque vache, pesées que vérifie périodiquement un inspecteur. Le plan B comporte des pesées faites chaque mois par un inspecteur durant la période de lactation. Depuis quelques années, un fort pourcentage d'éleveurs ont abandonné ce Plan A en faveur du Plan B, ce qui s'explique par le fait que l'on considère le Plan B aussi précis que le A. Dans les deux cas, l'inspecteur prélève des échantillons qui servent à déterminer la teneur du lait en graisse butyrique. Les contrôles officiels font état de la quantité de lait produit en 305 jours. Les éleveurs qui désirent se renseigner davantage sur ces programmes sont priés de s'adresser à l'inspecteur en chef du Contrôle d'aptitudes des bovins laitiers de race, Direction de la production et des marchés, ministère de l'Agriculture du Canada, Ottawa.

\section{Programmes d'amélioration des troupeaux laitiers}

Chaque province offre un programme de contrôle laitier à l'intention spéciale de l'éleveur commercial. Les contrôles ainsi obtenus ne bénéficient pas de la reconnaissance "officielle", à l'échelle nationale et internationale, mais fournissent des termes de comparaison au sein du même troupeau et de guides pour déterminer les ventes qui s'imposent. La Colombie-Britannique, la Saskatchewan, le Manitoba et l'Ontario offrent des programmes surveillés d'amélioration des troupeaux laitiers. Les participants sont groupés en associations comptant chacune de vingt à vingt-quatre membres. Une fois par mois, le contrôleur chargé de chaque association passe une journée en visite chez chaque membre. Il consigne, vache par vache, la production de deux traites consécutives, prélève un échantillon de chaque traite et analyse l'échantillon composite du lait de chaque vache. Les résultats de l'analyse sont envoyés au service provincial où sont gardées les données cumulatives de la lactation de chaque vache.

Les provinces ont chacune un programme comportant le "prélèvement effectué par le propriétaire". Ces programmes ne sont pas contrôlés et ils varient d'une province à l'autre. Ils sont destinés essentiellement à fournir à chaque propriétaire une norme d'appréciation des sujets à vendre. Les droits d'inscription sont très minimes. Une fois par mois, le propriétaire du troupeau n'a qu'à peser le lait de chaque vache et à en prélever un échantillon. Il expédie ensuite les chiffres de la production et les échantillons de lait à un centre d'analyse où s'accumulent les données de la production. A la fin de chaque lactation, le centre délivre un état de la production.

Dans certaines provinces, le programme d'amélioration du troupeau prévoit la communication de renseignements sur les coûts de production, d'alimentation et de gestion. Les producteurs qu'intéresse ce programme doivent communiquer avec leur agronome. 


\section{INSEMINATION ARTIFICIELLE}

$\mathrm{Au}$ cours des vingt-cinq dernières années, l'insémination artificielle chez les bovins laitiers est passée du stade de simple innovation technique à celui d'importance pratique courante qui a fortement influé sur le cours et le rythme d'amélioration des bovins laitiers.

\section{Organisation}

Il y a actuellement au Canada huit grands centres d'insémination artificielle (I.A.): deux dans les provinces Maritimes, un au Québec, trois en Ontario et deux en Colombie-Britannique. Ce sont des organismes à but non lucratif dirigés par les agriculteurs-propriétaires.

Des sept centres qui existaient en Ontario en 1966, il n'en reste plus que trois. Cette diminution résulte de la tendance à établir de grands centres et à utiliser les taureaux aux meilleures fins possibles. Tous les centres possèdent des taureaux de race Holstein-Frisonne, mais la tendance veut que l'on garde des taureaux de chacune des autres races dans l'un des centres et à faire la distribution de la semence congelée, technique maintenant en application dans tous les centres.

\section{Envergure du programme}

Le premier centre d'I.A. a été fondé en 1941, à Waterloo, en Ontario, et durant la première année d'exploitation, 317 inséminations ont été réalisées. En 1968, on a pratiqué environ un million de premières inséminations au Canada, ce qui représente à peu près $20 \%$ du nombre d'enregistrements de bovins de races laitières et à boeuf au pays. Signalons qu'en 1968, environ $67 \%$ des enregistrements de bovins de races laitières intéressaient des sujets issus de vaches inséminées artificiellement.

\section{Importance pratique de l'insémination artificielle}

A ses débuts, l'insémination artificielle était un moyen de fournir aux propriétaires de troupeaux commerciaux les services de taureaux de qualité supérieure qu'ils n'auraient pu se permettre d'acheter et d'utiliser pour la fécondation naturelle. Mais elle s'est découvert au surplus, des applications beaucoup plus étendues. Si les taureaux exploités en I.A. sont vraiment de qualité supérieure et si l'éleveur choisit pour son troupeau ceux qui ont établi leurs aptitudes par l'excellence de leur descendance, la nouvelle méthode offre plus d'avantages que la monte pour l'amélioration de la race et du troupeau. Voici quelques considérations à l'appui de cette affirmation:

1. L'I.A. permet l'essai pratique et l'identification des reproducteurs qui sont génétiquement supérieurs que l'on désigne "taureaux cotés plus". 
2. Les taureaux génétiquement supérieurs employés en I.A. servent infiniment plus qu'ils ne le pourraient en monte naturelle. Un taureau coté "plus" à l'épreuve peut féconder plusieurs milliers de vaches par la méthode d'insémination artificielle; plusieurs reproducteurs de cette catégorie ont servi à inséminer plus de 10,000 vaches par année. On trouvera d'autres considérations sur les reproducteurs cotés sous la rubrique intitulée Sélection du taureau. Dans l'intervalle, signalons d'autres avantages de l'insémination artificielle:

1. économie - le coût de l'insémination artificielle est minime en comparaison des frais occasionnés par la garde d'un taureau de monte.

2. prévention des maladies - l'I.A. prévient la propagation de maladies transmises par l'accouplement naturel, telles sont la vibriose, la brucellose et la trichomonase.

L'insémination artificielle est une technique d'application courante dans les troupeaux laitiers du Canada. Sous direction compétente, cette méthode de reproduction ne pose pas de problèmes particuliers. L'accroissement de la production des filles issues de taureaux éprouvés atteint le but de l'insémination artificielle et en confirme l'avantage.

\section{PROGRAMMES D'AMELIORATION DES RACES}

En plus des programmes de contrôle laitier offerts par les gouvernements fédéral et provinciaux, les associations d'éleveurs ont mis au point des programmes et elles décernent des prix d'encouragement pour l'amélioration des bovins laitiers. Ces prix varient d'une association à l'autre, mais ils sont généralement attribués en reconnaissance de succès marquants obtenus par les membres en élevage et en amélioration de la vache laitière. Les programmes prévoient aussi la reconnaissance du mérite exceptionnel des vaches d'élevage et des taureaux reproducteurs.

Les éleveurs canadiens de bovins laitiers ont présentement un vaste marché d'exportation. En 1968, les exportations d'animaux de race pure ont atteint le chiffre de 22,896 têtes auxquelles s'ajoutent annuellement un nombre élevé de bovins laitiers non enregistrés. Les bovins laitiers canadiens sont activement recherchés à l'étranger. Les éleveurs ne sont pas sans savoir qu'actuellement les acheteurs préfèrent des animaux de belle apparence dont la conformation se rapproche du type de la race. Aussi longtemps que les acheteurs consentiront à payer le prix pour des vaches d'un certain type, le producteur laitier, dont une partie des recettes provient de la vente de bovins, pratiquera la sélection des vaches qui se conforment au type et qui possèdent de grandes aptitudes laitières. Pour maintenir le rythme de nos exportations de bovins laitiers, il nous faut travailler sans cesse à l'amélioration de leurs aptitudes. L'accroissement de la productivité prendra de plus en plus d'importance, à mesure que la population mondiale augmentera. Sous la rubrique suivante, on trouvera un exposé du rapport entre le type et la production. 
Les associations d'éleveurs encouragent les éleveurs d'animaux de race à sélectionner en tenant compte de la conformation. A cette fin, elles offrent depuis plusieurs années des programmes de classement d'après le type. L'objectif premier de ces programmes est d'encourager les éleveurs à faire classer leurs animaux d'après le type de la race, en espérant qu'ils se serviront de cet étalon lors de la sélection d'animaux de remplacement.

\section{Type et production}

De nombreuses études ont démontré que l'évaluation générale, au moyen de l'expertise visuelle de la conformation ou du type, ne constitue pas une méthode sûre d'identification des meilleures vaches productrices. La méthode ne vaut pas à cet égard le relevé d'une seule lactation. En réalité, le type et la production laitière sont liés à deux caractères génétiques indépendants. A preuve, certains reproducteurs des centres d'I.A., ayant établi leur valeur, quant à la transmission de l'aptitude laitière, ne transmettent pas nécessairement à leur descendance la fidélité au type.

Tous les producteurs, autant ceux qui ont des troupeaux de race que ceux qui exploitent des troupeaux commerciaux, doivent reconnaître que la sélection pratiquée exclusivement d'après le type n'augmentera pas nécessairement l'aptitude laitière. Par contre, la seule sélection effectuée en vue d'accroître le rendement en lait n'apportera pas d'amélioration de la conformation. Cependant, il ne s'ensuit pas que les deux caractères, production supérieure et type, ne peuvent se rencontrer chez le même animal. Si l'on désire améliorer ces deux caractères, on doit les prendre tous deux en considération lors de la sélection des animaux. Néanmoins, le taux d'amélioration conjointe de chacun des caractères sera plus lent que si l'on perfectionne isolément ou le type ou la production. L'amélioration des deux caractères à la fois prend tout simplement plus de temps que l'amélioration d'un seul. Un des caractères du type, le "caractère laitier", est un indicateur utile de la production, en l'absence de relevés, étant donné qu'il est effectivement associé génétiquement au caractère de la production.

On reconnaît depuis longtemps que la conformation prend un aspect utilitaire très important. Il est primordial qu'une vache ait une constitution robuste pour produire de grandes quantités de lait durant de nombreuses années. Beaucoup de vaches doivent être réformées chaque année à cause de mammite ou de blessures au pis. A cet égard signalons que le pis de la vache s'allonge au rythme d'un pouce par période de lactation et que les pis allongés sont les plus sujets à la mammite et aux blessures. Ainsi, la sélection de vaches qui portent le pis au-dessus du jarret, minimise les pertes imputables à ces causes.

Des recherches plus poussées devront être entreprises afin de déterminer le type de vache qui résistera le mieux à la fatigue inhérente à plusieurs lactations à fort rendement. Si les résultats de ces études démontrent que l'on doit modifier de quelque façon l'idéal que l'on s'est fait de la vache, 
les éleveurs et leurs associations devront consentir à ces changements, sans quoi ils sacrifieront l'utilité à l'idéal. Il est hors de doute que l'amélioration de la race demande l'application d'efforts soutenus en vue de l'augmentation de la production.

\section{SELECTION DES BOVINS LAITIERS}

Pour le débutant, Ia sélection commence avec la formation du troupeau. Aussi, le producteur éventuel serait bien avisé, lorsqu'il effectue ses premiers achats, de demander les conseils d'un spécialiste en vulgarisation ou d'un producteur bien établi. Une fois le troupeau réuni, la sélection continue de s'effectuer par le choix des reproducteurs mâles et femelles aptes à donner des descendants propres à maintenir la qualité du troupeau. A moins de sélectionner d'une part des vaches et des reproducteurs de qualité supérieure comme parents de la nouvelle génération de veaux, et d'autre part, de réformer les vaches médiocres, tout en veillant à ne pas utiliser de taureaux inaptes, le commerçant n'améliorera pas la valeur génétique de son troupeau.

La présente section entend exposer quelques-uns des principes sur lesquels s'édifient un bon programme d'élevage de bovins laitiers.

\section{Objectif de l'élevage}

Chaque producteur de lait doit fixer un objectif à son programme d'élevage, et l'ayant déterminé, le poursuivre avec détermination. L'objectif s'établit en

\section{TABleAU 3. Caractères d'importance pour le producteur de lait}

\begin{tabular}{ll}
\hline Caractère & Effet des caractères \\
\hline $\begin{array}{l}\text { Coefficient d'hérédité faible } \\
\text { Tarissement }- \text { durée en jours }\end{array}$ & $\begin{array}{c}\text { Production laitière et coût de remplace- } \\
\text { ment } \\
\text { Production laitière et coût de remplace- } \\
\text { ment } \\
\text { Intervalle entre les gestations }-\end{array}$ \\
$\begin{array}{c}\text { durée en jours } \\
\text { ment } \\
\text { Intervalle entre les vêlages }\end{array}$ & $\begin{array}{c}\text { Coût de remplacement } \\
\text { Production laitière et coût de remplace- } \\
\text { ment }\end{array}$
\end{tabular}

Coefficient d'hérédité moyen

Production de lait

Fidélité au type

Résistance à la mammite

Facilité de traite

Coefficient d'hérédité élevé

Pourcentage de matière grasse

Pourcentage d'extrait sec dégraissé

Pourcentage de protéines

Taille à l'âge adulte

Ventes directes de lait

Ventes de reproducteurs

Production laitière et frais de traitement

Coût de la main-d'oeuvre

Ecart de recettes

Aucun actuellement

Aucun actuellement

Coût d'entretien et produit de la vente 
fonction de l'exploitation de producteur et des caractères qui ont le plus d'importance économique chez la vache laitière. Dans la mise à exécution d'un programme d'élevage, l'importance relative à accorder à certains caractères varie d'une exploitation à l'autre, selon le marché du lait, les possibilités de ventes de bétail et la sorte de bovins qui constituent le troupeau. Le producteur de lait ne peut espérer améliorer par la sélection que les seuls caractères héréditaires (tableau 3).

Les caractères importants sont plus ou moins héréditaires. Le coefficient de transmissibilité d'un caractère est la mesure d'amélioration que l'on peut espérer chez la génération issue directement des animaux possédant éminemment le caractère en question. Il est généralement reconnu que le coefficient d'hérédité de la production laitière est de .25 , ce qui veut dire qu'environ $25 \%$ de la différence de production observée chez deux animaux provient de la diversité de leur patrimoine génétique ou de leur hérédité. Mettons que dans le même troupeau, la vache A donne 12,000 livres de lait à deux ans, et que la vache $\mathrm{B}$ n'en donne que 10,000 au même âge. L'écart constaté n'est pas entièrement dû à la différence de l'hérédité des deux vaches. En effet, compte tenu du coefficient de transmissibilité du caractère "production laitière", savoir .25, seulement, 25\% de la différence de 2,000 livres, soit 500 livres de lait, est attribuable à la supériorité génétique de la vache $\mathrm{A}$. Le coefficient d'hérédité de l'ensemble des caractères s'échelonne de 0 à 1 et celui de la plupart des caractères d'importance économique, de .1 à .4 . Un coefficient très bas, de 0 à .2 , indique tout simplement que les différences entre les animaux ne sont pas dues principalement aux différences de leur hérédité mais, pour la plus grande partie, aux conditions d'environnement, tels que l'alimentation et la gestion. Par contre, pour les caractères tels que le pourcentage de matière grasse, dont le coefficient d'hérédité est relativement élevé, les différences observées entre les vaches sont pour la majeure partie d'ordre génétique. Les caractères peuvent se grouper de façon générale en trois catégories quant à leur coefficient de transmissibilité: faible, moyen, élevé. Ceux dont le coefficient d'hérédité est faible ne peuvent être améliorés de façon sensible par la sélection d'animaux de qualité supérieure, mais ils réagissent rapidement à l'amélioration de la gestion ou de l'alimentation. Le producteur de lait averti ne conduit pas son programme de sélection en fonction de caractères à faible coefficient d'hérédité. Il est primordial, lors de l'élaboration de l'objectif de son élevage, qu'il concentre son attention sur les caractères qui ont un coefficient d'hérédité pour le moins dans la moyenne.

En résumé, le producteur, lorsqu'il établit son programme d'élevage doit envisager son genre d'exploitation, déterminer les caractères qui ont pour lui le plus d'importance économique, et praiiquer la sélection en vue d'améliorer les caractères qui sont héréditaires. Il doit en même temps réviser ses méthodes de gestion et d'alimentation afin d'améliorer les caractères à faible coefficient d'hérédité qui réagissent néanmoins aux conditions d'environnement. 


\section{Caractères à faire valoir pour la sélection}

Chaque année, les producteurs de lait doivent réformer un certain nombre de vaches pour raison de reproduction anormale, de mammite aiguë ou de blessures, ou simplement de vieillesse. De façon générale, les troupeaux perdent autant de bonnes vaches pour ces raisons que de vaches médiocres. C'est seulement après avoir disposé de ces vaches que l'éleveur peut entreprendre la véritable sélection en vue d'améliorer les caractères qu'il tient comme importants. L'efficacité de la gestion diminue le pourcentage de vaches qui quittent le troupeau pour causes de maladies, blessures ou autres, et augmente les occasions de sélectionner pour les caractères qui constituent l'objectif du programme d'élevage.

Il y a lieu, dans l'établissement de l'objectif de son programme d'élevage, d'écarter les caractères qui ont un faible coefficient d'hérédité. Il n'y a actuellement aucun avantage économique à sélectionner les vaches en vue de l'extrait sec dégraissé ou de la teneur en protéine du lait. En outre, les recherches récentes démontrent qu'il n'y a pas lieu de placer beaucoup d'importance sur la taille comme moyen d'augmenter la production laitière. La question de grosseur, si le troupeau est géré efficacement et reçoit une alimentation suffisante, ne devrait recevoir que peu d'attention, à moins que certains animaux ne soient excessivement gros ou petits. L'importance à accorder au pourcentage de la matière grasse varie selon le marché du lait, mais ce caractère doit certainement être pris en considération pour la plupart des troupeaux. Une façon de maintenir le pourcentage de matière grasse au niveau désiré est d'établir le seuil du pourcentage pour l'ensemble du troupeau et d'employer des taureaux dont les descendantes produisent un haut pourcentage de matières grasses, jusqu'à ce que l'objectif fixé ait été dépassé. On peut maintenir le pourcentage de matière grasse au seuil déterminé en employant des reproducteurs dont les descendantes produisent un pourcentage au moins égal à l'objectif. Restent les caractères à coefficient d'hérédité moyen. Ce sont ceux auxquels il importe d'accorder le plus d'importance dans un bon programme d'élevage de bovins laitiers. Ce sont: la production de lait, la fidélité au type, la facilité de la traite et peut-être la résistance à la mammite. Un bon programme de contrôle de la mammite devrait réprimer efficacement cette maladie, au point de lui enlever son caractère de gravité et de permettre à l'éleveur de concentrer son attention sur l'amélioration de la production laitière, le pourcentage de la matière grasse, et jusqu'à un certain point, la conformation et la facilité de la traite.

L'éleveur qui désire procéder avec méthode à la réforme doit se procurer des rapports de contrôle exacts pour chaque vache. Ceux ayant trait à la production de lait et au pourcentage de matière grasse peuvent s'obtenir en participant à l'un des contrôles laitiers énumérés précédemment. L'observation attentive du troupeau, lors de la traite, renseigne aussi sur la facilité de la traite. Muni de rapports de contrôle complets, l'éleveur peut réformer les vaches qui ne possèdent pas les caractères qu'il considère importants. Environ $80 \%$ des recettes brutes du producteur ordinaire proviennent de la vente du lait et des produits laitiers et $20 \%$, des ventes de bestiaux. Les éleveurs de 
races pures réalisent sans doute un pourcentage plus élevé de leurs recettes brutes au moyen de la vente d'animaux de reproduction. Toutefois, tous les programmes d'élevage accordent une importance première à la production laitière. Les méthodes appliquées à la réforme des vaches pour cause de production insuffisante peuvent généralement s'appliquer aussi à l'élimination des vaches à cause du faible pourcentage de matière grasse, de défauts de conformation et de traite difficile.

\section{Augmentation de la production au moyen de la réforme}

La réforme des vaches médiocres est un moyen d'augmenter la production d'un troupeau laitier. Il n'est pas difficile de décider du sort des vaches dont la production est nettement faible, mais la décision à prendre à l'égard de celles dont la production se rapproche de la moyenne de l'ensemble du troupeau demande réflexion. Vaut-il mieux éliminer une vache âgée et donner une autre chance à une génisse dont la première lactation est médiocre? Les vaches médiocres de deux ans s'amélioreront probablement lors des lactations subséquentes, mais leurs relevés seront généralement inférieurs à ceux des autres vaches par une marge d'environ 50\% de'la différence entre la moyenne $\mathrm{du}$ troupeau et leur première lactation. Une très bonne raison de garder la bonne vache âgée plutôt que la vache de deux ans est que la vache adulte produira environ de 25 à $30 \%$ de plus que sa jeune concurrente.

On peut résumer de la façon suivante les règles de la réforme en vue d'accroître la production:

1. Inscrire le troupeau à un programme de contrôle laitier.

2. Avant de réformer, pratiquer le contrôle de chaque vache. Cette méthode peut valoir dans la plupart des troupeaux comptant de 20 à 25 vaches, mais elle n'est pas pratique dans les troupeaux plus importants, étant donné que le nombre de vaches primipares est trop élevé. Les propriétaires de troupeaux nombreux devraient garder les génisses de remplacement issues des vaches dont la production est la plus élevée et des taureaux raceurs quant aux aptitudes laitières. Tous les taureaux comptent de bonnes descendantes, mais les meilleurs parmi les taureaux éprouvés auront un pourcentage beaucoup plus élevé de leurs filles, de qualité supérieure.

3. Apprécier toutes les vaches du troupeau selon leur production laitière et beurrière en regard de la moyenne de la classe pour la race (M.C.R.). Cet indice permet de corriger les relevés en fonction de l'âge, de comparer les relevés des vaches d'âges différents, et de réformer rationnellement celles dont la production est inférieure.

4. La sélection la plus stricte devrait porter sur les vaches qui en sont à leur première ou leur deuxième lactation. Dans la mesure du possible, éliminer aussi les vaches âgées dont la production est continuellement inférieure de la moyenne du troupeau. 
5. Lorsqu'il est difficile de décider entre deux vaches, il faut tenir compte de toutes les différences entre elles. Les différences d'âge, de production de matière grasse, de qualité du pis, de tempérament, de facilité de traite et d'aptitudes de la descendance, détermineront généralement le choix.

6. La réforme, pour se faire à bon escient, doit tenir compte de tous ces relevés et de les comparer à la moyenne du troupeau au temps où ils ont été faits. Le tableau A 13 de l'Annexe illustre les données sur lesquelles se fonde l'appréciation de la valeur reproductive d'une vache, compte tenu du mérite de chacun de ses relevés.

Les méthodes qui ont été exposées sont très utiles pour l'évaluation des vaches en vue de la production laitière. C'est le caractère particulier auquel l'éleveur doit accorder le plus d'importance lors de la sélection des vaches. Ma1s s'll recherche des caractères autres que celui de la production, il doit se renseigner sur chacun d'eux et évaluer chaque qualité des vaches avant de pouvoir pratiquer une sélection judicieuse. Il n'existe pas de méthode simple permettant d'évaluer les vaches et de les classer sur un nombre élevé de caractères, spécialement si l'on accorde une importance différente à chacun d'eux lors de la sélection. La figure 1 fait voir une méthode propre à classer les vaches pour deux caractères. A remarquer que la production, exprimée en moyenne de la classe pour la race (M.C.R.), est portée en ordonnée et que le coefficient de fidélité au type, en abscisse. Chaque numéro représente une vache particulière; par exemple, la vache numéro 32 a le coefficient de fidélité au type de 80 et la moyenne de la classe pour la race de 146. A noter que dans ce troupeau aucun rapport étroit ne ressort entre la fidélité au type et l'excellence de la production. Si les vaches de ce troupeau devaient être sélectionnées en tenant compte seulement de la production, les vaches numéros 9 et 21 seraient à réformer les premières; par ailleurs, si le type seul entrait en ligne de compte les premières vaches à réformer seraient les numéros 12 et 7 . Les producteurs qui sélectionnent en vue de deux caractères élimineraient les vaches qui sont inférieures pour les deux. Dans la figure, les vaches numéros 10,35 et 36 tombent dans cette catégorie. Ce genre de diagramme peut servir à classer le troupeau pour deux caractères; par exemple, production laitière et pourcentage de matière grasse, production laitière et type, ou pourcentage de matière grasse et type. Il permet à l'éleveur d'identifier et de réformer les vaches qui sont inférieures pour un certain nombre de caractères.

Dans cet exemple, la production laitière est exprimée en moyennes indiciaires réelles de la classe pour la race, mais elle aurait pu s'exprimer aussi comme la différence entre la moyenne des relevés de chaque vache et la moyenne de l'ensemble du troupeau, selon la méthode exposée au tableau A 13 de l'Annexe.

La comparaison de deux vaches appartenant à deux troupeaux différents ne vaut qu'à la condition d'avoir au préalable fait le rapprochement des relevés de chacune avec la moyenne du troupeau dont elle fait partie. Par exemple, mettons que l'on projette d'acheter l'une de deux vaches qui ont 
chacune un indice M.C.R. de $120 \%$ pour le lait; que la vache A provient d'un troupeau dont la moyenne de l'indice M.C.R. est de $100 \%$ pour le lait, alors que la vache B provient d'un troupeau dont la moyenne est de $120 \%$. Ainsi, la vache $\mathrm{A}$ a donc 20 points de plus que la M.C.R. de son troupeau, alors que la vache $\mathrm{B}$ atteint à peine la moyenne de son troupeau. Etant donné que la plupart des différences entre les troupeaux sont dues au milieu plutôt qu'au patrimoine génétique, il serait avantageux d'acheter la vache $\mathrm{A}$, à conditions égales par ailleurs.

\section{La notion de "taureau coté plus"}

L'amélioration des bovins laitiers commence par le choix du taureau. Les producteurs progressistes tiennent compte de ce fait, et ce n'est qu'après avoir pesé les qualitiés de plusieurs taureaux qu'ils prennent la décision d'en

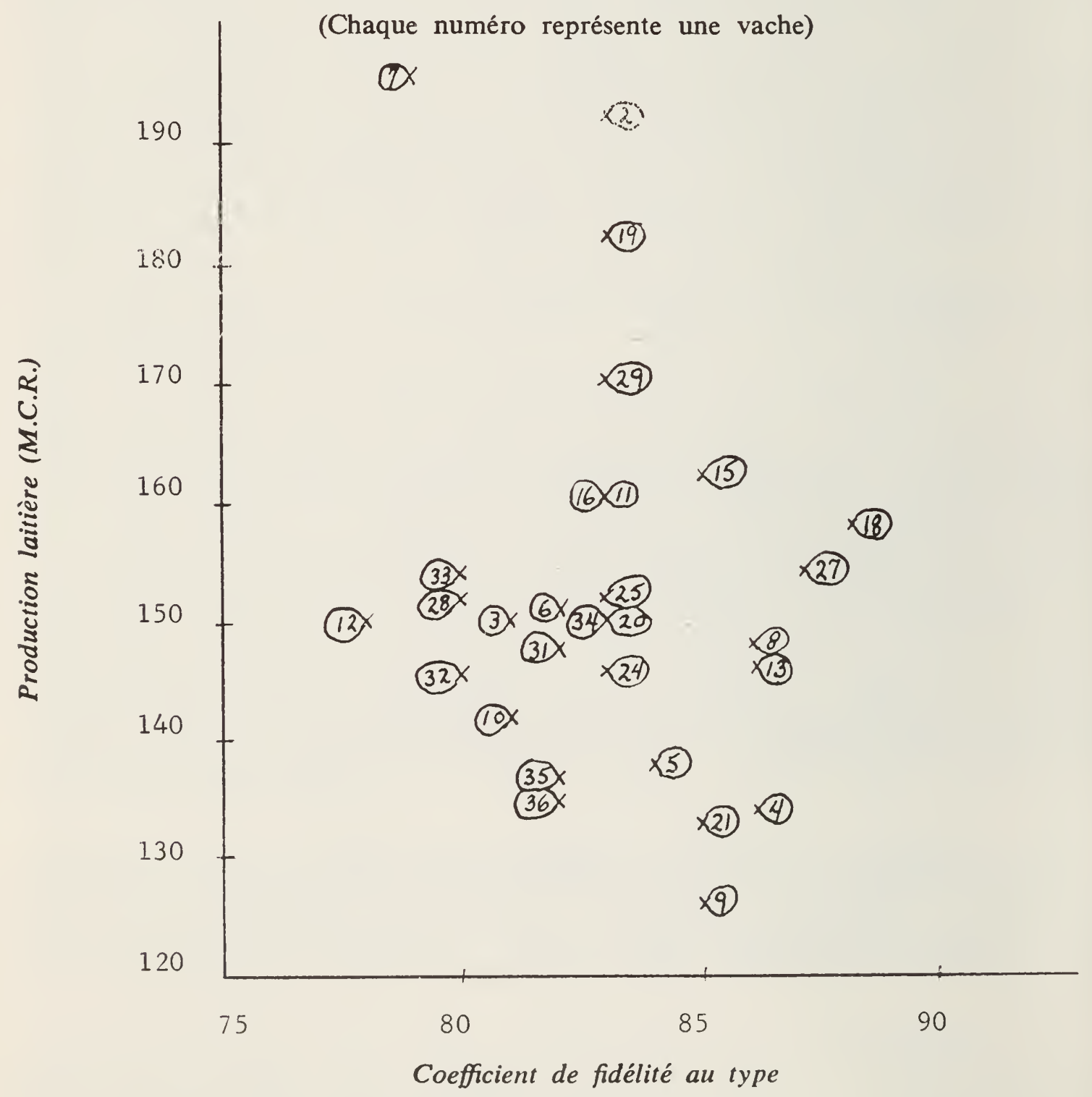

Figure 1. Méthode permettant de classer les vaches pour deux caractères 
choisir un ou deux à employer au maximum en vue de l'amélioration de leurs troupeaux.

L'indication la plus sûre de la valeur génétique d'un taureau laitier se trouve dans les données relatives aux aptitudes d'un grand nombre de ses filles réparties au hasard dans un grand nombre de troupeaux. Avant l'introduction de l'insémination artificielle, il était rare pour un taureau d'engendrer dans plus d'un troupeau. Les aptitudes de la progéniture d'un taureau dans un seul troupeau ne sont pas une indication sûre de sa valeur génétique. On peut dire qu'au meilleur des choses, les données sur les aptitudes de même une quarantaine de filles faisant partie d'un même troupeau, ne sont sûres qu'à $50 \%$ par rapport au contrôle d'un nombre modéré de descendantes obtenues par insémination artificielle. Aujourd'hui, grâce au contrôle de la descendance engendrée par fécondation artificielle, nous savons très exactement la valeur génétique d'un grand nombre de taureaux et leurs services peuvent être obtenus aux centres d'insémination artificielle.

Certains éleveurs continueront de sélectionner les jeunes taureaux en s'appuyant sur leur papier d'origine et de les employer de façon intensive dans leurs troupeaux. Une certaine proportion des reproducteurs choisis de cette manière, donneront de bons résultats, mais d'autres se révéleront de qualité inférieure et seule l'épreuve de la descendance pourra établir avec exactitude la démarcation entre les bons et les médiocres. Il est presque inévitable qu'à l'avenir la majorité des éleveurs pratiquent l'insémination artificielle, au moyen de la semence de taureaux ayant fait leurs preuves par la qualité de leur descendance et gardent leurs jeunes taureaux pour les essayer en croisement avec les génisses et les jeunes vaches. Les éleveurs qui continueront d'employer leurs propres reproducteurs tenteront sans doute de vendre assez de semence aux autres éleveurs pour permettre d'effectuer un contrôle sûr de leur descendance.

Pour conclure, disons que la meilleure indication de la valeur génétique d'un reproducteur s'obtient par le contrôle d'un grand nombre de ses filles réparties dans un grand nombre de troupeaux. Le producteur qui emploie constamment, pour l'insémination des vaches de son principal troupeau, des taureaux dont la haute qualité s'établit par le contrôle de leur descendance, assure l'amélioration génétique continue de son bétail. C'est ainsi que s'exprime en trois mots la notion de "taureau coté plus".

\section{Sélection des taureaux}

Le taureau dont les filles sont supérieures à celles d'autres reproducteurs, pour un caractère donné, est un raceur à cet égard, seulement sans qu'il affirme pour autant sa valeur génétique pour d'autres caractères. Toutefois, un reproducteur réellement supérieur engendre des filles supérieures pour tous les caractères d'importance économique. Résumons brièvement les moyens d'identifier les vrais raceurs pour les caractères d'importance économique qui intéressent le producteur de lait canadien. 


\section{Production de lait}

Tous les résultats du Contrôle d'aptitudes des bovins laitiers de raceR.O.P.- (et d'autres contrôles exercés au Canada), intéressant les primipares, forment la base d'évaluation des taureaux laitiers. La comparaison des relevés d'un assez grand nombre de filles (dites "contemporaines" en terme de métier), indique pour chaque taureau le coefficient de transmissibilité du caractère laitier. La Section de la production de la Division des bestiaux du ministère de l'Agriculture du Canada publie les résultats de ces comparaisons dans un rapport semi-annuel sur l'évaluation des taureaux. Tous les éleveurs de bovins enregistrés inscrits au contrôle d'aptitudes officiel en reçoivent un exemplaire. Les bulletins de nouvelles des centres d'I.A. communiquent ces mêmes informations de sorte que les producteurs de lait soient parfaitement renseignés sur un grand nombre de taureaux qui ont établi leur valeur génétique par les aptitudes de leur descendance dans de nombreux troupeaux.

Comment savoir au moyen de l'épreuve de sa descendance, si le taureau améliore la race? Prenons par exemple le caractère de la production laitière. Le tableau 4 tiré des publications semestrielles du ministère fédéral de l'Agriculture renseigne sur l'évaluation de plusieurs taureaux. Le renseignement le plus important pour la sélection des taureaux qui amélioreront la production laitière figure dans la colonne intitulée "Cote laitière M.C.R." située à l'extrême droite du tableau. A noter qu'aux taureaux les moins cotés correspond une cote laitière M.C.R. précédée du signe moins; les taureaux cotés avantageusement n'ont pas de signe devant leur cote.

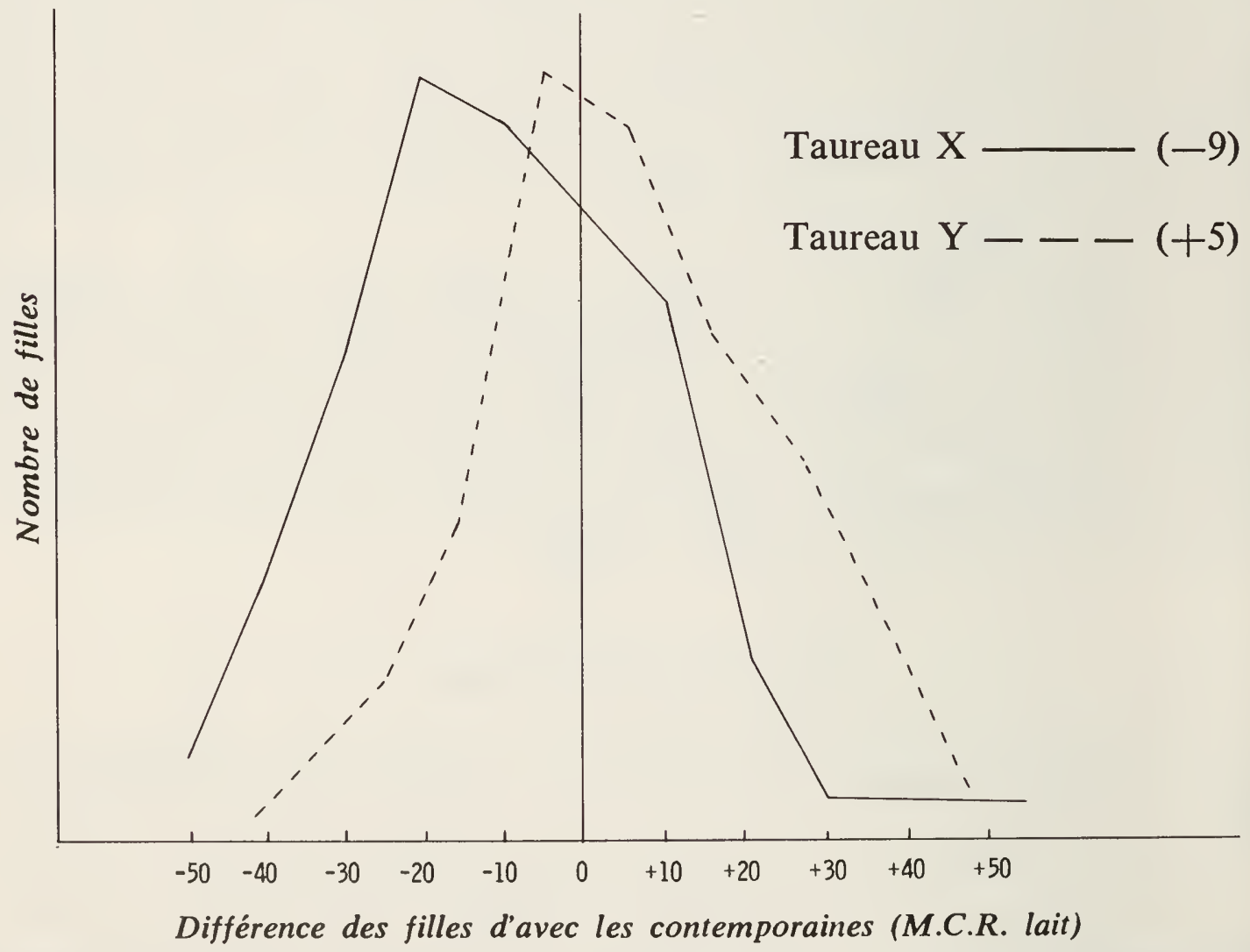

Figure 2. Répartition des filles de deux reproducteurs au moyen de la comparaison entre les "contemporaines" 
Pour mériter la cote "plus" un taureau doit compter au moins vingt filles qui, à l'âge de deux ans, surclassent leurs contemporaines (c'est-à-dire, les filles d'autres reproducteurs qui mettent bas la même année et dans le même troupeau que les filles du taureau en question). Ces taureaux améliorent la production laitière de la race. Au contraire, les taureaux cotés "moins" font généralement baisser la production de lait. On doit donc sélectionner les reproducteurs parmi les améliorateurs de la race (c'est-à-dire parmi les taureaux qui ont mérité la cote "plus", M.C.R.). Comme le fait voir la figure 2, plus la cote d'un taureau est élevée, meilleures sont les chances de l'éleveur d'obtenir des filles dont la production sera supérieure. Le taureau Y, qui a une cote de +5 , a engendré un pourcentage beaucoup plus élevé de filles dont la production de lait est supérieure à leurs contemporaines, alors que le taureau $\mathrm{X}$, bien qu'il ait un certain nombre de filles supérieures, en a beaucoup plus dont la production est médiocre.

L'amélioration des aptitudes de nos bovins laitiers ne peut résulter que de l'accouplement de taureaux éprouvés et reconnus en ce qui a trait à la M.C.R. avec toutes les vaches.

Cette règle souffre néanmoins une exception. Il arrive que le lait de certains troupeaux soit pauvre en matière grasse. En l'absence d'un taureau éprouvé possédant la cote laitière "plus" et qui est apte en même temps à améliorer la teneur en matière grasse, l'éleveur serait justifié d'employer tel reproducteur ayant une cote laitière à peine "moindre" que la M.C.R., à la condition que sa cote pour le pourcentage de matière grasse soit élevée.

A remarquer que le tableau 4 compte autant de taureaux cotés "plus" que de taureaux coté. "moins". Les taureaux vivants et en service dans les centres d'I.A. sont marqués d'un astérique. Le chiffre dans la colonne marquée "Propriétaire" indique le centre d'I.A. où le taureau est gardé. On peut se procurer la semence des taureaux d'I.A. vivants en s'adressant à son centre d'I.A. le plus rapproché. Pour obtenir des renseignements sur les taureaux appartenant à des particuliers, on voudra bien s'adresser à l'association d'éleveurs de la race en cause. Rappelons qu'en général les preuves établies sur le rendement d'un groupe de filles dans un seul troupeau ne sont pas un indice sûr de la valeur génétique d'un taureau. 


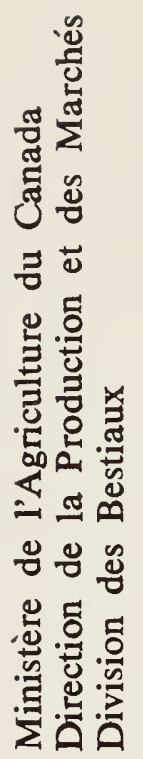
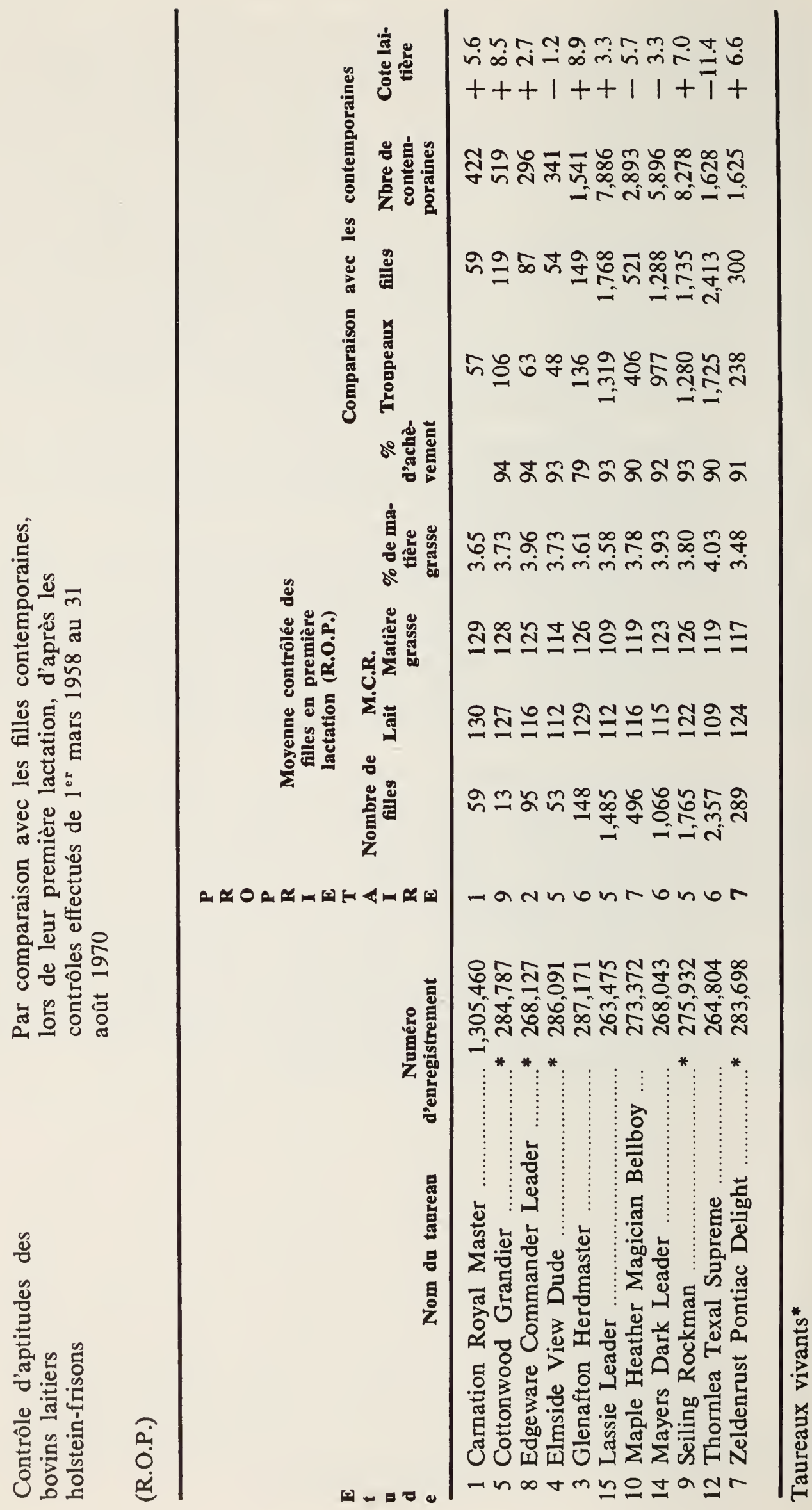

절

\%ั 


\section{Pourcentage de matière grasse}

La sélection des reproducteurs aptes à améliorer le pourcentage de matière grasse du lait se fait en comparant la moyenne procentuelle de la graisse butyrique de leurs filles avec celle de la race en question. Le tableau suivant donne, pour l'année 1968, les moyennes du rendement en matière grasse de certaines races.

\section{TABleau 5. Pourcentage moyen de la matière grasse de diverses races laitières}

Race

Matière grasse

Ayrshire

4.02

Guernsey

4.85

Holstein-Frisonne

3.73

Jersey

L'alimentation et les autres pratiques gestionnaires exercent peu d'effet sur les résultats de l'essai de la matière grasse; il n'est donc pas nécessaire d'effectuer la comparaison avec les contemporaines pour ce qui est de ce caractère. Les bulletins de nouvelles des centres d'I.A. et les rapports d'évaluation des taureaux indiquent toujours en pourcentage la moyenne de matière grasse des descendantes de chaque taureau. Les raceurs à cet égard sont ceux dont les filles ont un pourcentage supérieur à la teneur moyenne de la race. Cependant, lorsque le troupeau atteint un niveau suffisamment élevé, l'éleveur serait bien avisé de sélectionner des reproducteurs qui se rangent dans la juste moyenne de la race, ou légèrement au-dessus quant à la richesse en matière grasse, et de rechercher des raceurs à d'autres égards.

\section{Type}

Les filles d'un taureau qui possède une conformation supérieure à la moyenne dépassent généralement le coefficient moyen de fidélité au type ou comptent dans leurs rangs un pourcentage plus élevé de filles cotées au moins "bonnes plus". On peut obtenir la liste périodique de tous les reproducteurs de chaque race laitière ayant au moins dix descendantes ainsi classées; on a qu'à en faire la demande aux associations d'éleveurs, au Département de la zootechnie du Collège d'agriculture de l'Université de Guelph ou aux centres d'I.A. Ces listes présentent horizontalement les renseignements concernant chaque reproducteur. Chaque résumé porte en tête de tableau la moyenne générale du classement de la race et de chaque article de la fiche d'évaluation. Dans le cas où la moyenne des descendantes d'un reproducteur est supérieure à celle du classement général de la race, et de tout autre article de la fiche d'évaluation on peut considérer que le reproducteur améliore la race soit pour le classement général, soit pour un certain article de la fiche. Généralement, si un éleveur trouve que son troupeau laisse à désirer à certains égards de 
conformation, par exemple un pourcentage élevé de vaches dont le pis est allongé ou mal formé, il pourra rechercher le service d'un taureau dont les filles se rangent bien au-dessus de la moyenne de la race quant au port et à la conformation du pis. La technique qui consiste à utiliser un reproducteur qui réussit bien, pour les caractéristiques où il existe des faiblesses dans le troupeau, est désignée croisement correctif. On doit sans aucun doute donner la première place au caractère laitier, qui est un bon indice de l'aptitude laitière, aussi bien qu'à la forme et aux attaches du pis, aux pieds et aux membres, si l'objectif de l'éleveur comporte la fidélité au type.

Dans le cas où le producteur désire sélectionner pour le type, il ferait bien en premier lieu, de choisir parmi les taureaux ceux qui ont une cote plus élevée que la M.C.R. pour le lait, avec une cote pour la matière grasse égale ou supérieure à la moyenne de la race. Parmi les taureaux laitiers de qualité nettement supérieure, il arrêtera son choix sur ceux qui sont aptes à corriger les défauts de conformation des vaches de son troupeau. Ce procédé permet non seulement d'améliorer la conformation mais aussi de poursuivre l'amélioration constante de la production laitière et beurrière.

\section{BESOINS ALIMENTAIRES DES BOVINS LAITIERS}

Les aliments doivent fournir à l'animal laitier de l'énergie, des protéines, des matières grasses et certaines vitamines. La quantité de chaque principe nutritif dépend du sexe, de l'âge, du taux de croissance et de la production de lait de l'animal à nourrir.

La valeur énergétique, qui provient des hydrates de carbone, des protéines et des matières grasses, doit être assez forte pour permettre la croissance, la lactation et la reproduction, ainsi que pour suffire à tous les besoins de l'activité physique et pour maintenir la température du corps. Chez les jeunes animaux, l'insuffisance de l'apport d'énergie se traduit par des gains de poids médiocres et peu rentables. La reproduction demande une consommation suffisante d'aliments énergétiques; une lactation abondante est encore plus exigeante à cet égard.

\section{Energie}

Les sources d'énergie les plus abondantes et les plus économiques pour le bétail sont les hydrates de carbone que contiennent les aliments, y compris les extraits non azotés (amidons, sucres) et les matières cellulosiques. L'action des micro-organismes du rumen permet aux bovins et aux autres ruminants de digérer une grande partie de la cellulose qu'ils consomment. Les aliments à forte teneur cellulosique sont appelés fourrages grossiers, catégorie qui comprend les herbages, les foins et les silages, ainsi que le maïs fourrager, les tiges et les rafles de maïs, les enveloppes des grains et des graines. Les aliments comme les graines, qui ont une haute teneur en sucres et en amidons mais qui ne contiennent que peu de cellulose, sont appelés "concentrés" énergétiques. 
Le terme Principes nutritifs digestibles (P.N.D.), qui désigne la valeur énergétique d'un aliment, comprend tous les hydrates de carbone, protéines et matières grasses (ces dernières étant multipliées par $21 / 4$, puisque leur valeur énergétique est supérieure à celle des autres). Plus l'indice P.N.D. est élevé, plus grande est la valeur énergétique d'un aliment.

\section{Protéines}

Les protéines sont des substances nutritives complexes à base d'azote. Indispensables à la vie de tous les animaux, elles servent à la formation des muscles, des organes, des os, du lait et de certaines autres parties constituantes du corps. Les besoins protéiques sont plus élevés en période de croissance rapide, de reproduction et de lactation.

La croissance de l'animal en période de développement sera ralentie si on ne lui fournit pas assez de protéines pour suffire aux besoins de la croissance de ses tissus. Les gains précoces et rapides sont généralement les plus économiques, et les animaux doivent recevoir assez de protéines pour leur permettre ce genre de croissance. Il faut cependant se rappeler que les protéines sont généralement les substances nutritives les plus coûteuses; il est rarement rentable d'en donner plus que le nécessaire. La vache en gestation requiert un complément protéique pour constituer le corps du veau, et en période de lactation ce besoin est encore plus élevé, en raison des grandes quantités de protéines que contient le lait.

Certaines catégories d'animaux (par exemple, les volailles et les porcs) sont très exigeants en ce qui concerne certaines protéines particulières de "haute qualité". La flore bactérienne du rumen permet à la vache de transformer en protéines de bonne qualité d'autres substances azotées, protéiques ou autres. Ainsi, l'urée peut remplacer une certaine partie des protéines dans les rations des bovins. A toute fin pratique, le seul facteur à considérer dans les aliments protéiques des bovins est leur digestibilité dont le pourcentage varie d'un aliment à l'autre.

\section{Matière grasse}

La matière grasse du lait ne provient pas toute de la matière grasse contenue dans les aliments; une grande partie vient de la transformation des hydrates de carbone. Toutefois, la santé et la production affectées par la quantité de matière grasse contenue dans la ration. Les concentrés de la ration devraient contenir au moins $3 \%$ de matière grasse. Bien que cela arrive assez rarement, une quantité excessive de matière grasse (plus de 6\%) peut causer des troubles digestifs et la diarrhée.

\section{Vitamines}

Les vitamines sont une catégorie particulière de principes nutritifs nécessaires aux animaux, mais en quantités très minimes, comparativement aux hydrates de carbone et aux protéines. Toutefois, elles sont essentielles à l'équilibre de la santé et à la production. Chaque vitamine a son rôle particulier à jouer, mais on peut dire qu'elles sont toutes des substances régulatrices des fonctions physiologiques. 
Seulement deux vitamines, $\mathrm{A}$ et $\mathrm{D}$, demandent une attention spéciale pour l'alimentation des bovins. La flore bactérienne du rumen synthétise la vitamine $\mathrm{K}$ et toutes les vitamines du groupe $\mathrm{B}$ : aucun apport extérieur de ces vitamines n'est requis dès l'âge de deux mois. Dans l'intervalle, le lait fournit ces vitamines au veau. Il n'est pas prouvé que des suppléments de vitamine E soient nécessaires aux bovins laitiers s'ils sont alimentés normalement.

\section{Vitamine A}

La vitamine A est contenue dans les aliments sous forme de pigment, le carotène, substance colorée en jaune, qui se transforme dans l'organisme de l'animal en vitamine A incolore. Une partie de la vitamine A, qui n'est pas requise pour le fonctionnement de l'organisme de la vache, s'accumule dans le foie, les tissus adipeux et le pis qui la sécrète avec le lait. Des quantités variables de carotène non transformé se logent à ces niveaux, ce qui donne la coloration jaune aux tissus adipeux et à la graisse butyrique.

Cette vitamine est nécessaire à la croissance, à la bonne vision et pour le maintien en bon état des tissus du système digestif, de l'appareil respiratoire et des yeux, ainsi que pour le bon fonctionnement des appareils de reproduction et de lactation. Une carence de vitamine A entraîne un retard de la croissance; de sérieuses déficiences peuvent se traduire par la cécité la nuit, des ophtalmies, la titubation, l'incoordination des mouvements et des troubles de l'appareil de reproduction. Les carences bénignes sont beaucoup plus communes que les déficiences graves; elles entraînent un ralentissement de la croissance, de la lactation et de la reproduction.

La source habituelle de carotène pour les bovins sont les herbages verts. On en trouve abondamment dans les herbes fraîches. Plus celles-ci sont jeunes et feuillues, plus la teneur en carotène est élevée. A conditions égales, le trèfle et la luzerne en sont de meilleures sources que les graminées.

Les herbages desséchés contiennent très peu de carotène. Le foin séché au soleil en contient moins que le foin frais coupé, étant donné que l'exposition au soleil et à l'air détruit facilement le carotène. Les nouvelles méthodes de séchage en grange donnent d'habitude un foin plus riche en carotène que le foin séché au champ, étant donné qu'elles évitent la longue exposition au soleil. Le foin entreposé en meules perd graduellement de son carotène. L'ensilage d'herbe et de foin, lorsqu'il est bien fait, conserve une bonne partie du carotène de ces fourrages. La couleur verte des foins et des ensilages est un bon indice de leur richesse en carotène, bien qu'en soi, la couleur verte ne soit pas celle du carotène. On trouve aussi du carotène dans le maïs jaune, et l'alimentation au maïs-grain ou à la farine de maïs en épi enrichit la ration en vitamine $\mathrm{A}$.

L'aptitude qu'ont les bovins de mettre en réserve une partie de l'excédent de vitamine A ingérée durant les périodes de consommation surabondante, provenant d'herbages de haute qualité, leur est très utile pour s'entretenir durant les périodes de pénurie de carotène, par exemple en périodes de sécheresse estivale ou d'hivernement prolongé. 
On peut donner aux veaux des compléments de vitamine A sous forme de préparations sèches ou huileuses. Les huiles de foie de poisson, particulièrement celles qui sont faibles en principes actifs, ne conviennent pas aux vaches en lactation, mais les préparations sèches sont acceptables pour les bovins âgés qui ont cessé de produire.

\section{Vitamine D}

Les animaux en croissance ont besoin de vitamine D pour la formation d'os et de dents et les animaux adultes, pour les conserver en bon état. Les minéraux, calcium et phosphore, qui constituent la plus grande partie du squelette, ne sont pas absorbés ni déposés correctement en l'absence d'une quantité suffisante de vitamine $D$. Une carence de cette vitamine entraîne le rachitisme chez les veaux, trouble caractérisé par l'enflure des articulations et des boiteries puis, aux stades avancés, par le ralentissement de la croissance, le traînement des membres postérieurs et finalement la courbure, voire la rupture des os.

Les bovins obtiennent ordinairement la vitamine D de deux façons: par l'exposition au soleil, qui forme la vitamine dans l'organisme, et par l'alimentation. Les fourrages séchés au soleil contiennent de la vitamine D produite par irradiation solaire. A cet égard, il y a lieu de faire remarquer que les méthodes de séchage du foin qui évitent l'exposition au soleil permettent de conserver un plus haut pourcentage de carotène, mais empêchent en même temps l'enrichissement du fourrage en vitamine $D$. De même, le fourrage conservé par ensilage ne contient guère de vitamine $\mathrm{D}$.

Les veaux, particulièrement ceux qui sont gardés à l'intérieur, ont parfois besoin d'un apport de vitamine D sous forme d'huile de foie de poisson ou d'un complément vitaminique $\mathrm{D}$ mélangé à sec avec les concentrés.

\section{Minéraux}

Plusieurs des nombreux minéraux que l'on sait essentiels aux bovins laitiers sont contenus en quantités suffisantes dans les aliments habituels. D'ordinaire, seulement le calcium, le phosphore, le sel (chlorure de sodium), l'iode et le cobalt demandent une attention particulière. L'emploi de compléments minéraux autres que ceux-ci n'est pas recommandé pour usage général de nos jours, malgré que des carences d'oligo-éléments puissent se produire dans certaines régions.

\section{Calcium et phosphore}

Le calcium et le phosphore sont traités ensemble, étant donné que l'organisme les utilise conjointement et que certaines sources complémentaires les contiennent tous deux. Ces deux éléments sont les principaux constituants des os et des dents. L'organisme en demande de grandes quantités durant la croissance et la gestation pour la formation de nouvelles structures osseuses. Etant donné que le lait est très riche en calcium et en phosphore, la demande de compléments est grande durant la période de lactation.

Une carence de l'un ou de l'autre de ces minéraux, ou des deux à la fois, cause des défauts de squelette semblables à ceux qui sont imputables à 
l'avitaminose D. Une grave carence de phosphore dans les rations cause aussi d'autres anomalies, tels que la perte de l'appétit ou même le pica. Dans ce dernier cas, l'animal mâche des os, du bois, de la terre, etc. Le phosphore est essentiel aussi à la reproduction normale chez la femelle.

Plusieurs terres manquent de phosphore; les aliments qui y poussent sont également pauvres en ce minéral. L'alimentation des bovins est donc plus souvent déficiente en phosphore qu'en calcium. Les fourrages sont des sources médiocres de phosphore, les céréales et autres grains en contiennent plus. D'autre part cette dernière catégorie est pauvre en calcium, alors que les fourrages en ont plus, mais en quantités variables. Les légumineuses sont beaucoup plus riches en calcium que les graminées. Les jeunes veaux reçoivent des quantités suffisantes de calcium et de phosphore dans le lait.

On remédie aux carences de calcium et de phosphore en ajoutant aux rations des produits tels que la farine d'os, le phosphate bicalcique, le phosphore monocalcique et les phosphates de roche défluorés. Le phosphate bisodique ne fournit que du phosphore, alors que la chaux ne fournit que du calcium. Ces produits sont disponibles sous différentes marques de commerce. Les

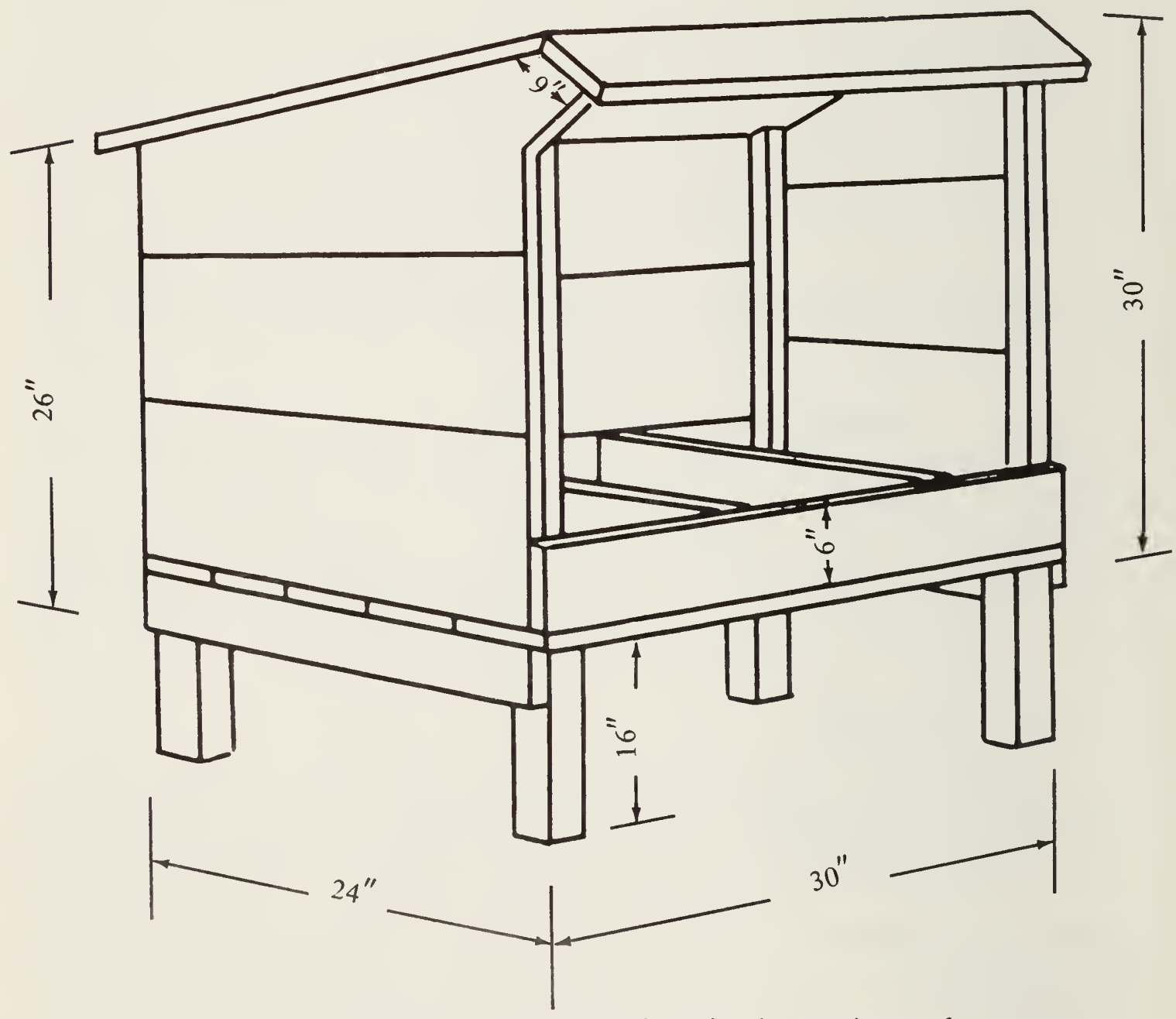

Caisse à sel et à minéraux de construction simple protégeant le contenu contre les intempéries

Voir le plan $n^{0} 2663$ du Service canadien de plans de constructions rurales. 
quantités et les proportions à administrer dépendent dans une certaine mesure des autres composants de la ration, particulièrement de la nature et de la quantité du fourrage. La meilleure méthode consiste à ajouter un pour cent de sel et de un à deux pour cent de compléments minéraux au mélange de grain, et de permettre aux animaux l'accès à un mélange de sel et de minéraux contenus dans une auge séparée.

La plupart des mélanges de concentrés commerciaux contiennent des compléments minéraux. Il n'est donc pas nécessaires de les enrichir. Il est bon toutefois, de permettre aux animaux alimentés à ces concentrés, le libre accès à un mélange de minéraux.

\section{Sel, iode, cobalt}

Le sel ordinaire (chlorure de sodium) a plusieurs fonctions à remplir; il aide à la production du lait et sert à améliorer l'appétibilité de la ration et à stimuler l'appétit.

Bien que l'iode ne soit requise qu'en quantités minimes, c'est un minéral essentiel à l'activité de la glande thyroïde qui régularise toutes les fonctions de l'organisme. La venue de veaux atteints du goître, ou grosse gorge, est un indice de carence en iode. On recommande un complément iodé pour plusieurs régions et le moyen le plus pratique et le plus efficace est de donner du sel iodé.

Les récoltes en certaines régions du Canada sont assez pauvres en cobalt et les bovins alimentés à partir de ces cultures n'absorbent pas toujours suffisamment de ce minéral, d'où la nécessité d'un apport complémentaire. La carence produit l'apathie chez les animaux, le ralentissement de la croissance et une diminution graduelle de l'appétit, avec la perte de poids, la grossièreté du pelage et l'anémie. Il se produit parfois du pica (dépravation de l'appétit), comme dans les cas de carence en phosphore, et même des troubles de reproduction.

La petite quantité de cobalt requise peut être facilement fournie sous forme de sel enrichi de cobalt, formule que l'on recommande pour tous les bovins laitiers.

Le sel iodo-cobalté peut se mélanger aux concentrés dans la proportion de un pour cent ou être placé dans une caisse couverte, avec les autres minéraux, dans la cour ou le pâturage.

On doit rappeler que la couleur des blocs de sel qui contiennent de l'iode (rouge-brun) et du cobalt (bleu ou pourpre) provient de l'addition de substances colorantes et non des oligo-éléments. Le sel iodo-cobalté, granulé et qui n'est pas coloré n'est en aucune façon inférieur du point de vue nutritif.

\section{Compléments et mélanges minéraux}

Différents mélanges des compléments de calcium et de phosphore répondent à des besoins particuliers. Voici quelques mélanges généralement recommandés:

a. 67 livres de phosphate bicalcique, 33 livres de sel iodo-cobalté.

b. 50 livres de phosphate bicalcique, 25 livres de phosphate monocalcique, 25 livres de sel iodo-cobalté. 
c. 50 livres de phosphate bicalcique, 17 livres de phosphate bisodique, 33 livres de sel iodo-cobalté.

d. 50 livres de farine d'os alimentaire autoclavée, 25 livres de phosphate bisodique, 25 livres de sel iodo-cobalté.

e. 50 livres de farine d'os alimentaire autoclavée, 25 livres de phosphate monocalcique, 25 livres de sel iodo-cobalté.

f. 50 livres de phosphate monocalcique, 17 livres de pierre à chaux pulvérisée, 33 livres de sel iodo-cobalté.

g. 67 livres de farine d'os autoclavée, 33 livres de sel iodo-cobalté.

Plusieurs autres mélanges complémentaires produisent des résultats satisfaisants. Chaque minéral peut aussi être déposé dans une caisse séparé qui permet l'alimentation au choix. On trouvera au tableau 6 la teneur moyenne en calcium et en phosphore des compléments habituels et des mélanges recommandés ci-dessus.

TABleau 6

\begin{tabular}{|c|c|c|c|c|}
\hline & \multicolumn{2}{|c|}{ Calcium } & \multicolumn{2}{|c|}{ Phosphore } \\
\hline & $\%$ & g/livre & $\%$ & g/livre \\
\hline \multicolumn{5}{|l|}{ Compléments } \\
\hline farine d'os alimentaire autoclavée & 29.1 & 132.1 & 14.3 & 64.9 \\
\hline phosphate bicalcique $\ldots \ldots \ldots \ldots . . .$. & 26.5 & 120.3 & 20.5 & 93.1 \\
\hline phosphate monocalcique & 16.0 & 72.6 & 24.0 & 109.0 \\
\hline phosphate bisodique & 一 & - & 18.0 & 81.7 \\
\hline pierre à chaux (calcite) & 38.3 & 173.9 & 一 & 一 \\
\hline phosphate de roche (défluoré) & 27.0 & 122.6 & 13.4 & 60.8 \\
\hline \multicolumn{5}{|l|}{ Mélanges } \\
\hline …… & 17.8 & 80.9 & 13.7 & 62.3 \\
\hline (n................. & 17.2 & 78.2 & 16.2 & 73.6 \\
\hline$\overline{\mathrm{C}}$ & 13.2 & 60.0 & 13.3 & 60.5 \\
\hline D & 14.6 & 66.4 & 11.6 & 52.7 \\
\hline ㄱ................ & 18.6 & 84.4 & 13.2 & 59.9 \\
\hline $\mathbf{F}$ & 14.5 & 65.9 & 12.0 & 54.6 \\
\hline $\mathbf{G}$ & 19.5 & 88.5 & 9.6 & 43.6 \\
\hline
\end{tabular}

\section{CARACTERISTIQUES DES ALIMENTS DU BETAIL}

Les aliments du bétail se répartissent en deux catégories principales: les fourrages grossiers et les concentrés. Les premiers sont des aliments grossiers et volumineux, d'une faible teneur en principes nutritifs. Les concentrés, comme le nom l'indique, ont une faible teneur en cellulose et une haute teneur en principes digestibles. La présente section donne un bref aperçu des aliments des deux catégories d'emploi courant. Pour de plus amples renseignements sur la composition moyenne des différents aliments, veuillez consulter le tableau A 3 figurant en annexe. 


\section{FOURRAGES GROSSIERS}

Cette appellation s'applique à une large gamme d'aliments, notamment tous les types de foins, d'ensilages, de pâturages et plantes-racines. Notre but dans le cadre du présent ouvrage n'est pas d'examiner en détail tous les types de fourrages grossiers. La teneur en eau de ces aliments variant très sensiblement de l'un à l'autre, du fourrage sec au fourrage vert en passant par les racines, il importe de tenir compte de ce facteur lorsqu'on apprécie au poids la valeur nutritive de tel ou tel produit.

La tendance actuelle veut que l'on utilise de plus en plus les fourrages grossiers conservés sous forme d'ensilage, en raison de leur manutention automatisée et de l'affranchissement relatif des conditions atmosphériques qu'ils autorisent au temps de la moisson.

\section{Le foin}

Le foin séché au champ et engrangé en vrac, en balles ou haché a constitué longtemps l'alimentation de base des bovins laitiers. La qualité du foin est très variable; elle dépend en premier lieu du degré de maturité de l'herbe au moment de la fenaison, de sa composition botanique et des conditions dans lesquelles la fenaison a été faite. En règle générale, les foins mélangés à forte proportion de légumineuses sont les meilleurs, pour autant qu'ils aient été fauchés lorsque l'herbe était encore jeune et qu'il y ait eu au cours de la fenaison un minimum de dégâts dus aux intempéries. Le foin coupé tôt est supérieur en qualité au foin coupé plus tard dans la saison, même si le premier a subi certains dégâts durant la fenaison et que le second ait été rentré dans des conditions idéales. Le séchage artificiel du foin réduit les pertes dues aux agents atmosphériques, mais il convient d'examiner la rentabilité du matériel de conditionnement en fenil avant de procéder à son installation.

\section{Ensilages}

\section{L'ensilage de maïs}

Cet aliment en plus du foin constitue un fourrage grossier dont l'utilisation est très répandue pour l'alimentation des vaches laitières. Son rendement élevé et l'extension de la culture du maïs dans l'Ontario et d'autres provinces en font un fourrage de plus en plus courant.

L'utilisation de variétés hâtives, moissonnées presque à maturité et entreposées dans de bonnes conditions, permet l'obtention d'un fourrage grossier possédant à la fois beaucoup d'appétibilité et une haute valeur énergétique. Toutefois, sa teneur en protéine est faible par rapport au foin de bonne qualité. Dès lors, si l'ensilage de maïs constitue la majeure partie de la ration de fourrage grossier, des dispositions doivent être prises pour corriger cette pénurie au moyen d'un mélange de concentrés appropriés.

\section{Ensilage d'herbe à haute teneur en matière sèche}

Les fourrages peuvent être ensilés à différents degrés d'humidité, mais les résultats sont les meilleurs lorsque la teneur en eau est de 45 à $60 \%$, ce qui exige un préfanage au champ avant la mise en silo. Cet ensilage mi-fané (sous 
le rapport de la matière sèche) a une valeur alimentaire comparable au foin obtenu à partir des mêmes espèces et fait au même stade de maturité. Lorsque le fourrage est ensilé alors que sa teneur en eau est plus élevée, c'est-à-dire dès le fauchage ou tout juste préfané, les vaches ingèrent moins de matières sèches, au détriment possible de la production.

\section{LES CONCENTRES}

\section{Maïs}

\section{Céréales}

L'utilisation du maïs comme grain de base des aliments concentrés se répand de plus en plus, surtout dans les régions qui conviennent à la culture du maïsgrain. Bien que la teneur du maïs en protéine brute soit la plus basse de toutes les céréales, sa teneur globale en principes nutritifs digestibles est par contre la plus élevée. Le maïs est d'un goût agréable et peut être distribué en grandes quantités, à condition de lui adjoindre des compléments de concentrés protéiques grossiers. Le broyage est préférable à la mouture fine, le maïs étant un aliment lourd. Pour cette raison aussi, pour l'alimentation intensive des vaches à grand rendement laitier, le maïs doit être mélangé avec des aliments plus grossiers comme l'avoine et le son. La quantité de matières énergétiques ingérées constituant souvent le principal facteur limitatif de la production laitière, il convient de noter qu'une acre de maïs fournit environ deux fois autant de principes nutritifs digestibles (P.N.D.) que toute autre céréale.

\section{Farine de maïs en épi}

Dans les régions où l'on cultive le maïs, les épis entiers, y compris la rafle, sont moulus pour l'alimentation des animaux. Ce mélange contient moins de protéine, beaucoup plus de cellulose et de 10 à $15 \%$ moins de P.N.D. que le grain de maïs; au surplus il est plus grossier.

\section{Maïs à grain humide}

L'ensilage de maïs égrené ou d'épis moulus d'une teneur en eau de 25 à $35 \%$ donne de bons résultats. Il a en effet été démontré que la valeur nutritive de ce type d'ensilage, exprimée en matière sèche équivalente, est égale à celle du fourrage sec correspondant. En raison de sa grande teneur en eau, l'animal doit en ingérer un plus gros volume pour obtenir la même quantité de principes nutritifs fournis par du maïs sec. De plus, il faut tenir compte du fait que l'ensilage de fourrage à haute teneur en eau exige que l'on sorte du silo au jour le jour juste les quantités nécessaires, pour éviter qu'il ne se gâte. Il ne se prête donc pas au mélange préalable en grandes quantités avec des concentrés. Cet inconvénient est à peser contre les avantages qu'offrent la conservation et la manutention des aliments ensilés.

\section{Avoine}

L'avoine constitue depuis longtemps la base de la plupart des mélanges de concentrés destinés aux vaches laitières. Cet état de chose est sans doute attribuable au fait que d'une part, sa culture se pratique sur de vastes régions et qu'elle réussit presque toujours, et que d'autre part, elle est savoureuse et 
peut être donnée sans danger au bétail de tout âge. Par contre, un des gros désavantages de l'avoine en tant qu'aliment concentré pour les bovins laitiers tient au fait que de toutes les céréales communément utilisées, elle vient au dernier rang pour la quantité de principes nutritifs qu'elle donne à l'acre. C'est la raison pour laquelle les superficies affectées à cette culture vont en diminuant d'année en année. La valeur énergétique de l'avoine (P.N.D.) est inférieure à celle des autres céréales en raison de la teneur élevée en cellulose de la balle. Aussi, on lui préfère d'autres céréales lorsque la valeur énergétique du régime est capitale, comme c'est le cas pour les vaches à grand rendement. Il faut au surplus, lors de l'achat de l'avoine, tenir compte de sa moindre valeur énergétique. L'avoine a une teneur en protéine plus élevée que le maïs, et plus ou moins égale à celle de l'orge et du blé. Les veaux, contrairement aux bovins plus âgés, mastiquent à fond les graines tendres et valorisent avantageusement l'avoine non décortiquée. Pour le bétail plus âgé, l'avoine doit être broyée grossièrement ou aplatie. La balle d'avoine a peu de valeur nutritive. La composition de l'avoine varie très fort d'une variété à l'autre. Les avoines légères ont généralement peu de valeur nutritive, tandis que le poids élevé au boisseau est d'ordinaire l'indice d'une avoine de bonne qualité.

\section{Orge}

L'orge est plus riche en principes nutritifs digestibles que l'avoine mais plus pauvre que le maïs ou le blé. Sa teneur en cellulose n'est qu'environ la moitié de celle de l'avoine. L'orge s'ajoute aux rations principalement pour en augmenter la valeur énergétique. La mouture d'orge est lourde et ne devrait donc pas constituer plus de la moitié de la ration des vaches laitières. On la mélange d'ordinaire avec des aliments grossiers, comme l'avoine aplatie et le son, et avec un concentré protéique grossier.

\section{Blé}

Le blé remplace l'orge dans l'alimentation des vaches laitières lorsque la substitution est rentable. La teneur en protéine et en principes énergétiques du blé se compare favorablement à celle de l'orge. Pour l'alimentation des vaches laitières, le blé doit être moulu ou broyé grossièrement et ne pas constituer plus du tiers du mélange, car c'est un aliment très dense. En raison de sa nature pâteuse, le blé doit être mélangé avec un concentré grossier. Le blé tendre d'hiver aplati donne du volume aux rations.

\section{Soja}

\section{Aliments riches en protéines}

De toutes les graines alimentaires usuelles, le soja est le plus riche en protéine; il peut dès lors constituer un concentré protéique. Broyé ou concassé, le bétail l'apprécie modérément; il a un effet légèrement laxatif. Le soja a une teneur élevée en matière grasse et lorsqu'il est distribué en grandes quantités, le beurre devient mou bien que le lait ne prenne guère de goût. Une ingestion excessive de soja diminue l'assimilation du carotène. C'est la raison pour laquelle le lait des vaches nourries au soja perd sa couleur jaunâtre normale, à moins qu'on ne donne un complément suffisant de fourrage de bonne qualité ou toute autre source de carotène. 


\section{Tourteau de soja}

Le tourteau de soja est l'un des nombreux sous-produits de l'extraction de l'huile de soja. Sa haute teneur en protéine de bonne qualité et en P.N.D., son appétibilité et son prix compétitif en font actuellement le complément protéique le plus utilisé dans l'alimentation de tous les types de bestiaux. D'une manutention aisée, il se mélange bien aux graines pour constituer un complément protéique idéal.

\section{Tourteau de lin}

Le sous-produit de l'extraction de l'huile de graine de lin est communément désigné comme tourteau de lin. Sa teneur en protéine est relativement élevée ce qui en fait un complément protéique. Cette farine est très savoureuse pour le bétail et elle est particulièrement appréciée pour l'alimentation du bétail d'exposition et pour les vaches amouillantes (qui viennent de vêler). Le tourteau de lin est inférieur au tourteau de soja, tant sous le rapport de sa teneur en protéine qu'en P.N.D., fait dont il faut tenir compte au moment de l'achat de compléments protéiques.

\section{Tourteau de coton}

Le tourteau de coton est l'une des meilleures sources de protéine pour les bovins laitiers mais il n'est pas toujours disponible. C'est le sous-produit de l'extraction de l'huile de coton. Il ne convient guère aux vaches amouillantes, mais assez bien aux vaches en lactation, en mélange avec les céréales et autres mélanges d'aliments. Ainsi, le son et le tourteau de soja font un excellent mélange avec le tourteau de coton et les céréales.

\section{Drêche de brasserie séchée}

Le résidu du maltage est désigné drêche de brasserie. Au cours des opérations, le grain perd la majeure partie de son amidon et de ses sucres, de sorte que la drêche est pauvre en hydrates de carbone solubles et relativement riche en cellulose et en protéine brute. Sa teneur en P.N.D. est égale à celle du son, mais sa teneur en protéine digestible lui est nettement supérieure. Le bétail n'est pas particulièrement friand de la drêche, aussi faut-il l'incorporer à d'autres mélanges. Dans l'alimentation des vaches laitières, elle donne de bons résultats lorsqu'elle ne dépasse pas un tiers du mélange de concentrés. Etant volumineuse, elle est utile pour alléger les rations lourdes. Au surplus, elle enrichit notablement les rations laitières en matière grasse.

\section{Drêche de distilierie}

La drêche de distillerie est le résidu de la fabrication de l'alcool et des liqueurs à partir de céréales tels le maïs et le seigle. Elle constitue un bon complément pour les vaches laitières, particulièrement lorsque leur ration contient plus de maïs que de seigle.

\section{Gluten de mais}

Cet aliment est un sous-produit de la fabrication d'amidon de maïs. Sa teneur en protéine digestible est assez élevée, soit en moyenne les deux tiers de celle du tourteau de lin. Comme cet aliment est constitué de fin gluten et de 
son de maïs, sa teneur en cellulose est relativement élevée. N'étant pas d'un goût aussi agréable que le maïs, l'avoine ni le son de blé, on le mélange d'habitude à un produit savoureux. Sa teneur moyenne en P.N.D. varie entre 74 et $75 \%$, soit plus que celle de l'avoine ou du son, mais moins que celle du maïs.

\section{Urée}

L'urée peut s'utiliser en tant que produit de remplacement de la protéine pour l'alimentation des bovins. La microflore du rumen, en présence d'hydrates de carbone transforme l'azote de l'urée en acides aminés. Pour faciliter la synthèse de la protéine à partir de l'urée, la flore bactérienne a besoin d'hydrates de carbone rapidement assimilables, tel l'amidon ou le sucre. Ainsi, l'adjonction d'urée aux rations de foin de fléole des prés, dans lequel les hydrates de carbone se présentent sous forme de cellulose difficile à digérer, ne donne pas les meilleurs résultats.

On utilise généralement avec l'urée des aliments riches en hydrates de carbone rapidement assimilables, telles les céréales et la mélasse. L'amidon des céréales est plus efficace sous ce rapport que le sucre de la mélasse. Les précautions suivantes sont indiquées:

1. L'urée doit être parfaitement mélangée à la ration; c'est pourquoi il est préférable de ne pas faire ses mélanges sur place.

2. L'urée ne doit pas servir à élever la teneur protéique des mélanges de concentrés au-delà de $16 \%$.

3. L'urée ne doit pas constituer plus de $3 \%$ de la ration de concentrés, autrement elle perdrait de son appétibilité.

4. L'urée ne doit pas constituer plus du tiers de l'équivalent protéique de la ration totale. Les vaches ne sont guère friandes d'urée, elles lui préfèrent les tourteaux d'oléagineux.

5. L'urée ne doit pas être mélangée à des concentrés médiocres d'une haute teneur en cellulose, simplement pour répondre aux besoins des vaches laitières en protéines. Un tel mélange serait impropre en raison de sa mauvaise qualité, et de sa faible valeur énergétique.

6. L'adjonction de $5 \%$ de mélasse aux céréales contenant de l'urée améliore l'appétibilité du mélange.

\section{Farine hominy}

\section{Concentrés divers}

Ce sous-produit de la fabrication de la farine et du gruau hominy a une valeur alimentaire comparable à celle du maïs et peut être utilisé de la même manière que le maïs entier.

\section{Son de blé}

Le son de blé, sous-produit de la mouture du blé, est d'utilisation courante pour l'alimentation des vaches laitières. Sa teneur en protéine, en minéraux, (particulièrement en phosphore) et en cellulose est supérieure à celle du blé entier mais il lui est inférieur en principes nutritifs digestibles. Il est laxatif, agréable aux bestiaux; étant volumineux, il sert à alléger les concentrés lourds. 


\section{Gru rouge}

Le gru rouge, sous-produit du blé, est quelque peu plus lourd que le son et plus riche que celui-ci en P.N.D., moins riche en cellulose et d'une teneur semblable ou légèrement supérieure en protéine. Son utilisation pour le bétail n'est pas aussi courante en raison de sa nature légèrement pâteuse.

\section{Pulpe de betteraves séchée}

Sous-produit du raffinage du sucre, la pulpe est souvant donnée à la place de l'ensilage ou des racines fourragères. C'est un aliment volumineux, laxatif et d'une faible teneur en protéine. Les animaux la préfèrent mélangée à environ trois fois son poids d'eau. On peut aussi lui ajouter de la mélasse au cours du trempage, bien que l'adjonction préalable de mélasse de betteraves soit de pratique courante actuellement.

\section{Mélasse}

On ajoute couramment de la mélasse aux aliments moulus pour en améliorer l'appétibilité et les rendre moins pulvérulents. Elle augmente la teneur des mélanges en hydrates de carbone, mais son apport en protéines est minime.

\section{ALIMENTATION DES VACHES LAITIERES}

Les nombreuses études faites en divers pays ont permis d'établir les quantités exactes des divers principes nutritifs qu'il faut donner aux animaux, suivant leur taille, leur âge, et leurs différents stades de production. Les besoins varient d'un animal à l'autre, même lorsque les conditions sont analogues; les quantités recommandées se rapprochent généralement des besoins maximums. Les recommendations varient dans leur présentation suivant les chercheurs; elles figurent d'ordinaire sous les titres de normes ou de rations alimentaires. On est prié de consulter l'annexe, tableau A1 qui présente les besoins quotidiens des bovins laitiers en principes nutritifs.

On obtient les meilleurs résultats en donnant aux vaches des rations généreuses de fourrages grossiers de bonne qualité, plutôt que des grosses quantités de grains ou de concentrés. Toutefois, les fortes laitières ne donnent pas leur rendement maximum, ou ne le maintiennent pas, si elles sont nourries exclusivement de fourrages grossiers. Elles ne peuvent en effet ingérer assez de ces aliments volumineux pour s'assurer l'apport de tous les principes nutritifs nécessaires. C'est pourquoi elles exigent des grains et des sous-produits sous une forme plus concentrée.

\section{FOURRAGES GROSSIERS}

Le meilleur foin pour l'alimentation des vaches est un foin vert, feuillu, à tiges grêles, fait de légumineuses ou d'un mélange de légumineuses et de graminées, exempt de moisissures, d'odeurs et de manuvaises herbes. En règle générale, il faut donner aux vaches autant de foin qu'elles peuvent en ingérer sans gaspillage. Elles consomment plus de foin de bonne qualité que de fourrage de qualité médiocre où prédominent des tiges grossières. En outre, la consommation est d'autant plus forte que l'animal est nourri plus 
souvent. Lorsque les stocks de foin varient en qualité, il est préférable de mélanger les qualités chaque jour, plutôt que de faire alterner les périodes de bonne qualité et de qualité inférieure. De même, ce sont les vaches en pleine lactation qui doivent recevoir davantage de foin de bonne qualité, plutôt que les vaches en période de tarissement. Les ensilages, le maïs ou de l'herbe de bonne qualité constituent un excellent fourrage grossier pour les vaches et pour les génisses en croissance. La consommation dépend de la qualité de l'ensilage et du complément de foin qu'elles reçoivent.

Pour être bien nourries, les vaches doivent ingérer quotidiennement un volume de fourrage grossier, exprimé en matière sèche, représentant de 2 à $3 \%$ de leur poids, soit $2.5 \%$ en moyenne. Lorsque le fourrage est de mauvaise qualité, ou que la ration est constituée en grande partie d'ensilage à haute teneur en eau, l'ingestion de matière sèche sous forme de fourrage grossier peut tomber à $2 \%$ du poids de l'animal ou même moins. Pour fixer les idées, une livre de foin sec contient à peu près la même quantité de matière sèche que deux livres d'ensilage préfané ("haylage") (55\% d'humidité) ou trois livres d'ensilage de maîs (65 à $75 \%$ d'humidité). Voici quelques règles fort simples pour l'affouragement des vaches par 100 livres de poids vif:

Donner de 2 à 2.5 livres de foin;

ou

1.5 livre de foin, plus 3 livres d'ensilage de maïs;

ou

1.5 livre de foin, plus 2 livres d'ensilage préfané;

ou

2 livres d'ensilage préfané, plus 3 livres d'ensilage de maïs;

ou

4 livres d'ensilage préfané;

ou

6 livres d'ensilage de maïs ou de graminées.

Quand le fourrage est peu abondant, on peut en réduire très sensiblement les quantités, à condition d'augmenter les rations de concentrés en conséquence. Toutefois, lorsque l'ingestion quotidienne de matière sèche sous forme de fourrage tombe en deçà de $1 \%$ du poids de l'animal, la teneur du lait en matière grasse est portée à diminuer.

\section{PROGRAMME D'AFFOURAGEMENT EN ETE}

\section{Le pâturage}

La jeune herbe verte de pâturage constitue l'aliment presque idéal des vaches laitières. Un excellent pâturage est apte à maintenir une plus forte production laitière que l'alimentation ordinaire à l'étable; sous l'aspect de l'économie, c'est le facteur le plus important en production laitière. Malheureusement, la saison d'excellents pâturages est souvent très courte et il faut avoir recours aux compléments de principes nutritifs pour assurer une production laitière élevée. 
Les herbages de printemps ont beaucoup d'appétibilité, contiennent beaucoup d'eau, sont riches en protéines et pauvres en cellulose. A mesure que le pâturage vieillit, la teneur en protéine baisse, celle en cellulose s'accroît et l'appétibilité et la digestibilité décroissent. Il est de première importance de savoir juger avec exactitude de la grande variabilité nutritive des pâturages au cours de la saison. Seule une exploitation avisée et la culture de fourrages d'appoint peuvent remédier à ce manque d'uniformité.

Dans la gestion des pâturages, les principales erreurs à éviter sont la paissance prématurée et excessive d'une part, et d'autre part, la pousse immodérée; la fertilisation et la destruction des mauvaises herbes sont des impératifs. Le surpâturage en fait baisser les rendements, accroît les effets pernicieux de la sécheresse et favorise la croissance des mauvaises herbes. Le sous-pâturage, par ailleurs, est une erreur plus rare et moins grave aussi, cependant outre le gaspillage, elle stimule la croissance d'herbes grossières et ligneuses. Le hersage des pâturages à la fin de l'automne épand les déjections et prévient la formation des touffes de refus.

La quantité d'herbe consommée chaque jour varie. Elle dépend surtout de l'appétibilité et de l'abondance de la pâture. Les vaches de taille moyenne ou grande mangent de 125 à 150 livres d'herbe par jour, ce qui devrait leur assurer les principes nutritifs nécessaires à leur entretien et à la production d'environ 30 à 35 livres de lait par jour. Ces chiffres approchent du maximum; ils ne valent que dans des conditions quasi idéales.

Etant donné que plusieurs vaches au pâturage produisent plus de 35 livres de lait par jour, il faut leur donner des compléments pour maintenir leur poids et assurer la production du troupeau. L'éleveur doit aborder l'alimentation complémentaire des vaches au pâturage avec soin et intelligence, s'il veut éviter d'une part le gaspillage et d'autre part le fléchissement de la production de lait et l'amaigrissement des vaches. On trouvera plus loin des barèmes d'alimentation des bovins, mais avant de les appliquer, il faut tenir compte de l'état du pâturage, de l'époque de l'année et du niveau de la production laitière.

Etant donné la richesse en protéine de l'herbe tendre, il n'est pas nécessaire que le complément des vaches au pâturage aient une teneur protéique élevée; néanmoins, il doit leur apporter des principes nutritifs immédiatement assimilables pour subvenir à leurs besoins énergétiques. Les céréales produites à la ferme peuvent très bien suffire. A mesure que l'herbage vieillit, il y a lieu d'augmenter la teneur en protéine du mélange complémentaire. Pour déterminer la richesse du mélange il faut tenir compte de l'état du pâturage, du rendement des vaches, du prix des aliments et du prix courant du produit.

Les vaches aiment la régularité. Pour que les rendements en lait demeurent élevés il faut, non seulement leur fournir des quantités régulières de fourrage, pendant tout l'été et au besoin, compléter celui-ci avec des concentrés, mais encore tenir compte des facteurs autres que celui de l'alimentation.

Les vaches ont besoin d'eau fraîche en grande quantité (le lait en contient $85 \%$ environ). Dans la mesure du possible, assurer la présence d'eau fraîche en permanence dans le pré et surtout, éviter absolument de laisser le bétail 
s'abreuver d'eau stagnante dans les ornières et les marécages. Bien qu'elle ne soit pas absolument indispensable, l'ombre ajoute sans conteste au bien-être des bovins. Quelques arbres dans le champ ou le long de la clôture offrent aux animaux un abri contre l'ardeur du soleil sur le haut du jour.

Les pâturages réguliers doivent, de toute nécessité, faire partie intégrante du système d'assolement de l'exploitant. Cependant, chaque fois que la chose est possible, le pré devrait se trouver à proximité de l'étable. Une longue distance entre le pré et l'étable, ne favorise pas la production laitière. En plus d'une dépense d'énergie, les vaches risquent de se blesser le pis et d'avoir des maux de pattes.

\section{Programme d'appoint pour l'affouragement d'été}

On a déjà parlé de certaines limitations des programmes d'alimentation d'été axés avant tout sur les pâturages. Bien qu'un bon pâturage stimule à bon compte une production laitière élevée, les rendements de lait par acre d'herbage peuvent être améliorés par l'application de méthodes visant à restreindre la paissance. Dans les conditions où le coût de la terre est élevé et que la production par unité de terre est importante, il faut étudier des possibilités de rechange. D'autant plus que la variation de la quantité et de la qualité des herbages se traduit par l'instabilité de la production laitière. Pareille situation peut être redressée en grande partie: (1) en donnant des fourrages complémentaires (foin, fourrages ensilés ou hachés en vert), ou des compléments de concentrés lorsque diminue la qualité ou la quantité des herbages; (2) en engrangeant tous les aliments et en suivant le même programme d'alimentation à longueur d'année; (3) en alimentant tous les jours aux herbages fauchés et hachés verts, au lieu de faire paître (apâturage); ou (4) en ayant recours aux pâturages d'appoint.

\section{Fourrages complémentaires}

Ce mode d'alimentation offre le moyen le plus simple et le moins cher de maintenir l'approvisionnement en aliments et de soutenir la production laitière à un niveau constant pendant tout l'été. Il permet de tirer avantage du fait que la production laitière est plus abondante en début de saison de paissance et qu'à cette époque, il y a souvent surabondance d'herbe que l'on peut faucher et conserver comme foin ou comme ensilage pour parer à l'insuffisance des pâturages. Les restes de foin ou d'ensilage de l'hivernement peuvent également servir à compléter les pâturages. Lorsqu'on distribue de l'ensilage aux vaches au pâturage, ne pas oublier de mesurer l'exacte ration quotidienne afin d'éviter tout gaspillage, surtout par temps chaud. Pour sa part, le complément de foin donné en été présente un avantage additionnel, celui de prévenir dans une certaine mesure les ennuis de la météorisation.

\section{Alimentation permanente aux fourrages et à l'ensilage}

L'alimentation entièrement axée sur les aliments conservés permet d'exploiter au maximum les terres mises en fourrages. Ces derniers peuvent être récoltés à un stade de maturité où, la teneur en principes nutritifs digestibles est supérieure à celle qui s'obtiendrait par la paissance ou l'alimentation en vert. 
La récolte se faisant très rapidement, la qualité du fourrage est uniforme, ce qui favorise une production laitière soutenue. Garder les vaches à l'étable et les y nourrir pendant l'été demande évidemment des installations plus élaborées, des équipements et une capacité d'entreposage accrue et davantage de main-d'oeuvre. A production de lait égale, les vaches soumises à ce système ont probablement besoin de plus de compléments qu'en régime de pâture. Plusieurs fermes possèdent déjà une capacité d'entreposage suffisante pour les mois d'été au cas où cette solution serait envisagée. Cependant, un programme d'alimentation aux fourrages et ensilage à longueur d'année convient mieux aux grosses unités laitières qui sont déjà équipées pour la manutention mécanique des aliments.

\section{Alimentation en vert (apâturage)}

$\mathrm{La}$ fauche quotidienne des fourrages verts pour alimenter les vaches laitières en enclos représente, par rapport à la paissance ordinaire, l'utilisation intense des terres de pâturage et permet de nourrir les vaches d'une herbe fraîche et succulente. Grâce à ce système, on perd moins d'aliments qu'en laissant paître les animaux ou en rentrant les foins. La capacité d'entreposage n'a pas besoin d'être augmenté, mais en revanche, il est souvent nécessaire de compléter le matériel de récolte et de distribution. En raison de l'augmentation de la main-d'oeuvre nécessaire pour faucher et transporter l'herbe verte chaque jour, les producteurs de lait prisent moins ce mode d'exploitation.

\section{Pâturage d'appoint}

On a parfois recours à des cultures d'appoint pour suppléer au manque de pâturage. L'avoine verte, le sorgho du Soudan, les hybrides de sorgho, le seigle d'automne et d'autres cultures ou combinaisons se prêtent à cet usage. Ces pâturages provisoires, ou d'appoint, rendent moins que les pâturages établis régulièrement. Ils supportent mal le piétinement et leur ensemencement entraîne toujours des frais et une main-d'oeuvre supplémentaires. Néanmoins, ce sont d'importants compléments des pâturages ordinaires, aptes à prolonger la saison de paissance.

Le sorgho du Soudan ou ses hybrides constituent d'excellents pâturages de la mi-été surtout en saison chaude et sèche. Ils rendent beaucoup et sont appétissants. L'ensemencement se fait à la fin de mai ou au début de juin à raison de 12 livres de semence par acre. Ces fourrages conviennent également très bien aux programmes de paissance et d'alimentation en vert. Malheureusement, ils présentent certains inconvénients. Si la saison est froide et humide, les rendements sont généralement faibles et, comme tous les membres de la famille des sorghos, ils présentent certains dangers d'empoisonnement à l'acide prussique. Le sorgho du Soudan n'est pas très dangereux mais, par mesure de précaution, ne pas faire paître les animaux lorsque les plants sont encore courts ou qu'ils sont gravement gelés ou rabougris. Faire paître ou rentrer ce fourrage lorsque les tiges ont au moins vingt-quatre pouces de hauteur. 
Le seigle d'automne, semé à raison de deux boisseaux environ à l'acre entre le $1^{\text {er }}$ et le 15 août, est utile comme pâturage à la fin de l'automne ou au début du printemps. Lorsque les vaches sont au pâturage dans un champ de seigle, faire attention à ce que le lait n'en prenne pas le goût. Par précaution, ne laisser paître les vaches que quelques heures par jour et les retirer deux heures environ avant la traite. Quelques producteurs de lait mélangent de l'avoine au seigle pour obtenir un pâturage d'automne plus dense.

\section{COMPLEMENTS DES FOURRAGES}

La quantité et la nature du mélange de concentrés dépendent de la quantité et de la qualité des fourrages. En règle générale, plus le fourrage est riche en légumineuses et moins il est mûr, moins il faut de protéine dans le mélange.

\section{Guide pratique de l'alimentation aux concentrés}

1. Composition type du mélange de concentrés pour vaches en lactation, pourcentages totaux:

(1) protéine, 14 à $18 \%$ (selon les fourrages),

(2) principes nutritifs digestibles, 72 à $77 \%$,

(3) cellulose, 10 à $12 \%$ au maximum,

(4) matière grasse, $3 \%$ au minimum.

2. Donner des concentrés d'après le niveau de production des vaches et la qualité du fourrage (en règle générale, 1 livre de mélange de concentrés environ pour 3 à 5 livres de lait produit quotidiennement).

3. Incorporer au mélange du sel et un complément approprié de minéraux, à raison de 2 à 3 livres pour 100 livres de mélange

ou

employer un mélange minéral du commerce en suivant les recommandations du fabricant.

4. Ne pas moudre les grains trop finement-broyage grossier ou simple, aplatissage des grains.

5. Donner la même quantité d'aliments à heures régulières.

6. Eviter tout changement brusque de la quantité et de la composition des aliments.

7. Nettoyer les mangeoires aussi souvent que nécessaire.

\$̣. Fournir de l'eau en quantité suffisante. 


\section{Mélanges de concentrés pour compléter certains fourrages}

TABLEAU 7. Mélanges contenant de 11 à $14 \%$ de protéine brute convenant aux vaches nourries aux fourrages suivants, constitués principalement de légumineuses de haute qualité:

(1) foin de légumineuses feuillu, coupe précoce (qualité de choix);

(2) foin mélangé de légumineuses et de graminées, à forte proportion de légumineuses (coupe précoce, qualité supérieure);

(3) ensilage bien conservé des fourrages mentionnés ci-dessus;

(4) ensilage de pois de bonne qualité;

(5) excellent pâturage.

\begin{tabular}{|c|c|c|c|c|c|c|}
\hline Aliments & $\begin{array}{c}\text { Mélange } \\
1 \\
\mathbf{l b}\end{array}$ & $\begin{array}{c}\text { Mélange } \\
\mathbf{2} \\
\mathbf{l b}\end{array}$ & $\begin{array}{c}\text { Mélange } \\
\mathbf{3} \\
\mathbf{l b}\end{array}$ & $\begin{array}{c}\text { Mélange } \\
4 \\
\text { lb }\end{array}$ & $\begin{array}{c}\text { Mélange } \\
\mathbf{5} \\
\mathbf{l b}\end{array}$ & $\begin{array}{c}\text { Mélange } \\
6 \\
1 \mathrm{lb}\end{array}$ \\
\hline Maïs & 950 & 1,000 & & & & \\
\hline Farine de maïs en épi $\ldots \ldots \ldots \ldots \ldots$ & & & 600 & 1,200 & 800 & 1,700 \\
\hline Avoine & 500 & 400 & 800 & 600 & 500 & \\
\hline Orge & & & & & 500 & \\
\hline Son de blé & 250 & 400 & 400 & & & \\
\hline Tourteau de soja & 150 & 200 & 200 & 200 & 200 & 300 \\
\hline Gluten de maïs ........ & 150 & & & & & \\
\hline
\end{tabular}

\begin{tabular}{|c|c|c|c|c|c|}
\hline Aliments & $\begin{array}{c}\text { Mélange } \\
7 \\
\text { lb }\end{array}$ & $\begin{array}{c}\text { Mélange } \\
8 \\
\text { lb }\end{array}$ & $\begin{array}{c}\text { Mélange } \\
9 \\
\text { lb }\end{array}$ & $\begin{array}{c}\text { Mélange } \\
10 \\
\text { lb }\end{array}$ & $\begin{array}{c}\text { Mélange } \\
\quad 11 \\
\text { lb }\end{array}$ \\
\hline Avoine & 1,000 & 650 & 600 & 1,000 & 700 \\
\hline Orge & 500 & 600 & 600 & & \\
\hline Maïs & & & & 600 & 650 \\
\hline 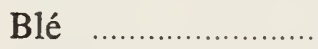 & 500 & 600 & & & \\
\hline Son de blé ...... & & & 400 & 400 & 250 \\
\hline Tourteau de soja & & 150 & 200 & & 250 \\
\hline Mélasse & & & 200 & & 150 \\
\hline
\end{tabular}

TABLEAU 8. Mélanges de concentrés contenant environ $16 \%$ de protéine brute destinés aux vaches nourries aux fourrages à teneur moyenne en protéine. Les fourrages devraient être d'assez bonne qualité et de composition botanique suivante:

(1) foin de légumineuses-coupe semi-tardive, perte considérable de feuilles et avaries dues à des intempéries plus graves que dans le tableau précédent;

(2) mélange de foins de légumineuses et de graminées de qualité moyenne, moindre proportion de légumineuses et coupe semi-tardive;

(3) foin de graminées de bonne qualité; 
(4) ensilage bien conservé de fourrages mentionnés ci-dessus;

(5) combinaison de foin et d'ensilage de maïs de haute qualité;

(6) pâturage de bonne ou moyenne qualité.

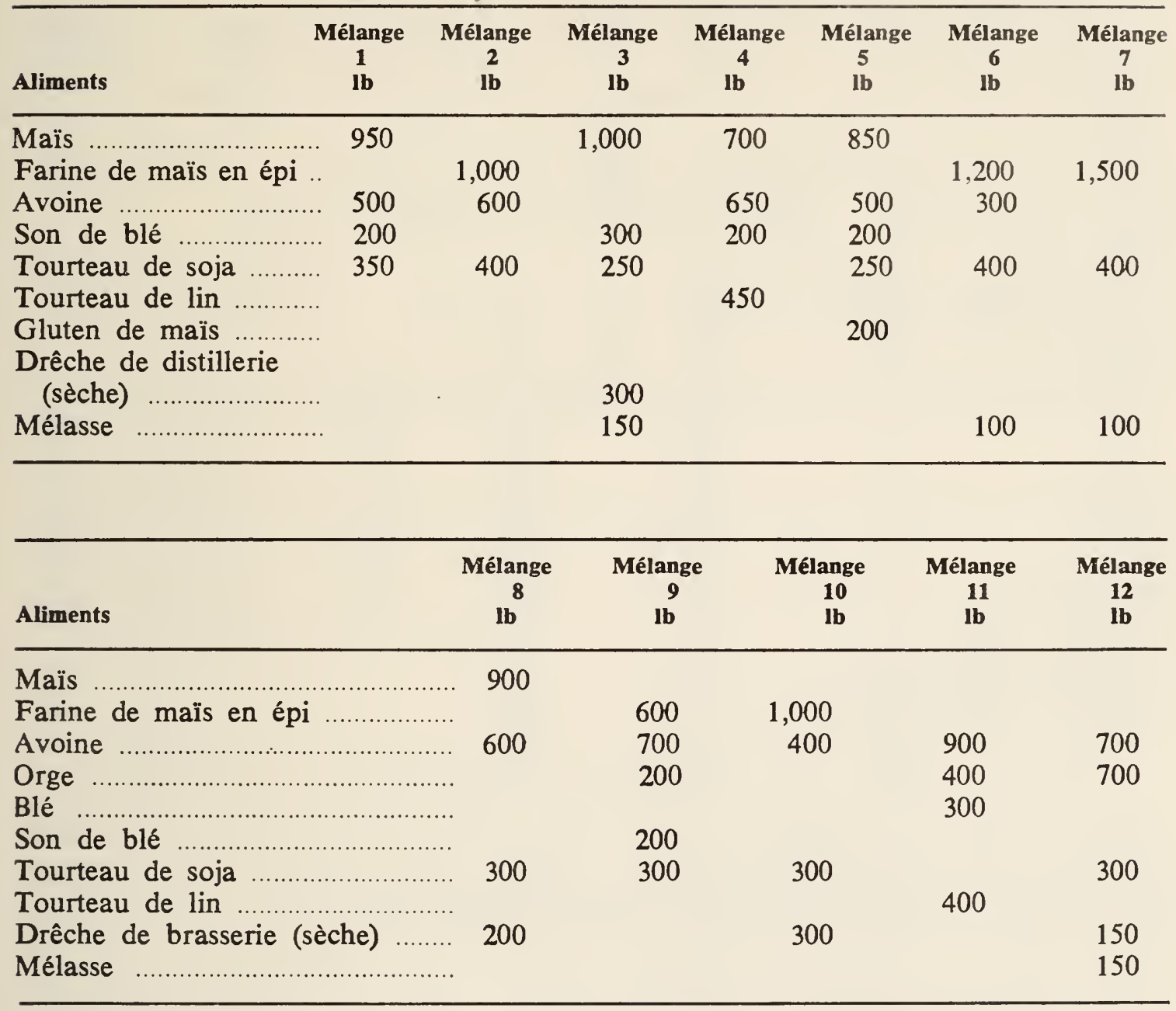

Fabrication de mélanges à $16 \%$, au moyen de concentrés à 32 ou $34 \%$

\begin{tabular}{|c|c|c|c|c|c|}
\hline Aliments & $\begin{array}{c}\text { Mélange } \\
1 \\
\text { lb }\end{array}$ & $\begin{array}{c}\text { Mélange } \\
\mathbf{2} \\
\text { lb }\end{array}$ & $\begin{array}{c}\text { Mélange } \\
\mathbf{3} \\
\mathbf{l b}\end{array}$ & $\begin{array}{c}\text { Mélange } \\
4 \\
\text { lb }\end{array}$ & $\begin{array}{c}\text { Mélange } \\
5 \\
\text { lb }\end{array}$ \\
\hline Avoine & 800 & 800 & 350 & 400 & \\
\hline Orge & 800 & 400 & & & \\
\hline Blé. & & 400 & & & \\
\hline Son de blé & & & 400 & & \\
\hline 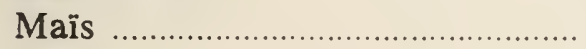 & & & 800 & & \\
\hline Farine de maïs en épi & & & & 1,000 & 1,300 \\
\hline Concentré à 32 ou $34 \%$ & 400 & 400 & 450 & 600 & 700 \\
\hline
\end{tabular}


TABlEaU 9. Mélanges de 17 à $19 \%$ de protéine brute destinés aux vaches sur pâturages médiocres ou nourries aux fourrages pauvres en protéine, soit:

(1) foin de légumineuses - mûr, ligneux et grossier;

(2) foin de graminées - coupe tardive ou altération par les intempéries;

(3) ensilage de maïs de bonne qualité (sans autre fourrage).

\begin{tabular}{|c|c|c|c|c|}
\hline Aliments & $\begin{array}{c}\text { Mélange } \\
1 \\
\text { lb }\end{array}$ & $\begin{array}{c}\text { Mélange } \\
\mathbf{2} \\
\text { lb }\end{array}$ & $\begin{array}{c}\text { Mélange } \\
\mathbf{3} \\
\text { lb }\end{array}$ & $\begin{array}{c}\text { Mélange } \\
4 \\
\text { lb }\end{array}$ \\
\hline Avoine & 750 & 500 & 400 & 800 \\
\hline Orge & 400 & & & 400 \\
\hline Blé .. & 350 & & & 400 \\
\hline $\begin{array}{l}\text { Farine de maïs en épi } \\
\text { Son de blé }\end{array}$ & & 1,000 & 1,000 & \\
\hline Tourteau de lin & & & & \\
\hline Tourteau de soja & 350 & 500 & 600 & 400 \\
\hline 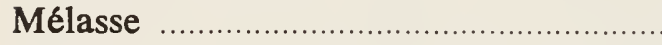 & 150 & & & \\
\hline
\end{tabular}

\begin{tabular}{|c|c|c|c|c|c|}
\hline Aliments & $\begin{array}{c}\text { Mélange } \\
5 \\
\text { lb }\end{array}$ & $\begin{array}{c}\text { Mélange } \\
6 \\
\text { lb }\end{array}$ & $\begin{array}{c}\text { Mélange } \\
7 \\
\text { lb }\end{array}$ & $\begin{array}{c}\text { Mélange } \\
8 \\
\text { lb }\end{array}$ & $\begin{array}{c}\text { Mélange } \\
9 \\
\text { lb }\end{array}$ \\
\hline Avoine & 600 & 500 & 600 & 500 & 400 \\
\hline (.) & 800 & 700 & 600 & 700 & 700 \\
\hline (.). & & 200 & 400 & 200 & 300 \\
\hline Tourteau de soja & 300 & 250 & 400 & 300 & 450 \\
\hline Gluten de maïs & & & & 300 & \\
\hline Drêche de brasserie (sèche) & 300 & & & & \\
\hline Drêche de distillerie (sèche) & & 350 & & & 150 \\
\hline
\end{tabular}

\section{Guide pratique de la distribution quantitative de concentrés}

La quantité de concentrés à donner aux vaches dépend de leur production de lait et de la teneur de celui-ci en matière grasse, de la quantité et de la qualité du fourrage qu'elles reçoivent, de l'état général des vaches, et du rapport entre le prix des concentrés et celui du lait. Il est évident aussi que pour obtenir les meilleurs résultats il faut noürir les vaches d'après leurs besoins individuels. Pour les mêmes raisons, composer empiriquement les rations (1 livre de concentré pour 3 ou 5 livres de lait, par exemple) laisse fort à désirer et se traduit souvent par la sous-alimentation des meilleures vaches et la suralimentation des vaches médiocres.

C'est au tout début de la lactation que la vache manifeste les besoins énergétiques les plus élevés et il est donc nécessaire d'augmenter sa ration de concentrés tôt après le vêlage. La plupart des vaches atteignent leur rendement maximal de trois à six semaines après la mise bas, et d'ordinaire, plus la production est abondante, plus le rendement total de la lactation sera élevé. Si la vache ne bénéficie pas d'un apport énergétique suffisant dans les premières semaines qui suivent la parturition, ou elle ne donnera pas son plein rendement, ou elle ira en s'amaigrissant. La meilleure méthode à suivre est de servir une ration modérée de concentrés avant le vêlage (comme il en est question au chapitre intitulé Alimentation et entretien des vaches taries) et, sans en avoir trop réduit la consommation au temps du vêlage, d'augmenter 
la ration d'une livre par jour (ou plus si la vache la prend) jusqu'à ce qu'elle atteigne sa production maximale. C'est une méthode de sollicitation ou de provocation; elle ne provoque pas de gaspillage d'aliments puisque les quantités ne sont augmentées que dans la mesure où la vache y répond par une augmentation de la production de lait.

Une fois que la vache a atteint sa production maximale, on peut suivre à son égard le guide pratique de distribution des concentrés établi d'après les normes d'alimentation, de manière à proportionner la consommation à la production laitière et à la qualité des fourrages.

TABLEAU 10. Rations de concentrés recommandées pour vaches sur pâturage d'excellente qualité

\begin{tabular}{ccccc}
\hline $\begin{array}{c}\text { Production quotidienne } \\
\text { de lait }\end{array}$ & \multicolumn{4}{c}{ Taux butyreux } \\
\cline { 2 - 5 } $\mathbf{l b}$ & $\begin{array}{c}\mathbf{3 \%} \\
\mathbf{l b}\end{array}$ & $\begin{array}{c}\mathbf{3 . 5 \%} \\
\mathbf{l b}\end{array}$ & $\begin{array}{c}\mathbf{4 \%} \\
\mathbf{l b}\end{array}$ & $\begin{array}{c}\mathbf{5 \%} \\
\mathbf{l b}\end{array}$ \\
\hline 30 & - & - & 1.0 & 1.5 \\
35 & 1.5 & 2.0 & 2.5 & 2.5 \\
40 & 2.5 & 3.5 & 4.5 & 5.0 \\
45 & 4.5 & 5.5 & 6.5 & 7.5 \\
50 & 7.0 & 8.0 & 8.5 & 10.0 \\
55 & 9.5 & 10.5 & 11.0 & 12.5 \\
60 & 12.0 & 13.0 & 14.0 & 16.0 \\
65 & 14.0 & 15.5 & 17.0 & 19.5 \\
70 & 16.5 & 18.0 & 20.0 & 23.0 \\
75 & 19.0 & 21.0 & 23.0 & 26.5 \\
80 & 22.0 & 24.0 & 26.0 & 30.0 \\
85 & 25.0 & 27.0 & 29.0 & - \\
90 & 28.0 & 30.0 & 33.0 & - \\
\hline
\end{tabular}

TABLEAU 11. Rations de concentrés recommandées pour vaches sur bon pâturage, ou nourries au foin ou à l'ensilage d'excellente qualité

\begin{tabular}{ccccc}
\hline $\begin{array}{c}\text { Production quotidienne } \\
\text { de lait }\end{array}$ & \multicolumn{4}{c}{ Taux butyreux } \\
\cline { 2 - 5 } $\mathbf{l b}$ & $\mathbf{3 \%}$ & $\mathbf{3 . 5 \%}$ & $\mathbf{4 \%}$ & $\mathbf{5 \%}$ \\
$\mathbf{l b}$ & $\mathbf{l b}$ & $\mathbf{l b}$ & $\mathbf{l b}$ \\
\hline 15 & - & - & 1.0 & 1.5 \\
20 & 1.0 & 1.5 & 2.0 & 3.0 \\
25 & 2.0 & 2.5 & 3.0 & 4.0 \\
30 & 3.5 & 4.0 & 4.5 & 5.5 \\
35 & 5.0 & 5.5 & 6.0 & 7.5 \\
40 & 7.0 & 7.5 & 8.5 & 10.0 \\
45 & 9.5 & 10.0 & 11.0 & 12.5 \\
50 & 11.5 & 12.5 & 13.5 & 15.5 \\
55 & 14.0 & 15.0 & 16.5 & 19.0 \\
60 & 16.5 & 18.0 & 19.5 & 22.5 \\
65 & 19.0 & 21.0 & 22.5 & 26.0 \\
70 & 22.0 & 24.0 & 26.0 & 30.0 \\
75 & 25.0 & 27.0 & 29.5 & - \\
80 & 28.0 & 30.0 & 33.0 & - \\
\hline
\end{tabular}


TABLEAU 12. Rations de concentrés recommandées pour vaches sur pâturage moyen, ou nourries au foin ou à l'ensilage de bonne qualité

\begin{tabular}{ccccc}
\hline $\begin{array}{c}\text { Production quotidienne } \\
\text { de lait }\end{array}$ & \multicolumn{4}{c}{ Taux butyreux } \\
\cline { 2 - 5 } lb & $\mathbf{3 \%}$ & $\mathbf{3 . 5 \%}$ & $\mathbf{4 \%}$ & $\mathbf{5 \%}$ \\
$\mathbf{l b}$ & $-\mathbf{l b}$ & $\mathbf{l b}$ & $\mathbf{l b}$ \\
\hline 15 & 1.0 & - & 1.0 & 1.5 \\
20 & 4.0 & 2.0 & 2.5 & 4.0 \\
25 & 6.5 & 4.5 & 5.0 & 6.0 \\
30 & 8.0 & 7.0 & 7.5 & 8.5 \\
35 & 10.0 & 11.0 & 9.5 & 11.0 \\
40 & 12.5 & 13.5 & 12.0 & 14.0 \\
45 & 15.0 & 16.5 & 15.0 & 17.5 \\
50 & 18.0 & 19.5 & 21.0 & 21.0 \\
55 & 21.0 & 22.5 & 24.5 & 28.0 \\
60 & 24.0 & 26.0 & 28.0 & 32.0 \\
65 & 27.0 & 30.0 & 31.5 & - \\
70 & 30.0 & - & - & - \\
75 & & & &
\end{tabular}

\section{GESTION DU TROUPEAU LAITIER}

\section{Tenue des registres}

Il est connu de longue date que la vache laitière est un animal routinier, qu'elle possède ses caractéristiques propres et que chaque animal demande donc une attention particulière. Cependant à mesure que s'accroît l'effectif, il devient de plus en plus difficile de traiter les vaches individuellement, à moins d'établir un dossier pour chacune. Pour ce faire, il faut attribuer à chacune un numéro d'identification, soit tatoué, soit attaché au bouton d'oreille ou sur un licou. Tous les veaux, qu'ils soient de race pure ou de races croisées devraient être identifiés dès leur naissance et leur dossier constitué à ce moment-là.

Le dossier comprend les pièces suivantes: fiches de production laitière (non seulement pour faciliter la sélection et la réforme, mais aussi comme guide de l'alimentation), fiche de reproduction et fiche sanitaire.

La méthode la plus satisfaisante pour tenir ces dossiers à jour est d'avoir un livre d'étable avec une page par vache. Il est facile de s'y référer au besoin pour contrôler à n'importe quel moment l'état d'un sujet quelconque. Voir au tableau A12 de l'annexe un modèle de fiche individuelle comportant la plupart de ces détails.

\section{Traite}

Lorsque la traite est faite correctement, c'est-à-dire avec efficacité et rapidité, on obtient du lait de haute qualité et on diminue la fréquence des troubles mammaires. Pour atteindre ces objectifs il faut établir un programme de travail régulier qui permet de s'assurer que rien n'est omis.

1. Bon fonctionnement des trayeuses - Pour traire avec rapidité, efficacité 
et un minimum de fatigue pour le pis de la vache, la trayeuse doit être en parfait état de fonctionnement. Le niveau du vide, la cadence des pulsations, la tension et la taille des manchons des gobelets trayeurs, le débit et la capacité de la pompe sont parmi les éléments à vérifier. La plupart des fabricants donnent des instructions très précises sur le fonctionnement de leurs machines et on ne peut que recommander de les suivre à la lettre. Ces sociétés désignent aussi des techniciens compétents pour remédier aux défectuosités de leurs machines.

2. Préparation de la vache - La préparation comporte deux étapes importantes; stimuler la vache pour qu'elle donne librement son lait et laver le pis et les trayons pour les débarrasser de toutes souillures qui pourraient contaminer le lait. Pour ce faire, utiliser des serviettes en papier individuelles trempées dans de l'eau chaude additionnée de désinfectant. Cette opération devrait être effectuée de trente secondes à une minute environ avant de mettre la trayeuse en place. Pour éviter que les trayons soient trop humides, essorer la serviette avant d'en frotter le pis. En outre, plusieurs producteurs prélèvent les premiers jets de lait de chaque quartier dans un récipient muni d'un tamis à mailles fines pour déceler toute anomalie du lait.

3. Traite - Les trayeuses doivent être mises en place une ou au plus deux minutes, après stimulation du pis. Le temps nécessaire pour traire à fond varie d'une vache à l'autre; l'exploitant doit connaître les particularités de chacune. Il ne faut en aucun cas laisser la machine en place (ou uniquement sur un quartier), une fois la traite terminée, par crainte de blesser les tissus mammaires. D'autre part, il est parfois nécessaire et à conseiller d'égoutter le pis à la machine pour achever la traite. Par là il faut entendre l'exercice d'une traction de haut en bas sur les gobelets vers la fin de la traite.

4. Précautions sanitaires - Pour produire du lait de haute qualité et empêcher toute infection de la mamelle de se propager, il faut vérifier l'état de propreté du matériel de traite, des bâtiments, des vaches et des préposés aux machines. Le matériel doit être lavé immédiatement après chaque traite; au surplus, il doit être démonté une fois par semaine et lavé à fond. Pour prévenir la contamination de se propager d'une vache à l'autre, immerger les gobelets après chaque traite dans un bain d'eau à $170^{\circ} \mathrm{F}$ une dizaine de secondes, ou trente secondes dans un désinfectant.

\section{Conseils supplémentaires}

1. Effectuer les opérations de traite avec régularité et à la même heure chaque jour. Il n'est pas nécessaire que l'intervalle entre la traite du matin et du soir et la traite du soir et celle du matin soit égal, mais l'heure de traite doit être respectée scrupuleusement. De plus, les vaches acquièrent un réflexe conditionné aux habitudes régulières et toute perturbation de ces dernières peut avoir des effets contraires sur l'écoulement du lait.

2. Ne pas essayer de faire fonctionner plus de trayeuses qu'on ne peut surveiller efficacement. Faire marcher plus de deux trayeuses par homme dans une étable à stalles, ou trois trayeuses dans une salle de traite, n'accélère pas forcément la traite. Pendant cette opération, laisser toute autre besogne. 
3. Garder pour la fin de la traite, les vaches malades ou lentes à traire.

4. Ne pas donner, trois heures avant ou pendant la traite, d'aliments à odeur forte, d'ensilage en particulier, qui pourraient altérer la saveur du lait.

5. Ne pas laisser le lait dans des récipients ouverts. Le transporter rapidement à la laiterie.

6. Refroidir le lait rapidement et s'assurer que le matériel fonctionne correctement.

\section{Rythme de reproduction}

Une production laitière rentable dépend, en grande partie du vêlage régulier des vaches chaque année. L'idéal serait un intervalle de douze mois entre les vêlages de chaque vache du troupeau. Il en résulterait un accroissement de la production laitière totale par vache au cours de sa vie, comparativement aux vêlages plus espacés. En outre, la récolte de veaux serait plus nombreuse pour une période donnée. Ces deux facteurs concourraient à l'augmentation des revenus. Comme les problèmes de reproduction sont imputables à la gestion, bien plus qu'à l'hérédité, les conseils suivants devraient contribuer à améliorer le rythme de reproduction:

1. Constituer un dossier exact et complet des dates des chaleurs, des saillies, des vêlages de chaque vache et de tout état anormal de son appareil génital. Voici un modèle du genre de fiche qui peut servir à cet effet:

\begin{tabular}{|c|c|c|c|c|c|c|c|c|c|c|c|c|c|}
\hline \multirow{2}{*}{$\begin{array}{l}\text { Nom ou } \\
\text { numéro } \\
\text { de la } \\
\text { vache }\end{array}$} & \multirow{2}{*}{$\begin{array}{l}\text { Date } \\
\text { des } \\
\text { vêlages }\end{array}$} & \multicolumn{4}{|c|}{ Date des chaleurs } & \multicolumn{5}{|c|}{ Saillies } & $3 e$ & \multirow{2}{*}{$\begin{array}{l}\text { Contrôle } \\
\text { de } \\
\text { gestation }\end{array}$} & \multirow{2}{*}{$\begin{array}{l}\text { Date prévu } \\
\text { du vêlage }\end{array}$} \\
\hline & & 1 & 2 & 3 & 4 & Date & Taureau & Date. & Taureau & Date & Taureau & & \\
\hline
\end{tabular}

2. Au moins deux fois par jour observer attentivement vaches et génisses en quête de signes de chaleurs. Pendant les mois d'hiver le fait de faire sortir au moins une fois par jour, les vaches logées dans une étable à cornadis est d'un grand secours pour déceler les chaleurs.

3. Accorder aux vaches un repos de soixante jours au moins après le vêlage. Toute vache normale devrait être saillie aux premières chaleurs qui suivent les soixante jours de repos pour que les vêlages aient lieu à intervalles de douze mois.

4. Faire saillir au moment le plus favorable à la conception; non pas au début des chaleurs. Pour obtenir les meilleurs résultats, les vaches qui mani- 
festent les premiers signes de chaleurs le matin devraient être saillies en fin de la journée; celles qui présentent les signes du rut l'après-midi devraient l'être le lendemain matin.

5. Accoupler les femelles à un mâle connu pour sa fertilité.

6. Six semaines après la dernière saillie, vérifier de façon régulière si la vache est pleine.

7. Pour un rythme de reproduction optimal, incorporer aux rations des quantités suffisantes de substances énergétiques, de protéines, de phosphore et de vitamine $\mathrm{A}$.

8. Consulter le vétérinaire dès qu'une vache présente une anomalie. Surtout: (a) si une vache n'a pas conçu après avoir été saillie à trois reprises par un taureau fertile; (b) si une vache ne présente aucun signe d'oestrus dans les soixante jours qui suivent le vêlage, ou si son cycle oestral est irrégulier; et (c) si une vache présente des symptômes de kyste ovarien ou de tout autre état anormal.

9. Ne pas faire saillir les vaches qui ont des pertes anormales et isoler celles qui ont avorté jusqu'à l'arrêt des pertes.

\section{ALIMENTATION ET ENTRETIEN DES VACHES TARIES}

Mettre les vaches au repos en les tarissant, de six à huit semaines avant la mise bas. Un repos prolongé est parfois nécessaire aux vaches très maigres ou aux jeunes vaches qui ont encore besoin de se développer. La date des saillies est indispensable pour le calcul d'une durée suffisante du tarissement, sans que les vaches soient improductives pendant plusieurs mois. Le marché du lait et le marché des bestiaux d'élevage surnuméraires sont des facteurs dont il faut tenir compte lorsqu'on prévoit l'époque des saillies, les périodes de repos et de vêlage.

Il peut être difficile de tarir une vache, surtout si elle a été maintenue en production jusqu'à deux ou trois semaines du vêlage. Dans ce cas, il est plus sage de continuer à la traire, de la nourrir généreusement et de s'attendre à la baisse de la lactation suivante. On peut tarir les vaches à quelques semaines du vêlage en réduisant leurs rations d'eau et d'aliments, en les trayant de temps à autre et si possible, en les séparant des vaches traites régulièrement.

Une autre méthode de tarissement consiste à arrêter brusquement de traire, à changer les habitudes de traite, à supprimer les aliments riches en protéines et à réduire les rations de concentrés et d'eau; aussi, en laissant monter la pression mammaire qui empêche la sécrétion du lait. Au cas où le pis serait anormalement congestionné, traire complètement et recommencer. Cette méthode n'est pas recommandée pour les vaches ayant déjà souffert de mammite.

Une fois tarie, la vache doit être nourrie généreusement pour qu'elle gagne du poids, fasse des réserves de minéraux et développe un foetus fort et vigoureux. Employer à cette fin de bons fourrages et des mélanges de concentrés qui soient plus que de simples aliments d'engraissement. La ration 
ordinaire de grain est satisfaisante; on peut aussi employer un mélange spécial sec et approprié à chaque cas.

La quantité de concentrés à distribuer dépend de l'état et de la taille de la vache. Elle peut varier de zéro à huit ou dix livres par jour. Les vaches en bon état et au régime du pâturage n'ont probablement pas besoin d'aliments complémentaires sous forme de concentrés.

Il est bon de nourrir assez généreusement les vaches la semaine qui précède le vêlage et les semaines suivantes. Pour ce, commencer à augmenter la ration de concentrés trois semaines environ avant la date prévue du vêlage, de façon que la vache en mange au moins $1 \%$ de son poids par jour au moment du vêlage. Ne pas restreindre la ration de concentrés au temps de la mise bas: la consommation de concentrés à ce moment n'est pas cause de congestionnement du pis, et, au surplus, une alimentation assez copieuse aide à prévenir la cétose.

\section{Vêlage}

Toutes les vaches ne présentent pas les mêmes signes avant-coureurs de vêlage mais chacune se comporte à peu près de la même manière à chaque mise bas. Chez certaines les signes apparaissent tôt, et plus tard chez d'autres. Voici les signes annonciateurs du vêlage:

(1) congestion de la mamelle et turgescence des trayons qui prennent une apparence cireuse quelques heures avant la mise bas;

(2) enflure de la vulve et relâchement caractéristique des muscles autour de l'attache de la queue;

(3) agitation et, au pâturage, tendance à s'éloigner du reste du troupeau.

Pendant la période de stabulation, faire vêler la vache dans une loge propre, désinfectée et pourvue d'une bonne litière. Même pendant la saison de pâturage, il est bon que la vache mette bas dans une loge ou un enclos proche de l'étable où l'on peut la surveiller. Après le vêlage, laisser la vache lécher son veau et la garder au chaud. Il est recommandé de lui faire boire de l'eau chaude et de lui servir une pâtée de son humide additionnée de mélasse pour l'aider à se remettre des fatigues du vêlage. La tenir sous observation pour déceler les premiers symptômes de fièvre vitulaire ou d'acétonémie. (Voir le chapitre sur la Santé du troupeau.) En cas de non-expulsion de l'arrière-faix dans les deux jours qui suivent la mise bas, faire appel au vétérinaire.

\section{ALIMENTATION ET SOINS DU VEAU}

Pour qu'un troupeau laitier soit rentable, il faut de bonnes génisses de remplacement. Dans un troupeau moyen, il faut remplacer $25 \%$ des vaches chaque année car elles ne sont plus rentables. Compte tenu des pertes chez les jeunes animaux, il faut donc trois ou quatre veaux femelles pour dix vaches.

Peu après sa naissance, le veau doit téter. Il est très important qu'il absorbe le colostrum ou premier lait, car il a des effets laxatifs, et il est riche en 
vitamine $\mathrm{A}$ et en anticorps qui aident à immuniser le veau contre les maladies. Pour éviter que l'ombilic s'infecte, l'immerger dans un désinfectant approprié.

Le veau peut rester deux ou trois jours avec sa mère, mais la pratique habituelle est de l'en séparer après douze ou dix-huit heures. Cette mesure empêche le veau de se suralimenter, de s'infecter ou d'être contaminé sur les lieux de la naissance. En outre, il est beaucoup plus facile d'apprendre à boire à un veau de cet âge. De plus, la vache alors se tourmente moins que si on lui enlève son veau plus tard, et elle se laisse traire plus facilement.

Le veau doit recevoir le colostrum de sa mère pendant au moins trois jours. S'il y en a trop, on peut le donner à des veaux plus âgés ou le congeler et le conserver plusieurs mois. Il est très important de ne pas suralimenter le jeune veau les tout premiers jours; de six à huit livres de lait par jour suffisent pour les gros veaux, et de quatre à six livres pour les veaux plus petits.

\section{Considérations sur l'élevage des veaux}

1. En matière d'alimentation, la régularité est importante. En général le veau n'a besoin d'être nourri que deux fois par jour; mais les veaux faibles et maigres devraient être alimentés trois fois le jour durant au moins la première semaine.

2. Veiller à ce que les aliments soient uniformes en qualité, en température (le lait) et en quantité.

3. Tout le matériel employé doit être propre.

4. Tenir les veaux au sec, propres, exempts de parasites externes et dans une loge bien éclairée et correctement aérée.

5. Eviter la sous-alimentation et la suralimentation.

6. Pour les jeunes veaux, on peut utiliser des seaux à tétine. Cependant, ils sont difficiles à garder propres et les veaux plus âgés ont tendance à enlever la tétine et à renverser le lait.

7. Donner aux veaux l'occasion de prendre de l'exercice.

Lorsque le veau a trois jours et qu'il démarre bien, on peut choisir entre plusieurs programmes d'alimentation. En voici trois des plus courants:

1. Lait entier rationné.

2. Aliments d'allaitement commerciaux.

3. Lait écrémé.

\section{Lait entier rationné}

Suivant cette méthode, le volume total de lait destiné à chaque veau est d'environ 350 livres. Les veaux de races lourdes en reçoivent plus chaque jour mais moins longtemps que les veaux de races plus petites. Le lait devrait toujours être frais et donné à la même température (préférablement entre 95 et $\left.98^{\circ} \mathrm{F}\right)$.

Voir au tableau 13 un guide pour l'alimentation au lait entier rationné.

Pendant la troisième semaine les veaux devraient recevoir à volonté deux fois par jour des aliments de démarrage secs. En fait, il est rare qu'ils mangent beaucoup au début, mais leur appétit s'améliore très rapidement avec l'âge. 


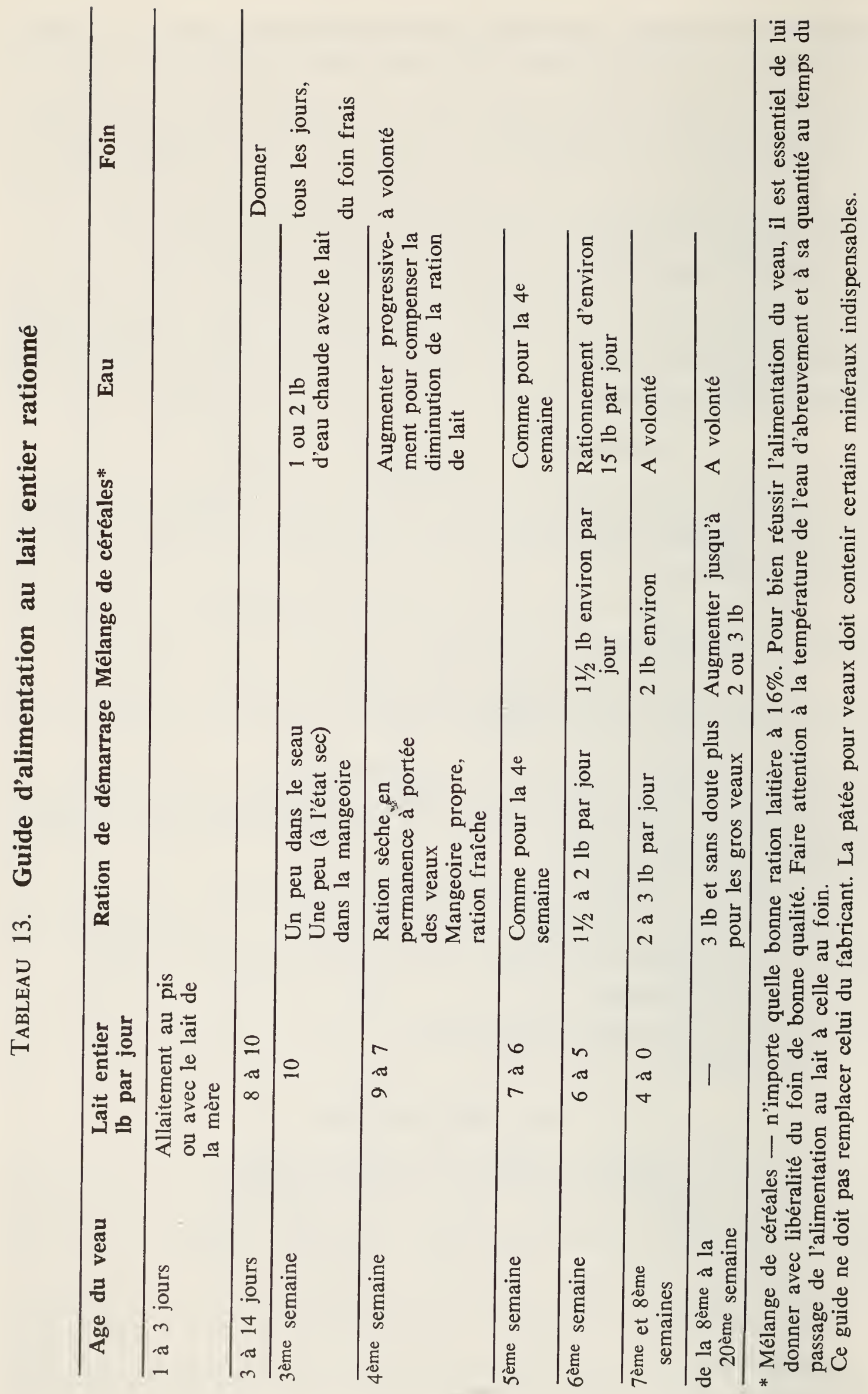


C'est pourquoi on devrait augmenter les rations toutes les semaines jusqu'à ce que la moyenne de la consommation quotidienne des veaux des races lourdes soit de quatre livres.

Les rations commerciales de début existent sous forme d'aliments secs ou de comprimés. Les unes comme les autres peuvent être données dans une mangeoire ou une auge, mais il faut enlever ce qui en reste avant la prochaine distribution. Les veaux commencent généralement à boire de l'eau vers la troisième semaine, aussi lorsqu'ils atteignent cet âge, il faut tous les jours mettre de l'eau propre et fraîche à leur portée. Il arrive parfois qu'ils prennent l'habitude de boire trop, c'est pourquoi, au début, il faut régler la quantité, de peur que la chose ne se produise.

Lorsque les veaux atteignent sept ou huit semaines la ration de démarrage doit être partiellement remplacée par des concentrés, et ce, progressivement jusqu'à substitution complète. En règle générale les veaux préfèrent les concentrés broyés assez grossièrement à ceux plus finement moulus; on voudra en tenir compte en procédant au changement. De fait, une bonne ration laitière ou même une simple ration d'avoine entière ou aplatie convient bien. Si le mélange ne contient ni sel ni minéraux, il faut en ajouter. En raison de son effet bénéfique sur la croissance, le foin de graminées et de légumineuses de bonne qualité constitue une partie essentielle de la ration.

Les rations de démarrage fabriquées par les sociétés sérieuses contiennent généralement toute une gamme d'ingrédients dont des céréales, des issues de meunerie, des protéines d'origine animale et végétale, des minéraux, des vitamines et parfois des antibiotiques. Cependant, à la suite de recherches on a constaté que si les veaux reçoivent du lait ou un produit d'allaitement en quantités recommandées, les mélanges de démarrage beaucoup plus simples réussissent bien. La formule de ration de démarrage suivante peut être préparée à la ferme même.

\section{Formule d'un aliment de démarrage}

Maïs concassé

570 livres

Avoine aplatie

500 livres

Son de blé

300 livres

Tourteau de soja

600 livres

Phosphate bicalcique

20 livres

Sel

10 livres

2,000 livres

A chaque tonne ajouter $3,000,000$ U.I. de vitamine A et 600,000 U.I. de vitamine D.

\section{Aliments d'allaitement du commerce}

De très nombreux producteurs emploient les produits d'allaitement en raison de leurs avantages économiques. On peut dire en gros que le lait valant plus de $\$ 3$ les 100 livres, il revient moins cher d'utiliser un produit de remplacement. Pour chaque produit, suivre les instructions du fabricant. Le mode d'emploi général est de mélanger une partie du produit à neuf parties d'eau chaude et de distribuer comme gruau. Les ingrédients principaux sont des sous-produits de lait séchés (de 60 à 90\%), auxquels s'ajoutent aussi des 
antibiotiques qui offrent une bonne protection contre les maladies. Pour ce mode d'élevage suivre le même guide que pour l'alimentation au lait rationné.

Selon la conjoncture économique, le lait en poudre écrémé reconstitué peut très bien remplacer les produits d'allaitement du commerce.

\section{Lait écrémé}

Le lait écrémé peut être substitué progressivement au lait entier en commençant lorsque le veau a trois semaines environ. A quatre semaines il devrait en recevoir quotidiennement l'équivalent d'environ $10 \%$ de son poids. Cette quantité peut être progressivement augmentée jusqu'à seize livres par jour, ration à donner au veau jusqu'à quatre ou cinq mois. Si l'on dispose d'assez de lait écrémé, il est bon de prolonger le régime mais quel que soit l'âge auquel s'effectue le passage du lait écrémé aux aliments secs, la transition doit se faire progressivement. Les veaux élevés au lait écrémé exigent, en plus du lait, de généreuses quantités de foin de bonne qualité, un peu de pâtée, du sel, des minéraux et de l'eau régulièrement.

\section{Les soins du jeune veau}

Quelle que soit la méthode d'élevage que l'on suit, il est certains soins qu'il ne faut pas négliger, faute de quoi on risque d'avoir des déceptions. La bonne qualité des aliments et la régularité de l'alimentation, la propreté du matériel et des enclos, l'absence de courants d'air et d'humidité excessive des locaux d'hivernement, et la protection contre les mouches et la chaleur au pâturage ne sont que quelques-unes des conditions dont dépend le succès de l'élevage des veaux.

Il faut enrayer l'habitude qu'ont les veaux de se téter mutuellement, manie qui peut déformer gravement le pis encore en formation. Certains veaux gardent cette habitude même à l'âge adulte et au stade de la production. Une loge individuelle offre la meilleure solution, mais si ce n'est pas possible, on peut attacher les veaux pendant quelque temps après les voir nourris au seau dans lequel on leur laisse une poignée d'aliments secs à mâchonner.

La croissance des cornes est facile à enrayer quand les veaux sont encore jeunes. Il suffit d'appliquer sur les boutons donnant naissance aux cornes l'une des préparations caustiques ou un fer électrique à décorner. L'identification des veaux par marque, tatouage ou photographie s'impose dès le jeune âge afin d'éviter toute erreur. L'ablation des trayons excédentaires est très facile chez les veaux; il faut aussi tailler les onglons au besoin. Les graves infestations de poux entravent le développement normal; l'état sec et hirsute du poil est un indice de pédiculose. Si le troupeau est soumis à la vaccination, les veaux doivent être inoculés à six mois environ.

A mesure que les veaux vieillissent, il est important d'utiliser les fourrages au maximum. Veiller à ce qu'ils croissent régulièrement en évitant qu'ils soient trop gras ou trop maigres. L'ensilage peut faire partie du régime dès que les veaux ont deux mois.

L'âge auquel les veaux peuvent aller au pâturage dépend de divers facteurs tels que la qualité du pâturage, la température et la quantité de compléments 
qu'ils y reçoivent. Il est établi qu'après quatre mois, les veaux se développent de façon satisfaisante si le pâturage est bien entretenu et si l'apport de compléments est approprié. L'alimentation complémentaire s'impose jusqu'à ce que le veau ait de huit à dix mois. Le complément peut consister en un mélange de céréales à raison de trois à cinq livres par jour plus foin à volonté.

\section{ALIMENTATION DES GENISSES}

A neuf mois les femelles peuvent être considérées comme des génisses. De neuf mois jusqu'au vêlage, le programme alimentaire doit faire appel aux fourrages dans toute la mesure du possible. Il est rarement rentable de leur donner des concentrés lorsqu'elles sont au pâturage. En hiver le foin et l'ensilage de bonne qualité assurent des gains normaux. La distribution de deux à quatre livres de concentrés, comme complément des fourrages, est parfois justifiée pour assurer une croissance plus rapide. Bien entendu, elles doivent toujours avoir accès au sel, aux minéraux et à l'eau.

\section{Croissance normale}

Les normes employées pour évaluer le rythme de croissance sont: le poids réel, la hauteur au garrot, le périmètre thoracique au niveau du coeur. A l'aide du tableau A 11 de l'annexe, il est possible d'évaluer le poids d'un animal d'après son tour thoracique. Le tableau A 10 de l'annexe donne le poids normal et la taille des génisses laitières. Dans toutes les races les mâles sont plus lourds et croissent plus rapidement que les femelles.

\section{Epoque de la saillie}

La taille ou la maturité sont aussi importantes que l'âge lorsqu'il s'agit de décider à quel temps faire saillir les génisses. L'une des considérations déterminantes est la saison la plus propice au vêlage par rapport au marché du lait. Des génisses bien développées peuvent être saillies à quinze mois; toutes doivent l'être avant l'âge de vingt-et-un mois. A en juger par la taille, on peut faire saillir les génisses ayant atteint les poids suivants: Ayrshire, 600 à 650 livres; Guernsey, 550 à 600 livres; Holstein, 750 à 800 livres et Jersey, 500 à 550 livres.

\section{ELEVAGE DE VEAU DE BOUCHERIE}

Chaque année un grand nombre de veaux laitiers sont vendus comme veaux de boucherie. Le poids du veau à sa naissance, le prix des aliments, le prix de la viande de veau, les disponibilités en main-d'oeuvre et son efficacité, représentent quelques-unes des données dont il faut tenir compte pour évaluer la rentabilité de la production de la viande de veau. Le poids auquel le veau commande le meilleur prix dépend du marché; il varie de 200 à 300 livres. Le régime du lait entier donne la viande de veau la meilleure. Il faut environ dix livres de lait par gain d'une livre. Toutefois, les produits de remplacement du lait s'emploient de plus en plus couramment, pour des raisons de rentabilité. 
Pour qu'un produit de remplacement du lait ou un aliment pour veau de lait, produise une croissance et un fini comparables à ceux obtenus avec du lait entier, il leur faut une valeur énergétique très élevée. Beaucoup d'industriels vendent pour les veaux de lait des produits d'allaitement spéciaux qu'ils enrichissent de 10 à $25 \%$ de graisse animale pour en accroître la valeur énergétique. Comme la valorisation des aliments varie suivant la façon dont cette graisse est incorporée à la ration, il n'est pas recommandé de faire soi-même le mélange de ce genre d'aliment. On peut également employer du lait écrémé pour élever les veaux de boucherie; selon sa disponibilité il peut constituer la base d'un régime relativement peu cher. Cependant les veaux ne croissent pas aussi vite et ne rapportent pas des prix de vente aussi élevés que ceux qui sont nourris au lait entier ou avec un produit de remplacement à haute valeur énergétique.

Le bien fondé de l'alimentation des veaux de boucherie aux rations de démarrage ou aux mélanges de céréales dépend du genre de spéculation laitière pratiquée et du poids auquel les veaux sont vendus. Il est à noter que si on donne de grosses quantités de concentrés ou de foin, la viande prend une couleur foncée que le marché accueille mal. Les céréales donnent probablement de meilleurs résultats en ce qui concerne la croissance et les bénéfices dans le cas des veaux élevés au régime du lait écrémé ou aux aliments de faible valeur énergétique, et aussi des veaux qui sont vendus à des poids plus élevés que ceux dont il est question ci-dessus.

\section{SANTE DU TROUPEAU}

Les bovins laitiers canadiens sont reconnus dans le monde entier pour leurs qualités: conformation, production et santé. Le ministère de l'Agriculture du Canada et les différents gouvernements provinciaux sont chargés de l'application de diverses lois, lignes de conduite et programmes d'aide, et de la direction des laboratoires de diagnostics vétérinaires à l'intention des éleveurs de bestiaux, de façon que les maladies du bétail fasseint l'objet d'une surveillance et d'un contrôle permanents. Par l'application de la Loi sur les épizooties, la Direction de l'hygiène vétérinaire à réussi à extirper, à enrayer ou à empêcher l'introduction de nombreuses maladies qui affligent les élevages dans d'autres pays. La tuberculose bovine est pratiquement vaincue, tandis qu'un plan d'action conjointe des gouvernements fédéral et provinciaux a réduit à un nombre infime les cas de brucellose.

Néanmoins, les éleveurs continuent à essuyer des pertes annuellement pour une valeur de millions de dollars, par suite de diverses maladies. Cependant, de nombreuses maladies peuvent être prévenues par la bonne conduite du troupeau et le service vétérinaire. Ainsi, un programme vétérinaire récemment mis en oeuvre permet la prévention ou le dépistage précoce des maladies du bétail. Ce programme prévoit notamment qu'éleveurs et vétérinaires doivent se mettre d'accord pour effectuer régulièrement des épreuves de gestation, des contrôles de la mammite et pour pratiquer d'autres examens. Cette action conjointe contribue très sensiblement à la productivité et à la santé des troupeaux. 


\section{Mammite}

De toutes les maladies de la vache, c'est la mammite qui occasionne les pertes les plus lourdes. Il a été démontré que près de $50 \%$ des vaches laitières sont atteintes, à un moment ou l'autre de leur vie, de cette affection sous une de ses multiples formes, ce qui est une proportion bien plus importante que celle qu'avaient atteinte la tuberculose ou la brucellose du temps où ces maladies sévissaient encore. La mammite est due en tout premier lieu à une conduite défectueuse du troupeau et on n'arrivera à l'enrayer que lorsque les éleveurs auront acquis les connaissances nécessaires à son éradication. Le mot "mammite" désigne un mal du pis, quelqu'en soit la cause. Il existe des mammites non infectieuses provoquées par une agression quelconque, bien que la forme infectieuse soit la plus répandue. Jusqu'ici, on est parvenu à isoler dix-huit bactéries ou autres organismes qui causent la mammite, dont six sont les plus répandus. Quatre-vingts pour cent de tous les cas de mammites sont provoqués par deux types de bactéries; il s'agit de Staphylococcus aureus et de Streptococcus agalactiae. Fort heureusement, les moyens utilisés pour lutter contre ces deux organismes sont efficaces contre tous les autres germes en cause.

La bactérie Streptococcus agalactiae vit dans la glande mammaire de la vache. Sortie de son milieu, elle ne survit guère longtemps. Quand un troupeau a été débarrassé de ce microbe par le traitement approprié et que des mesures d'hygiène ont été instituées, la maladie ne fera plus son apparition. Par contre, le Staphylococcus aureus vit sur la peau du pis, sur les mains du trayeur, sur l'installation de traite et dans l'étable tout entière, ce qui rend la lutte beaucoup plus difficile. Néanmoins, ce microbe peut également être détruit par l'application de rigoureuses mesures d'hygiènes et d'un traitement approprié.

La mammite se reconnaît normalement à deux symptômes particuliers: au stade aigu de la maladie, le pis ou un des quartiers manifeste de l'inflammation et de la tuméfaction; le lait est altéré et la vache se sent visiblement mal. D'autre part, le lait peut présenter des grumeaux, des flocons ou d'autres anomalies. En fait, les éleveurs ne reconnaissent qu'une très faibles proportion des mammites dont les troupeaux sont atteints. En effet, $80 \%$ des mammites sont du type chronique ou dissimulé et l'éleveur n'est guère capable de les diagnostiquer. Alors que l'on pourrait croire que la mammite chronique est inoffensive, il a été démontré de manière concluante qu'elle diminue la productivité des vaches. C'est ainsi qu'un troupeau moyen de trente vaches voit son rendement annuel baisser d'environ 16,000 livres de lait par suite de la mammite chronique. Au surplus, les vaches malades menacent de contaminer les sujets sains du troupeau.

\section{Traitement}

Pour être efficace, la lutte contre la mammite doit porter sur l'effectif tout entier plutôt que sur telle ou telle vache atteinte. La maladie peut être enrayée à condition d'effectuer la traite selon les conditions requises, de suivre des règles d'hygiène rigoureuses et d'appliquer le traitement approprié. Le chapitre sur la traite des vaches donne quelques règles dont l'application permet de diminuer très sensiblement les cas de mammite tant chronique qu'aiguë. 
De plus, les mesures indiquées ci-dessous aident à combattre la maladie:

\section{Introduction de nouveaux sujets au sein du troupeau}

L'introduction au sein du troupeau de germes nouveaux et peut-être résistants, par l'achat de vaches atteintes de mammite chronique, est un fait courant. L'achat de vaches ou de génisses contrôlées est donc une précaution à prendre.

\section{Détection de tous les foyers d'infection}

Les foyers d'infection chronique étant répandus chez les vaches dans de nombreux quartiers et dans toutes l'étable, le lait doit faire l'objet d'examens spéciaux. L'épreuve de Whiteside et l'épreuve anti-mammite de Californie donnent une réaction positive quand le nombre de leucocytes est anormalement élevé, ce qui est un signe d'inflammation. L'examen du lait au laboratoire détermine le germe en cause. Des épreuves de sensibilité des germes orientent le vétérinaire dans le choix du traitement à prescrire.

\section{Traitement}

Le traitement est efficace dans la mesure où il détruit les germes dans la glande. Dans les cas d'inflammation aiguë, le traitement thérapeutique peut apporter une amélioration clinique, mais l'animal ne demeure pas moins vecteur. Certaines formes de mammite résistent à tous les traitements connus à l'heure actuelle, les animaux qui en sont frappés doivent être réformés.

La vaccinothérapie a une valeur relative dans le traitement des mammites staphylococciques.

Le ministère de l'Agriculture et de l'Alimentation de l'Ontario a instauré un programme de lutte contre la mammite. La participation au programme est facultative; elle se fait pour une durée de six mois sur versement d'une cotisation minime. Pour plus de renseignement concernant ce programme, on s'adresse au ministère sus-mentionné. Des renseignements plus détaillés sur la mammite figurent dans le bulletin 1082 que publie le ministère de l'Agriculture du Canada.

\section{Acétose (Acétonémie ou cétose)}

L'acétose est une des maladies les plus graves; elle occasionne chaque année de lourdes pertes financières, plus particulièrement durant l'hiver, par une baisse du rendement, l'altération du goût du lait et parfois la mort des vaches.

L'acétose se présente soit comme une affection en soi, soit comme une complication d'autres maladies, tels les troubles rénaux, la réticulite traumatique et l'indigestion. En fait, tout état qui provoque l'anorexie chez les grandes laitières peut également causer l'acétose.

Cette affection est caractérisée par la présence de corps cétoniques (produits du métabolisme des lipides) en quantité anormale dans le sang, les urines et le lait et le manque de sucre dans le sang. L'animal malade utilise les lipides plutôt que les glucides comme source principale d'énergie, ce qui 
entraîne une perte rapide de tonus. Cette indolence, jointe à la perte d'appétit et à une baisse de la production de lait, constitue souvent le premier symptôme de la maladie. Par ailleurs, l'haleine et le lait de l'animal dégagent une odeur douceâtre caractéristique. La vache manifeste une certaine constipation et les fèces prennent une apparence visqueuse et luisante. Des symptômes nerveux peuvent faire leur apparition. La bête se met à lécher la mangeoire ou ses pattes de devant, à chanceler; - elle peut même être prise de convulsions. Ces symptômes ne doivent pas être confondus avec ceux de la rage.

L'acétose pouvant avoir plusieurs causes, il est préférable de faire examiner l'animal malade par le vétérinaire avant de commencer un traitement.

$\mathrm{Au}$ stade actuel de nos connaissances, il n'existe pas de traitement totalement efficace. Toutefois, voici d'utiles mesures de prophylaxie:

1. Donner un complément énergétique avant le vêlage et ne pas l'interrompre après la mise bas, comme il est de pratique courante.

2. Donner aux vaches un bon complément minéral.

3. Tenir les grandes laitières sous observation étroite; le moindre dérangement peut provoquer l'acétose.

4. Dès qu'une vache semble atteinte, la faire examiner par le vétérinaire.

\section{Fièvre vitulaire (ou fièvre de lait)}

Cette affection apparaît généralement dans les quarante-huit heures qui suivent le vêlage, mais elle peut aussi se produire juste avant la mise bas. Elle est caractérisée par une paralysie progressive avec impossibilité éventuelle de se relever, une température normale ou sous la normale; elle peut amener la mort, faute de traitement approprié.

Comme les vaches peuvent dépérir après le vêlage pour différentes raisons, il faut consulter le vétérinaire pour confirmer le diagnostic. En raison d'une paralysie possible de la gorge, il est dangereux d'administrer un breuvage à une vache qui pourrait être atteinte de fièvre vitulaire.

Certains auteurs ont suggéré que le nombre de cas pourrait être réduit en augmentant la teneur en phosphore du complément minéral proportionnellement à la teneur en calcium.

Bien que la prophylaxie de la fièvre vitulaire soit mal connue, on recommande les mesures suivantes:

1. Injection intraveineuse ou sous-cutanée de sels de calcium immédiatement après le vêlage. Cette intervention peut sans doute enrayer le mal, mais elle n'est guère applicable dans la pratique. Elle est indiquée pour les vaches ayant déjà été atteintes lors de gestations précédentes.

2. Administration d'un supplément de calcium et de phosphore. Bien que les vaches atteintes de la fièvre vitulaire présentent une hypocalcémie aiguë, l'administration d'importantes quantités de calcium avant la mise bas n'empêche pas l'apparition du mal; au contraire, elle peut créer une prédisposition à la maladie. L'alimentation complémentaire en phosphore, et le bon équilibre entre celui-ci et le calcium, durant la période de tarissement pourrait réduire le nombre de cas dans certains troupeaux. 
3. Traite incomplète durant les deux ou trois jours qui suivent la mise bas. Même si elle est d'une certaine efficacité, cette méthode est dangereuse lorsque la vache est atteinte de mammite.

4. Certains recommandent comme mesure prophylactique l'administration de doses élevées de vitamine D durant au plus une semaine avant la date du vêlage. Il faut toutefois veiller à ne pas prolonger indûment le traitement indiqué par le fabricant.

\section{Piétin}

Le piétin provoque la claudication chez les bovins. Les pertes financières sont dues non pas à la mort des animaux mais à la diminution du poids et de la production de lait.

L'affection a pour cause une infection du pied contractée lors d'une blessure bénigne. Traitée aussitôt, la guérison est rapide, mais si on la néglige, une intervention peut devenir nécessaire pour sauver le membre atteint.

Pour prévenir le piétin, il faut éviter de tenir les animaux dans des endroits où ils peuvent se blesser les pieds, notamment sur le gravier et la pierraille, les routes et les bourbiers. Des bains de pieds antiseptiques peuvent être disposés de façon à ce que les bêtes soient obligées d'y passer en sortant de l'étable et en y rentrant. L'adjonction de composés d'iode à la ration de sel ou de minéraux s'avère utile parfois. Il n'existe pas de vaccin efficace contre le piétin.

\section{Météorisation}

La météorisation ou ballonnement est due à l'accumulation de gaz dans la panse. Elle est un symptôme de troubles de la digestion. Les causes sont diverses. Elle se manifeste sous sa forme la plus dangereuse parmi le bétail mis en pâturage dans des herbages luxuriants, surtout lorsque la proportion des légumineuses est élevée; la mortalité dans ces conditions peut être très importante. Les légumineuses ne provoquent pas toujours la météorisation; les raisons pour lesquelles certaines provoquent la maladie ne sont pas encore entièrement connues. Il semblerait toutefois que les pâturages à croissance rapide et ceux qui ont été flétris par la sécheresse après une période de pousse luxuriante soient particulièrement dangereux.

Le traitement peut nécessiter l'emploi d'une sonde stomacale et, dans les cas aigus, une intervention chirurgicale. L'administration d'un breuvage composé de huit à douze onces d'une huile minérale ou de toute autre huile non toxique, additionnée de préférence d'un agent mouillant, donne de bons résultats dans les cas bénins, mais le breuvage doit être administré lentement et avec prudence. L'expulsion des gaz est également favorisée en plaçant un bâillon dans la gueule de l'animal, en surélevant son avant-train et en "pétrissant" le rumen avec le poing.

On réussit parfois à prévenir la météorisation par les moyens suivants:

1. Les mélanges de graminées et de légumineuses causent moins de météorisation que les légumineuses seules. Il a été démontré que les cas aigus sont rares lorsque les graminées constituent au moins 50\% du mélange. 
2. Des rations supplémentaires de foin données la nuit aux vaches en enclos réduisent les cas de ballonnement imputables aux pâturages de légumineuses. L'apport de foin au pâturage même peut également s'avérer utile.

3. L'alternance des pâturages de graminées la nuit et de légumineuses le jour prévient aussi le mal.

4. L'administration d'environ quatre onces d'huile d'arachide ou de toute autre huile comestible en breuvage ou ajoutée aux aliments juste avant de conduire le bétail aux pâturages provoquant le météorisme peut enrayer le mal pendant huit à dix heures.

5. Une méthode qui a fait ses preuves en Nouvelle-Zélande, et qui mériterait d'être essayée au Canada, consiste à combiner la paissance sur lisières et la pulvérisation préalable de celle-ci avec de l'huile.

\section{Troubles de reproduction}

La stérilité est un problème complexe qui concerne tous les éleveurs. Le coefficient de conception dépend des impératifs suivants:

1. examen du cycle oestral,

2. repos après la mise bas,

3. isolement des vaches pendant l'oestrus,

4. prophylaxie des maladies de la reproduction,

5. alimentation appropriée.

On notera de ce qui précède que le taux de conception dépend en tout premier lieu de la conduite du troupeau. Quelques mesures susceptibles de l'améliorer figurent au chapitre traitant du maintien du taux de conception.

\section{Avortements}

Les causes d'avortement chez les bovins sont nombreuses, dont certaines maladies infectieuses, telles la brucellose (autrefois cause fréquente d'avortement mais qu'on a réussi à enrayer dans une large mesure), la trichomonase et la vibriose, deux maladies vénériennes. Certaines maladies à virus comme la rhino-trachéite infectieuse bovine peuvent également provoquer des avortements.

L'avortement peut encore être la conséquence de maladies non infectieuses, comme les carences alimentaires et certains empoisonnements.

Le diagnostic clinique de la cause des avortements nécessite un examen de laboratoire. Tous les avortons devraient être soumis à cet examen. Consulter le vétérinaire pour l'examen du sang et des pertes utérines de la mère.

\section{Leptospirose}

La leptospirose est une affection bactérienne des bovins et d'autres animaux. Elle est également fréquente, parmi les animaux sauvages. Chez les bovins, elle provoque l'avortement et elle se manifeste par d'autres symptômes. Le diagnostic s'appuie sur des examens de laboratoire. Le traitement est de la compétence du vétérinaire. 


\section{Tuberculose}

Le Canada tout entier est actuellement réparti en zones de répression, dans le cadre du Plan de lutte contre la tuberculose bovine. L'examen périodique du bétail sera poursuivi et l'observation de toute lésion tuberculeuse à l'abattoir entraînera l'examen d'office du troupeau d'origine tout entier. La fréquence des examens de dépistage dans telle ou telle zone dépendra du nombre de cas décelés lors du dernier contrôle et de l'apparition de nouveaux cas dans la zone en question.

On peut toujours faire examiner et certifier exempt de tuberculose un troupeau particulier si on le désire, mais le gouvernement n'interviendra plus financièrement, l'objectif étant actuellement le dépistage par zones.

Le programme de dépistage et d'abattage devra vraisemblablement être appliqué encore pendant de longues années avant que le programme antituberculeux n'atteigne son objectif, soit l'extirpation de la maladie.

Adresser toute demande de renseignements au sujet du programme de lutte contre la tuberculose au bureau le plus proche de la Direction de l'hygiène vétérinaire, ministère de l'Agriculture du Canada.

\section{Maladies du tube digestif}

\section{Diarrhée des veaux}

La diarrhée des veaux est un des plus graves problèmes de l'élevage. Elle est plus fréquente parmi les veaux nourris au seau que parmi ceux qui sont allaités, mais elle peut frapper les veaux de boucherie à la mamelle.

La diarrhée des veaux est due à une infection intestinale, mais de nombreux autres facteurs interviennent dans son étiologie, notamment la suralimentation et l'irrégularité de l'alimentation. Fait très important, l'élevage des veaux âgés de moins d'une semaine avec des veaux plus âgés, ainsi que leur maintien dans des locaux malpropres, humides ou sans litière suffisante occasionnent la maladie. Avec le temps, les loges dans lesquelles de nombreux veaux ont été tenus deviennent contaminées, ce qui les rend impropres pour les veaux nouveau-nés; ceux-ci doivent toujours loger dans un local propre et pourvu d'une litière abondante.

Pour prévenir la diarrhée des veaux, la mère au moment de la mise bas doit être placée dans une loge propre et désinfectée et pourvue d'une litière abondante. Aussitôt après la naissance, la désinfection du nombril s'impose et il faut encourager le veau à téter une heure après sa naissance. Le colostrum contient de nombreux principes protecteurs mais l'intestin du veau ne peut les absorber que durant un court laps de temps. Laisser le veau auprès de la mère pendant les premières vingt-quatre ou quarante-huit heures, ou ne l'alimenter que toutes les quatre heures pendant les premières vingt-quatre heures. Lorsque le veau est enlevé de sa mère, le placer dans une loge individuelle, ce qui empêche la propagation de la maladie et permet de déceler les premiers signes de diarrhée. Après les premières vingt-quatre ou quarantehuit heures, donner au veau pas plus de 6 à $8 \%$ de son poids de lait (ou une quantité équivalente d'un produit d'allaitement), par jour, durant la première 
semaine. Répartir cette quantité en deux buvées par jour, ou en trois si le veau est malingre.

En cas de diarrhée, réduire la ration de lait de moitié. Veiller toutefois à remplacer la diminution par une quantité équivalente d'eau, la diarrhée causant la déshydratation de l'organisme. Pour être pleinement efficace, le traitement doit être institué dès l'apparition des premiers symptômes. Le traitement variant suivant le troupeau, les matières fécales devraient être envoyées périodiquement au laboratoire afin de déterminer le remède le mieux indiqué.

Lorsque la diarrhée des veaux fait son apparition dans les vingt-quatre heures qui suivent la naissance, les mesures sus-indiquées doivent être rigoureusement appliquées. L'administration de médicaments avant que ne survienne la diarrhée peut être bénéfique; il faut veiller en particulier à ce que l'ingestion de vitamine A soit suffisante, car les carences prédisposent à la maladie.

\section{Coccidiose}

La coccidiose, maladie intestinale, attaque les veaux âgés de un à neuf mois. Elle est plus courante parmi les animaux gardés à l'intérieur. Elle se traduit par une diarrhée grave accompagnée d'hémorragie et de glaire. Dans les cas aigus, l'irritation intestinale provoque des efforts expulsifs violents pouvant causer l'inversion ou même la ptose du rectum. L'hémorragie peut être telle qu'elle entraîne l'anémie, l'affaiblissement et la mort dans' certains cas. fèces.

Le diagnostic s'établit sur les symptômes et l'examen microscopiques des

Le traitement fait appel aux sulfamides administrés soit aux seuls animaux atteints, soit au troupeau tout entier, en mélange dans la nourriture ou l'eau d'abreuvement durant sept jours. Le traitement est difficile dans des locaux contaminés; il exige le nettoyage complet des logettes et la protection des aliments et de l'eau d'abreuvage contre la contamination.

\section{Parasites internes du bétail}

Beaucoup de veaux et de bovins adultes ont des vers stomacaux et intestinaux à des degrés divers d'infestation. La gravité des cas dépend directement de la mesure dans laquelle le bétail est exposé aux oeufs rejetés dans les matières fécales et de la résistance des animaux à l'affection. Une mauvaise alimentation, des étables et pâturages surpeuplés, l'absence de rotation des pâturages, le temps chaud et humide aussi, favorisent la propagation des vers.

En règle générale, seuls les jeunes animaux sont atteints. Le mal se reconnaît à la diarrhée suivie de périodes de constipation intermittentes. Il peut entraîner dans l'ordre, l'anémie, le dépérissement et la mort.

Le diagnostic relève du vétérinaire qui, d'après les résultats de l'examen des fèces, détermine le degré d'infestation, ainsi que le traitement le moins coûteux et le plus efficace.

La phénothiazine était jadis le seul remède connu mais depuis peu, plusieurs nouveaux produits très efficaces sont à la disposition des vétérinaires.

Le traitement vise à diminuer les contacts avec les oeufs de parasites que 
rejettent les animaux atteints dans leurs matières fécales, et à veiller à la qualité de l'alimentation pour accroître la résistance du bétail à l'infestation.

\section{Diarrhée à virus}

On distinguait jadis entre deux maladies-la maladie des muqueuses et la diarrhée à virus, que l'on groupait quelquefois sous l'appellation de "maladie complexe des muqueuses". On estime actuellement que les deux affections sont dues à l'action de plusieurs types du même virus mais pour des raisons inconnues, elles se présentent sous deux formes différentes suivant les circonstances.

L'affection se traduit presque invariablement par de la diarrhée, des efforts expulsifs et l'ulcération des intestins et de la bouche. Elle s'accompagne d'inappétence, de dépression et de bave à des degrés divers. Puis, la faiblesse fait son apparition souvent accompagnée d'écoulement par les naseaux. L'affection peut se circonscrire à un seul sujet ou à quelques-uns, ou prendre des proportions plus importantes; elle est généralement de courte durée. Dans certains cas, pratiquement tous les animaux atteints meurent, ailleurs les cas mortels sont rares. Le traitement consiste en majeure partie en soins appropriés, aucun remède spécifique n'étant connu actuellement. Les vétérinaires peuvent toutefois se procurer un vaccin contre la diarrhée virale.

\section{Entérité hémorragique infectieuse d'hiver}

L'entérite hémorragique infectieuse d'hiver des bovins est une maladie grave qui frappe généralement les animaux gardés à l'étable, et les animaux adultes plutôt que les jeunes. Elle semble se transmettre d'une ferme à l'autre par les visiteurs, les animaux ou l'équipement. Elle provoque une diminution considérable de la lactation mais la mortalité reste faible. Il faut faire appel au vétérinaire pour enrayer le mal qui éclate de façon foudroyante. Des transfusions de sang ou des perfusions électrolytiques sont souvent nécessaires pour sauver les animaux gravement déshydratés.

\section{Maladies des voies respiratoires}

\section{Pneumonie à virus du veau}

La pneumonie à virus, ou enzootique, menace les veaux de moins de six mois gardés à l'étable. Des locaux surpeuplés et une ventilation insuffisante prédisposent à la maladie.

Les veaux atteints gardent leur vivacité et leur appétit, mais ils ont une toux sèche et rauque, et une respiration accélérée. L'isolement s'impose et le traitement immédiat aux antibiotiques pendant trois à cinq jours pour empêcher l'apparition d'une pneumonie bactérienne secondaire est nécessaire. L'application rapide du traitement indiqué réduit les pertes à des proportions négligeables, faute de quoi le veau risque de demeurer malingre.

La prophylaxie consiste, en premier lieu, à assurer des locaux et une aération convenables. En cas d'enzootie grave, les veaux doivent être isolés des animaux adultes, vecteurs du virus, dès la naissance, et élevés dans des locaux séparés jusqu'à ce qu'ils aient six mois. 
La pneumonie bactérienne du veau est soit une infection primaire, soit une complication de la pneumonie à virus. Dans la plupart des cas, les antibiotiques ou les sulfamides donnent de bons résultats si le traitement est institué immédiatement.

\section{Septicémie hémorragique}

La septicémie hémorragique frappe le plus souvent les animaux à la suite de leur déplacement, d'où son nom de fièvre des transports.

Le mal fait son apparition dans la semaine qui suit le transport, soit après l'introduction de nouveaux effectifs, soit au retour d'une exposition. L'affection se manifeste par une perte d'appétit, la dépression, une respiration accélérée et une forte hyperthermie. Elle est généralement accompagnée d'écoulements nasaux et d'une toux humide. Faute de traitement immédiat, la mortalité risque d'être importante par suite de troubles respiratoires graves. Voici des mesures propres à enrayer le mal:

1. Isoler du troupeau les nouveaux effectifs pour un minimum de deux semaines.

2. Tenir le bétail dans des locaux secs et bien aérés.

3. Prendre la température des nouveaux effectifs ayant un air suspect et, si elle dépasse la normale (de $100.5^{\circ} \mathrm{F}$ à $102.5^{\circ} \mathrm{F}$ ), les isoler et faire venir le vétérinaire qui établira le diagnostic et prescrira le traitement.

4. Offrir au bétail, au choix, de l'eau fraîche et propre, du sel iodo-cobalté et un bon mélange de minéraux. Si le bétail a très soif à l'arrivée, restreindre l'eau au cours de la première journée à la moitié de la ration ordinaire.

Il est difficile de prévenir la septicémie hémorragique, mais il faut veiller à réduire autant que possible les fatigues subies en cours de transport, notamment à:

1. sevrer les veaux au moins un mois avant le transport;

2. avant le transport, le bétail doit être bien reposé et recevoir du foin et de l'eau;

3. les wagons ou les camions seront pourvus d'une litière abondante et le bétail protégé des courants d'air autant que possible;

4. ne pas surcharger wagons ou camions;

5. effectuer le transport aussi rapidement que possible; lorsqu'il s'agit d'un long trajet, charger le bétail, lui donner à boire et à manger et lui permettre de se reposer à intervalles réguliers;

6. l'injection d'antibiotiques à action prolongée, le jour de l'expédition, peut aider à prévenir la septicémie hémorragique.

Cette affection touche plus les bovins de boucherie que les bovins laitiers, mais dans les deux cas, les soins en cours de transport, l'isolement et la mise en observation des nouveaux effectifs et de ceux qui reviennent sont indispensables. Les vaccins et les tranquillisants n'ont pas donné les résultats escomptés. 
Cette maladie infectieuse des bovins est due à un virus. Bien que les bovins de tous âges et types y soient susceptibles, les symptômes varient suivant l'âge de l'animal attient. Ainsi, des veaux nouveau-nés peuvent avoir de la fièvre et présenter des symptômes de troubles gastro-intestinaux. Les veaux âgés de trois à quatre mois, ainsi que les adultes, présentent des symptômes d'infection des fosses nasales et de la trachée-artère. La rougeur des naseaux, la toux sèche et rauque, l'anorexie, l'écoulement nasal, l'inflammation des yeux comme dans les cas de kératite sont quelques-uns des principaux symptômes de la rhino-trachéite infectieuse. Les animaux de ce groupe d'âge manifestent généralement une forte hyperthermie et une respiration accélérée. Les vaches en gestation atteintes de la RIB risquent d'avorter dans les trente jours ou de mettre bas des veaux malingres présentant des symptômes de troubles digestifs.

La RIB entraîne des pertes principalement par avortement et par mortalité chez les veaux nouveau-nés; chez les animaux plus âgés, la maladie se complique d'une pneumonie bactérienne secondaire.

Il n'existe pas actuellement de traitement spécifique contre la maladie, aussi faut-il s'en tenir à des soins attentifs et dans certains cas, à l'administration d'antibiotiques pour prévenir toute infection bactérienne secondaire.

Il existe des vaccins contre la RIB mais ils doivent être utilisés avec prudence, des cas d'avortement ayant été signalés à la suite de leur injection.

\section{Bronchite vermineuse $d u$ veau}

C'est une maladie qui apparaît sporadiquement, surtout lorsque les animaux ont été gardés de façon continue dans des enclos ombragés, des vergers, des petits pâturages ou d'autres endroits où ils sont constamment en contact avec le fumier. Elle frappe le plus souvent les veaux âgés de quatre à dix mois. L'affection est favorisée par un temps humide et frais; aussi, la plupart des cas apparaissent à l'automne, après une période prolongée de fortes pluies.

La bronchite vermineuse ressemble par bien des symptômes à la pneumonie, seul le vétérinaire peut d'ordinaire établir un diagnostic sûr.

D'habitude, les veaux atteints ont tous une légère diarrhée, suivie au bout de quelques jours de toux et d'une respiration accélérée, souvent entrecoupée de râles. Bien qu'ils continuent à s'alimenter, les malades perdent rapidement du poids; ainsi un veau pesant $450 \mathrm{lb}$ et qui avait été infecté expérimentalement, a perdu $45 \mathrm{lb}$ en trente jours.

Le diagnostic est basé sur les antécédents, les symptômes et la présence d'oeufs du parasite dans le fumier, ce qui exige évidemment un examen microscopique. Quand la maladie est déclarée, tous les veaux doivent être soumis au traitement. La bronchite vermineuse étant d'ordinaire accompagnée de vers de l'estomac et des intestins, il faut soigner simultanément contre les trois types de parasites. Le traitement consiste principalement à assurer une bonne nourriture, des locaux convenables et la rotation des pâturages.

\section{Parasites externes}

Chez les bovins laitiers les parasites externes les plus répandus au Canada sont l'oestre et ses larves, les poux et les acariens de la gale. 
L'examen des animaux permet de détecter l'oestre et ses larves ainsi que les poux. Il existe de nombreux produits antiparasitaires, certains sont utilisés en applications locales sur la peau, d'autres sont administrés par voie orale. Le mode d'emploi des produits en question doit être strictement respecté, car une dose excessive peut être soit toxique pour l'animal lui-même, soit laisser des résidus toxiques dans le lait ou la viande.

Aux termes de la loi, tout cas de gale, avéré ou suspect, doit être communiqué au représentant local de la Direction de l'hygiène vétérinaire du ministère de l'Agriculture du Canada.

\section{Désinfection}

Les maladies infectieuses se propagent principalement par la contamination des litières, des planchers, des étables et des cours par les excrétions des animaux infectés.

Pour éliminer l'infection, les litières et le fumier des animaux atteints doivent être brûlés ou étalés en couches minces sur le sol à un endroit où les animaux n'ont pas accès. Nettoyer et désinfecter à fond stalles et planchers.

\section{Désinfectants chimiques}

Soude caustique -1 livre par 20 à 30 gallons d'eau bouillante.

Créoline - solution à $2 \%$.

Crésol U.S.P. - solution à 2 ou $3 \%$.

Acide phénique - solution de 3 à $5 \%$.

Bichlorure de mercure -1 partie de bichlorure pour 1,000 parties d'eau, en poids.

Autres désinfectants - utiliser suivant le mode d'emploi.

En règle générale, les désinfectants chimiques sont plus efficaces s'ils sont employés chauds. C'est le cas en particulier de la soude caustique, désinfectant peu cher et efficace contre la plupart des organismes pathogènes.

\section{Soude}

\begin{tabular}{clc} 
Solution & \multicolumn{1}{c}{$\begin{array}{c}\text { Dans } 1 \text { pinte } \\
\text { d'eau }\end{array}$} & $\begin{array}{c}\text { Dans un gallon } \\
\text { d'eau }\end{array}$ \\
\hline $2 \%$ & 6 cuillerées à thé & 3 onces \\
$3 \%$ & $21 / 2$ cuillerées à soupe & $41 / 2$ onces \\
$4 \%$ & 3 cuillerées à soupe & 6 onces \\
$5 \%$ & $31 / 2$ cuillerées à soupe & 7 onces
\end{tabular}

\section{DESINSECTISATION}

Tout propriétaire de troupeaux laitiers se trouve aux prises avec le difficile problème de la répression des insectes à la fin du printemps, durant l'été et les premiers mois d'automne. En général, plus l'été est chaud, plus grave est le problème, car les insectes se reproduisent rapidement. Certains insectes qui infestent les fermes laitières peuvent être considérés comme des parasites du bétail au pâturage, d'autres harcellent les animaux à l'étable et dans les cours, tandis que d'autres sont présents partout. 
La mouche faciale du bétail, parasite d'introduction relativement récente comparativement à certains autres insectes des fermes laitières, pénètre rarement, si jamais, dans l'étable avec le troupeau pour la traite. Mais par contre, la mouche des cornes, la mouche piquante des étables, la mouche domestique, le chrysops et le taon rayé du cheval pénètrent dans les étables avec les vaches qu'elles continuent de tourmenter à moins qu'on ne les détruise.

Certaines mouches sont pourvues d'organes qui leur permettent de piquer et de sucer le sang. Il s'agit des tabanidés (chrysops, taon de l'original, taon du cheval) de la mouche domestique piquante (mouche piquante des étables), des mouches des cornes et des moustiques. D'autres, comme la mouche domestique et la mouche faciale ont des organes différents avec lesquels elles peuvent laper des liquides; elles ne piquent pas ni ne sucent le sang. Ce dernier groupe, pourtant, harasse sans cesse les animaux.

La lutte contre ces parasites aux alentours de la ferme laitière est difficile et coûteuse; c'est pourquoi il faut veiller à:

(1) supprimer dans la mesure du possible les milieux de reproduction des mouches à l'intérieur ou aux alentours de l'étable; (A moins de disposer $\mathrm{du}$ fumier et des ordures de toutes sortes, les deux conseils suivants sont inutiles.)

(2) commencer la lutte assez tôt dans la saison;

(3) utiliser l'insecticide approprié et suivre à la lettre le mode d'emploi.

On ne traitera pas ici des insecticides à employer contre les mouches, car dans ce domaine, la situation change si rapidement que chaque année des nouvelles recommandations sont publiées ou mises à jour, au besoin.

L'hygiène est d'importance primordiale. Si les insectes se multiplient et se développent dans les tas de fumiers, si les logettes des veaux et les stalles des taureaux demeurent souillées des semaines durant, jamais on ne réussira à détruire les mouches, quelles que soient les quantités d'insecticides employées. En été, les mouches passent de l'oeuf au stade adulte en dix jours et parfois même moins, et quatre cents larves peuvent atteindre l'âge adulte dans une seule livre de fumier.

Enlever le fumier des étables tous les deux jours. Ne pas le laisser s'accumuler, dans la cour, mais l'épandre en minces couches dans les champs tous les cinq ou sept jours. Traiter de la même façon les déjections des porcs et de la volaille.

S'il faut absolument garder le fumier quelque temps avant de l'épandre, n'en faire qu'un seul tas de forme rectangulaire si possible. Si le tas de fumier se trouve sur une plate-forme ou une dalle de ciment bien drainées, on peut alors le charger par tous les temps. Que le tas soit bien tassé et les côtés aussi verticaux que possible; le tasser et l'égaliser avec une bêche ou une pelle. Dans certains cas, il peut être pratique de creuser une rigole autour du tas et de la remplir de mazout. Les larves en arrivant à maturité, quittent le fumier en grands nombres à la recherche d'un endroit sec où effectuer leur passage à l'état adulte. Beaucoup d'entre elles tombent alors dans le mazout et y périssent. 
Mettre des grillages à la laiterie, aux étables et porcheries si possible, et voir à ce qu'ils soient parfaitement adaptés aux portes et fenêtres et maintenus en bon état; un ou deux trous dans un grillage lui enlèvent toute utilité pratique. Les portes grillagées doivent toujours s'ouvrir vers l'extérieur.

\section{LOGEMENT DU TROUPEAU LAITIER}

Le logement du troupeau laitier joue un rôle de première importance pour la production d'un lait de qualité. Un bâtiment fonctionnel bien conçu doit non seulement assurer un logement approprié, des conditions de travail agréable, l'efficacité de la main-d'oeuvre, la valorisation optimale des aliments et une production laitière efficace, mais également créer un milieu sain et confortable pour le troupeau laitier.

L'examen approfondi de ces divers facteurs dépasserait le cadre de notre publication; il se borne donc à considérer brièvement les questions les plus importantes.

\section{Stabulation}

Les trois modes fondamentaux sont la stabulation à stalles, la stabulation libre et la stabulation libre à logettes.

La stabulation à stalles est la plus courante au Canada où de nombreuses annés de recherches et d'expérience pratique en ont permis la mise au point. Ce mode prévoit une stalle séparée pour chaque vache. Il permet la surveillance individuelle de l'alimentation, de l'entretien et de la traite. Des loges y sont pourvues aussi pour les veaux, les jeunes animaux et les vaches en vêlage.

A l'origine la stabulation libre comprenait une aire de couchage recouverte d'une litière épaisse, une aire distincte d'alimentation, un local de traite et une aire d'exercice. Les besoins en litière sont tels que ce mode est maintenant assez peu en vogue, sauf dans les régions où la litière abonde à bon compte.

La stabulation libre à logettes est la toute dernière conception du logement du troupeau; c'est également la plus en vogue chez les éleveurs qui construisent de nouvelles étables. Elle diffère principalement de la stabulation libre en ce que l'aire de couchage est divisée en loges individuelles et que les allées entre les loges sont pavées. Les vaches ne sont pas attachées dans leurs loges. Avec cette organisation il faut nettoyer les allées, mais les besoins de litière sont moindres et les vaches restent remarquablement propres.

La stabulation libre à logettes possède sur la stabulation à stalles plusieurs avantages. Elle permet de grossir facilement le troupeau, d'agrandir l'étable à peu de frais, d'améliorer l'hygiène du troupeau, d'économiser la litière, de faire la traite dans des conditions moins fastidieuses, d'économiser la maind'oeuvre et d'améliorer la gestion.

\section{Matériaux de construction}

Il est essentiel de choisir les matériaux de construction avec soin, en faisant attention particulièrement aux qualités suivantes: salubrité, résistance, solidité, ignifugation, porosité et isolation thermique. 
La tendance générale est aux bâtiments à un étage, à colombage léger construits avec l'un des nombreux matériaux nouveaux qui sont faciles à travailler et pourtant solides et résistants.

Le coût initial et les frais d'entretien sont d'importance primordiale dans la construction de bâtiments pour les bovins laitiers; ils sont en grande partie déterminés par les matériaux employés. Le béton est l'un des meilleurs pour les empattements, les sols, les rampes et les marches, car il ne coûte presque rien à entretenir, est facile à façonner à l'état initial, devient résistant, et surtout reste hygiénique.

On utilise surtout des charpentes en bois pour les murs, les cloisons et les toits, car le bois est facile à se procurer et se coupe aisément selon les besoins. Pratiquement tous les nouveaux panneaux de construction peuvent s'appliquer directement sur un cadre de bois. Une bonne isolation est indispensable autant qu'une aération appropriée des bâtiments fermés. Pour ce faire, on peut remplir les vides entre les membres de la charpente avec de la mousse plastique rigide, semi-rigide on en vrac. Pour l'extérieur, il est recommandé d'employer des matériaux résistants aux intempéries. Les surfaces intérieures, exposées à une humidité très élevée, comme dans la laiterie, doivent être recouvertes d'un matériau imperméable à l'eau.

En raison de la déperdition de chaleur et de la condensation, les fenêtres se salissent facilement. C'est pourquoi les nouvelles étables laitières n'ont très souvent que quelques fenêtres ou pas du tout, selon les règlements locaux.

Il existe de nombreux produit nouveaux tels que les matières plastiques et les panneaux lamellés pour murs-rideaux et toits, mais étant donné qu'un grand nombre d'entre eux n'ont pas fait leur preuve, il faut user de prudence à leur égard.

\section{Types d'étables à stalles}

Le type d'étable à stalles le plus courant est le traditionnel bâtiment à étage avec greniers et fenils pour les grains, le foin et la paille, et le logement des bovins au rez-chaussée. L'aménagement peut varier dans les détails mais la conception générale et les dimensions sont maintenant étalonnées. L'étable à étage tout en exigeant des fondations et un toit, permet une économie des frais de construction et d'entretien qu'il est difficile d'égaler avec deux granges traditionnelles de plein-pied ayant une capacité équivalente.

Cependant l'intérêt grandit pour les étables de plein-pied. Les dangers de combustion spontanée entraînant la perte éventuelle du bétail sont réduits dans les bâtiments de ce genre. Mais en fait, c'est surtout la généralisation de l'affouragement à l'ensilage et au foin presque toujours pressé en balles ou haché, qui a atténué le besoin de greniers de grande capacité. Des dispositifs spéciaux, propres à économiser la main-d'oeuvre ont été conçus pour faciliter le transport horizontal de l'ensilage et des fourrages grossiers à l'état sec. Aussi, la force de gravité n'est plus essentielle à la manutention des aliments. C'est pourquoi, à l'avenir on se souciera davantage de l'hygiène et de la disposition fonctionnelle des bâtiments de plein-pied conçus pour loger le troupeau laitier, les jeunes animaux, et les vaches taries. Pour emmagasiner aliments et paille on se contentera de simples abris. 


\section{ORGANISATION DE L'ETABLE A STALLES}

L'organisation d'une étable à stalles demande que l'on prenne en considération un certain nombre de facteurs dont l'arrangement fonctionnel, l'espace, l'hygiène et l'aération.

\section{Arrangement fonctionnel}

1. Disposition des stalles - Si la traite se fait dans les stalles, il est alors recommandé de placer les vaches face au mur puisqu'on passe plus de temps derrière la vache que devant. La disposition tête à tête est parfaitement valable si l'alimentation est complètement automatique, ou si la traite a lieu dans un local distinct.

2. Type de stalles - Les quatre types de stalles les plus courants sont: la stalle à cornadis, la stalle à attache coulissante verticale, la stalle confort et la stalle à baisse-tête ou dresseur.

La stalle à cornadis était jadis le type le plus courant. Cependant il existe d'autres types qui laissent plus de liberté aux vaches et qu'on installe maintenant dans les nouvelles constructions.

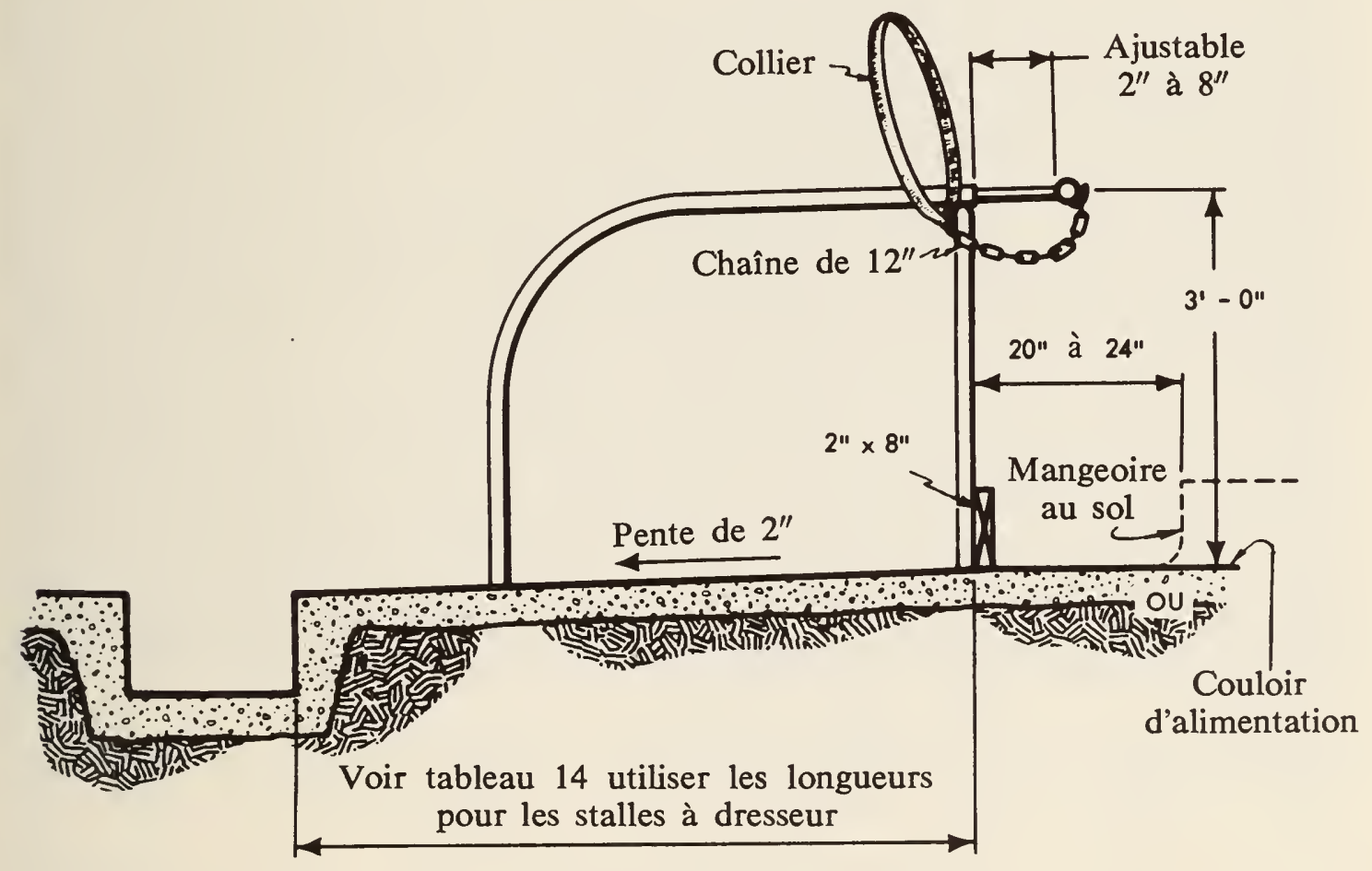

Détail de construction de cornadis pour étable à stabulation entravée

La stalle à attache coulissante verticale donne une plus grande liberté de mouvement aux vaches et le fait qu'il n'y ait rien au-dessus d'elles donne à l'intérieur un aspect très net. Les vaches sont attachées individuellement au moyen d'une chaîne ou d'un collier.

La stalle à baisse-tête unique est le type le plus économique à installer. Le baisse-tête est muni de chaînes individuelles qui s'attachent au collier des vaches. 
On trouvera les dimensions appropriées des stalles au tableau 14.

\section{TABLEAU 14. Dimensions des stalles à cornadis ou à collier pour les bovins laitiers}

\begin{tabular}{|c|c|c|c|}
\hline \multirow{2}{*}{$\begin{array}{l}\text { Poids de } \\
\text { l'animal } \\
\text { (lb) }\end{array}$} & \multirow{2}{*}{$\begin{array}{l}\text { Largeur de } \\
\text { la plate-forme } \\
\text { de la stalle }\end{array}$} & \multicolumn{2}{|c|}{ Longueur de la plate-forme de la stalle } \\
\hline & & Avec dresseur & Sans dresseur \\
\hline 800 & 3 pi et 4 po & 4 pi et 6 po & 4 pi et 10 po \\
\hline 1,000 & 3 pi et 8 po & 4 pi et 8 po & 5 pi et 0 po \\
\hline 1,200 & 4 pi et 0 po & 5 pi et 0 po & 5 pi et 4 po \\
\hline 1,400 & 4 pi et 4 po & 5 pi et 4 po & 5 pi et 8 po \\
\hline 1,600 & 4 pi et 8 po & 5 pi et 8 po & 6 pi et 0 po \\
\hline
\end{tabular}

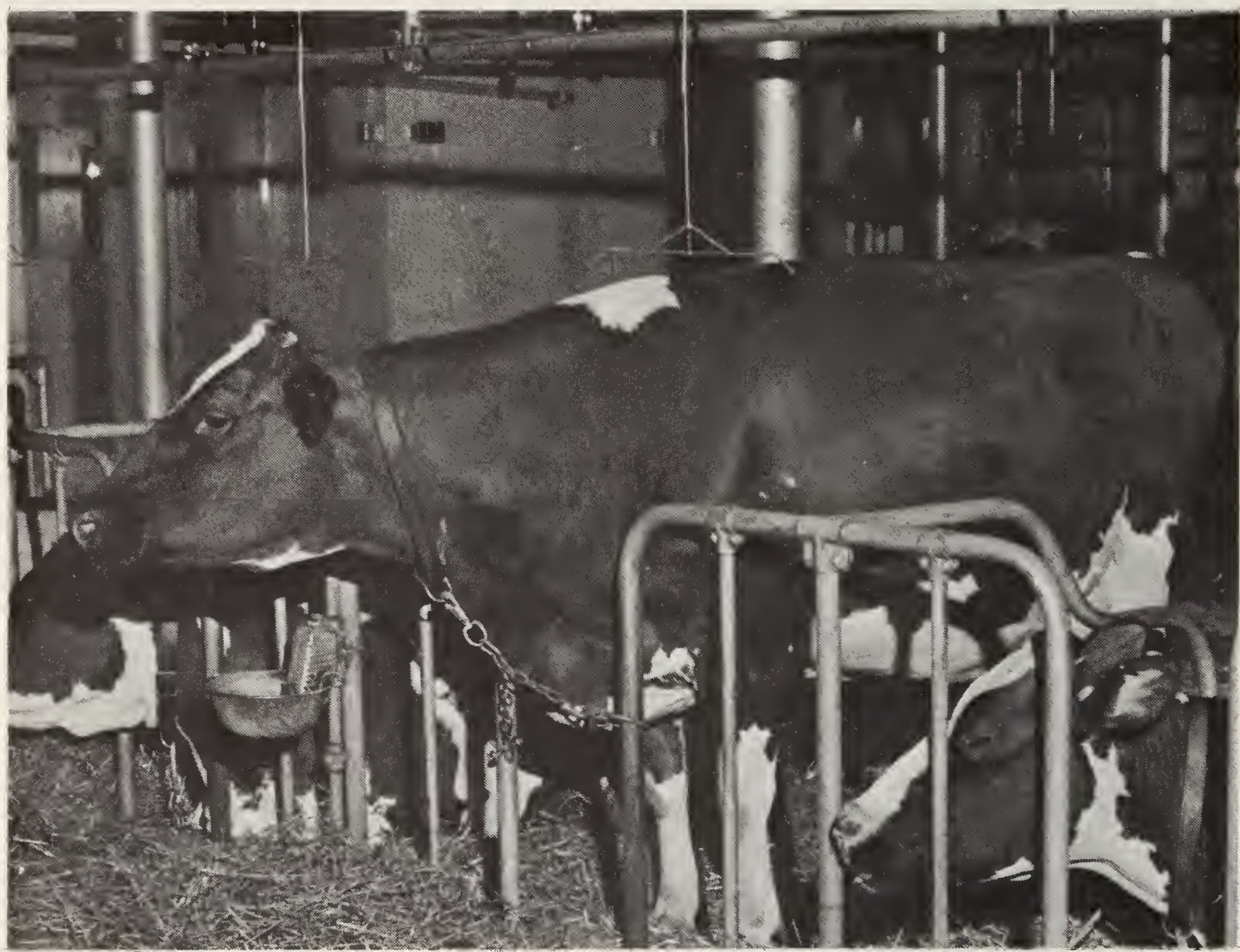

Vue intérieure d'une étable équippé de stalles à entraves. Remarquez le collier et le dresseur électrique au-dessus de la vache. Ceux-ci sont très importants dans les stalles à collier à chaine.

\section{STOCKAGE DES ALIMENTS}

Foin, pâtées et litières sont parfois entreposés au-dessus de l'étable; on peut ainsi les acheminer aux moyens de conduits ou de trappes ménagées dans le plafond. Dans les constructions à un seul étage, ils sont logés dans un bâtiment séparé, ce qui réduit les frais de stockage dans les nouvelles constructions et diminue la poussière dans les étables.

Pour les grands troupeaux, une aire de manutention séparée est utile pour faciliter les travaux de préparation et le mélange des céréales cultivées à la ferme. Le transport du matériel depuis l'aire de stockage à l'équipement de 


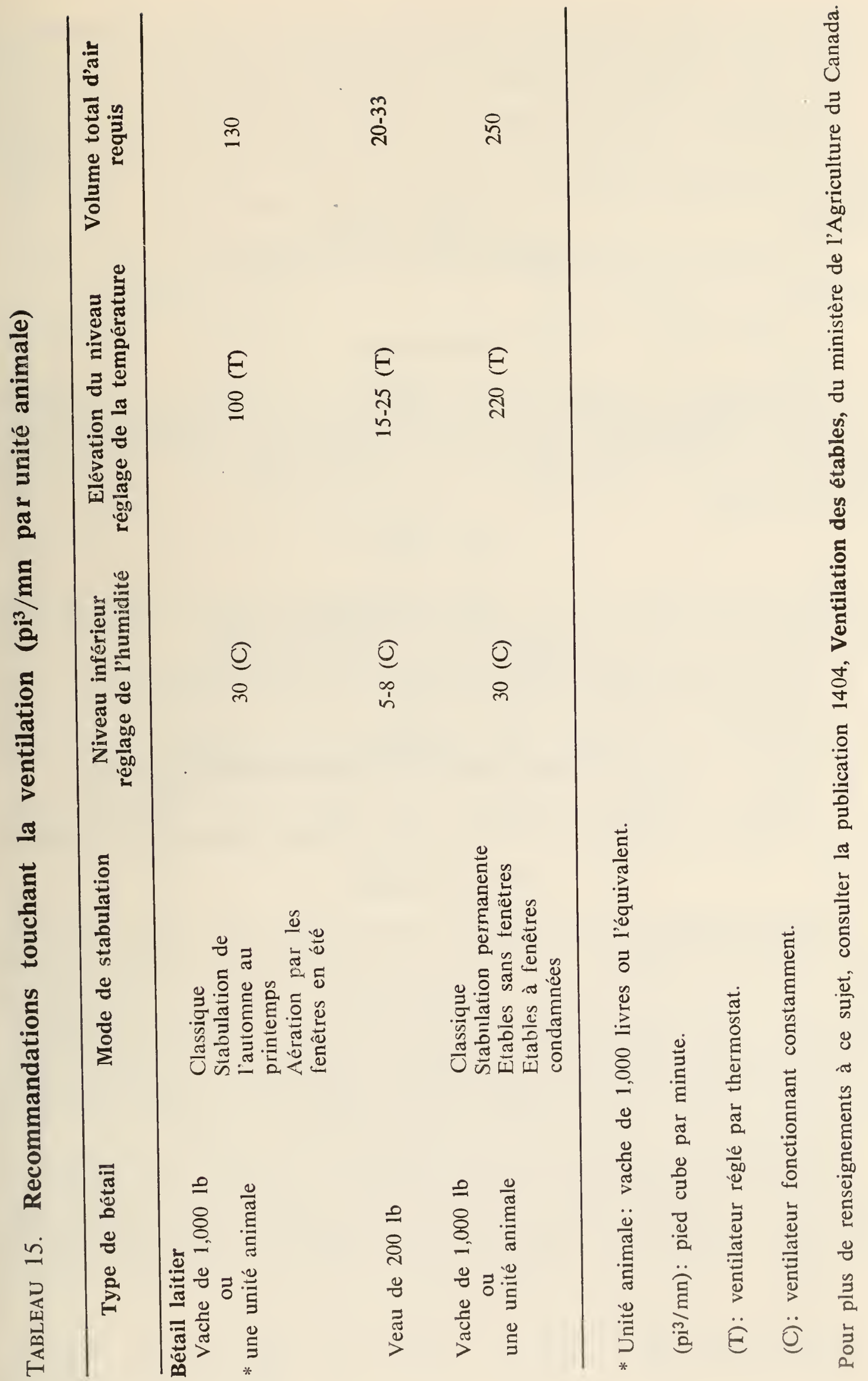


préparation se fait par simple vis sans fin ou par dispositifs d'élévation. Le même équipement sert aussi à l'acheminement direct des aliments jusqu'aux vaches. Les ensilages sont stockés dans des silos verticaux ou horizontaux.

Les silos-tours munis de désileuses et de transporteurs de fourrage facilitent l'alimentation et réduisent les pertes. Les silos horizontaux sont plus rentables pour les grosses installations (capacités de 1,000 tonnes ou davantage), l'augmentation des frais de manutention étant compensée par le coût initial moindre.

La capacité des silos de différentes dimensions figurent au tableau A7 de l'annexe.

\section{Mécanisation}

Diverses opérations qui exigeaient autrefois un travail souvent pénible ont été mécanisées au moyen d'évacuateurs de fumier, de convoyeurs d'aliments et d'installations de traite avec lactoduc. $\mathrm{Vu}$ la complexité et la diversité des plans d'étables, le choix de l'équipement se fait en fonction du cas particulier.

\section{AERATION}

L'aération de l'étable vise à y créer un milieu favorable à la santé et à la production du troupeau. Pour ce faire, elle doit notamment:

1. Maintenir une hygrométrie convenable à l'intérieur de l'étable.

2. Eliminer l'air vicié et les fortes odeurs.

3. Introduire de l'air frais sans provoquer de courants d'air.

4. Chasser l'excès de chaleur et maintenir une température optimale.

5. Eliminer tout excès d'humidité, évitant ainsi au bois de pourrir, à la peinture de s'écailler, au métal et aux appareils électriques de rouiller.

\section{Seuil d'aération}

Le bétail dégage une quantité importante de chaleur qui sert à maintenir une température suffisante dans l'étable. Une température variant entre 40 et $55^{\circ} \mathrm{F}$ et une humidité relative ne dépassant pas $75 \%$ constituent les conditions idéales pour la santé et le bien-être des animaux. Lorsque la température extérieure est inférieure à $0^{\circ} \mathrm{F}$, il faut de 25 à 30 pieds cubes d'air par minute et par vache de 1,000 livres pour maintenir l'hygrométrie et la température convenable. En été, avec l'élévation de la température extérieure, le besoin d'aération peut être jusqu'à dix fois celui qui convient en hiver.

La température extérieure variant constamment, le volume d'air nécessaire pour assurer une atmosphère convenable dans l'étable varie lui aussi. Un groupe de ventilateurs, bien installés et judicieusement disposés et munis de thermostats, maintient une température plus uniforme à l'intérieur de l'étable.

\section{STABULATION LIBRE A LOGETTES}

La stabulation libre à logettes comporte six différentes aires, chacune pouvant être subdivisée en plusieurs parties. Chaque aire peut être aménagée 
de plusieurs manières. La stabulation libre à logettes permet donc des dispositions et des types de construction très variés. Toutefois, certains principes fondamentaux doivent être respectés en matière de conception et de construction. Si l'on veut assurer le plein succès de ce mode de stabulation du bétail laitier.
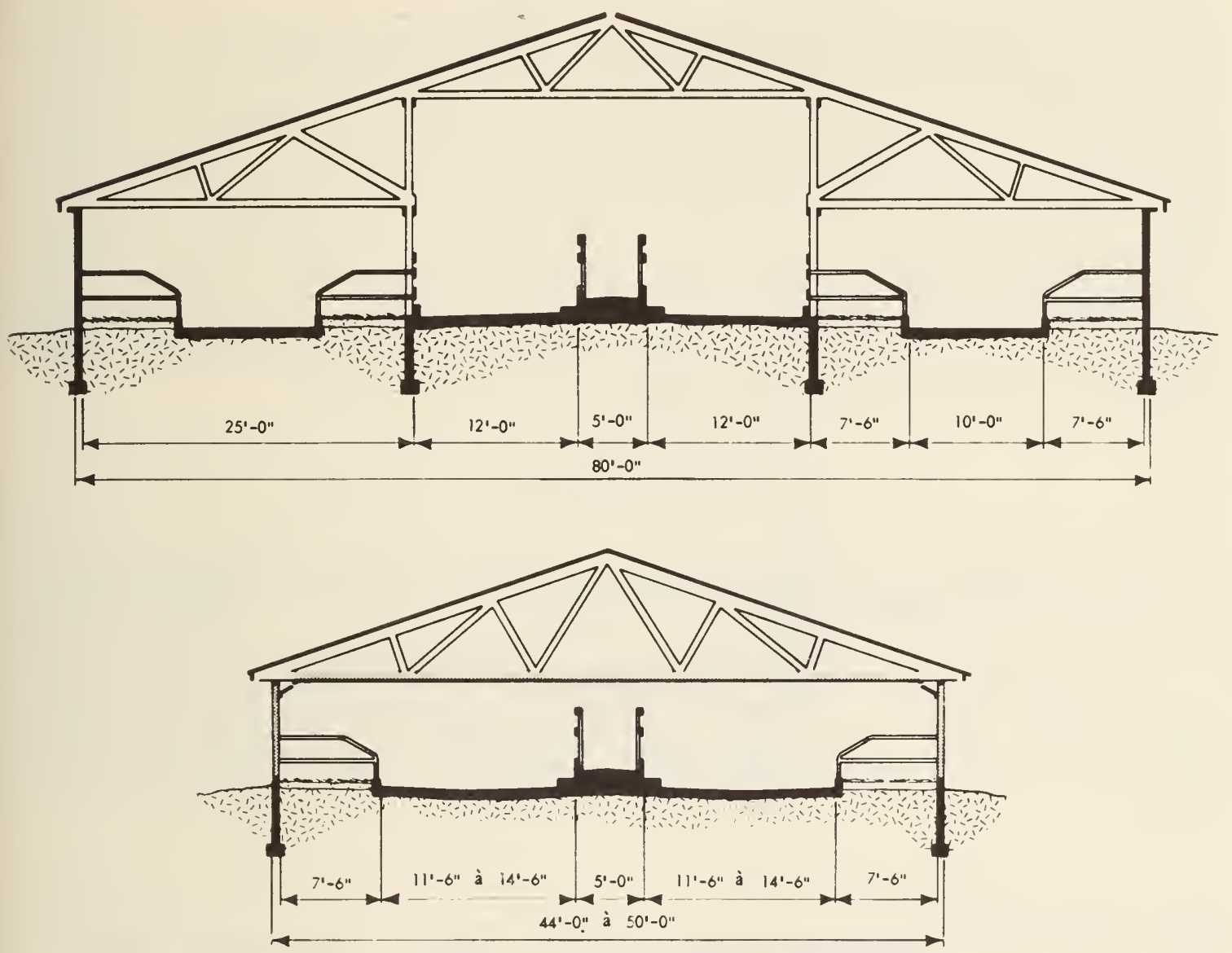

Coupe d'une étable laitière à stabulation libre pour grands et petits troupeaux.

\section{La laiterie}

La laiterie constitue le coeur de la stabulation libre à logettes; elle comporte la laiterie proprement dite, la salle de traite, l'aire d'attente, la salle d'entreposage et la salle de mélange des concentrés. Elle doit permettre de traire les vaches et de procéder à la manutention, au refroidissement et à la conservation du lait de façon efficace et hygiénique. La laiterie exige les investissements les plus importants en matière de construction et d'équipement; son fonctionnement nécessite le plus de temps et de travail et les règles d'hygiène doivent $\mathrm{y}$ être rigoureusement respectées. La réglementation variant d'une région à l'autre, il est préférable de consulter les agents régionaux des services d'hygiène ou de la salubrité du lait avant d'entreprendre les traveaux de construction.

L'aire d'attente est une surface pavée et de préférence couverte, de quatorze à dix-huit pieds carrés par vache, adjacente à la salle de traite, où les vaches sont tenues avant la traite. 
La salle de traite est équipée en vue de la traite continue. Les stalles de traite sont soit du type tandem à "tunnel", soit du type tandem avec entrée latérale, soit enfin du type de stalles "en épi". Pendant leur passage par les stalles, les vaches reçoivent généralement une partie ou la totalité de leur ration de concentrés. On applique à cette aire les mêmes règles d'hygiène, d'éclairage, de ventilation et d'isolation thermique qu'à la laiterie.

La laiterie proprement dite, tout en étant attenante à la salle de traite, doit en être séparée par une cloison. C'est ici que le lait est refroidi et conservé en attendant d'être enlevé, et que les machines à traire sont nettoyées et entreposées entre les traites. Ce bâtiment doit également satisfaire strictement aux règles d'hygiène.

La salle de mélange se situe soit au-dessus de la salle de traite, soit dans les cellules d'entreposage pour aliments en vrac. L'utilisation de transporteurs automatiques pour amener les aliments jusqu'aux mangeoires individuelles des stalles est en voie de généralisation.

\section{L'aire de repos}

L'aire de repos est un endroit abrité et séparé en logettes. Les cloisons des logettes et les couloirs permettent aux vaches de se reposer en toute tranquillité. Le couloir pavé sert à la circulation des bêtes ainsi qu'au transport du foin et à l'enlèvement du fumier. Le tableau 16 donne quelques dimensions recommandées pour les logettes suivant la taille des animaux. Toutefois, toutes les logettes auront une dimension moyenne et uniforme dans le même bâtiment.

\section{Tableau 16. Dimensions des logettes pour la stabulation libre du bétail laitier}

\begin{tabular}{|c|c|c|c|}
\hline \multirow[b]{2}{*}{ Type de bétail } & \multirow{2}{*}{$\begin{array}{c}\text { Largeur } \\
\text { des } \\
\text { logettes }\end{array}$} & \multicolumn{2}{|c|}{ Longueur des logettes, $\mathbf{y}$ compris le rebord arrière } \\
\hline & & $\begin{array}{l}\text { Logettes à sol } \\
\text { de terre }\end{array}$ & $\begin{array}{c}\text { Logettes à sol } \\
\text { pavé et surélevé }\end{array}$ \\
\hline Veaux, jusqu'à & & & \\
\hline 400 livres & 3 pi, 0 po & 6 pi, 0 po & 5 pi, 9 po \\
\hline Génisses d'un an & 3 pi, 0 po & 6 pi, 6 po & 6 pi, 3 po \\
\hline $\begin{array}{l}\text { Génisses ou vaches, } \\
\text { poids moyen }\end{array}$ & & & \\
\hline 800 livres & 3 pi, 4 po & 7 pi, 0 po & 6 pi, 9 po \\
\hline $\begin{array}{l}\text { Vaches, poids } \\
\text { moyen } 1,000 \text { livres }\end{array}$ & 3 pi, 6 po & 7 pi, 3 po & 7 pi, 0 po \\
\hline $\begin{array}{l}\text { Vaches, poids moyen } \\
1,200 \text { livres }\end{array}$ & 3 pi, 9 po & 7 pi, 6 po & 7 pi, 3 po \\
\hline $\begin{array}{l}\text { Vaches, poids moyen } \\
1,400\end{array}$ & 4 pi, 0 po & 8 pi, 0 po & 7 pi, 6 po \\
\hline
\end{tabular}


La bonne largeur des allées est de huit à douze pieds et la hauteur libre, de neuf pieds, ce qui permet de faire le nettoyage au tracteur équipé de la lame. L'aire d'emmagasinage de la litière est complètement séparée. De fait, les besoins en litière sont assez faibles et le travail d'épandage se fait plus facilement en circulant par les allées et en déchargeant directement dans les logettes. Il suffit de renouveler la litière deux ou trois fois par mois.

\section{Aire d'alimentation, d'abreuvement et de repos}

L'usage se répand de plus en plus en matière de logement des bovins laitiers d'aménager d'un seul tenant les logettes et les aires d'alimentation et d'abreuvement. Le complexe peut être bien isolé thermiquement et pourvu d'un groupe ventilateur pour régler la température en hiver, ou au choix, isolé tout juste assez pour réduire au minimum la condensation de la vapeur d'eau sur le plafond, en complétant l'installation de prises d'air le long de l'avant-toit et
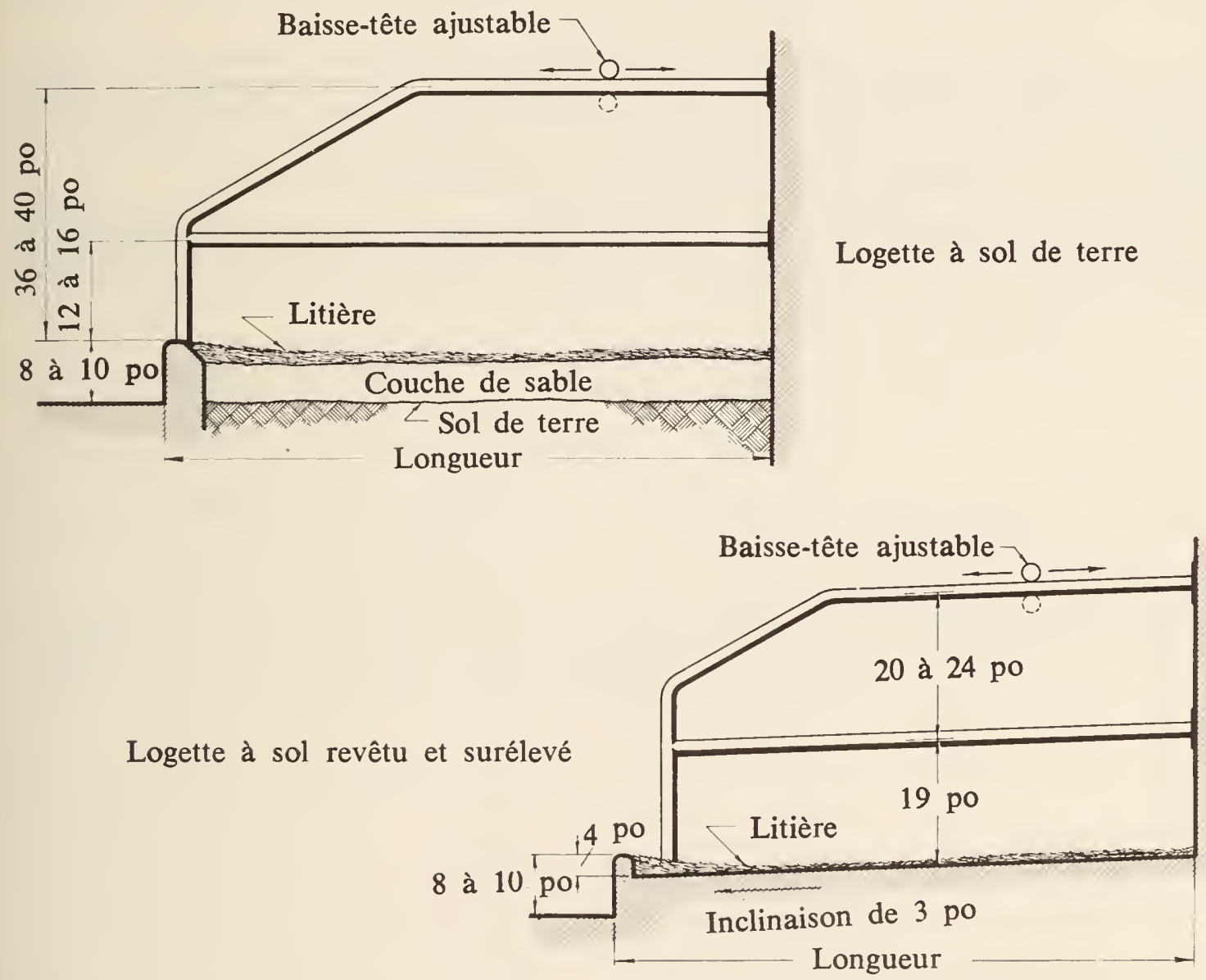

aux faîtes. Dans ce dernier cas, il faut un dispositif pour tiédir l'eau et en prévenir le gel.

Deux vues en profil font voir l'aménagement classique des deux aires qui recueillent le suffrage général des usagers.

L'agronome officiel se fera un plaisir de renseigner les producteurs qui envisagent de construire une installation de ce genre, en ce qui concerne les cours asphaltées, l'emplacement des bâtiments, les silos et les brise-vents. 


\section{Loges de mise bas, infirmerie, aire de monte et loges à veaux}

La plupart des exploitants préfèrent aménager ces aires dans un bâtiment fermé et isolé thermiquement, ou du moins dans un section à part, où ils peuvent régler suffisamment les conditions du milieu. Une ancienne étable répond parfaitement à ce besoin, à la condition qu'elle soit exempte d'humidité et de courants d'air et qu'elle soit bien éclairée, isolée thermiquement et aérée.

\section{LOGEMENT DES JEUNES ANIMAUX ET DES VACHES TARIES}

Le logement de ces classes d'animaux doit être séparé de celui du troupeau laitier. Par souci d'économie de la main-d'oeuvre, il est préférable qu'il soit du type de la stabulation libre. Il y a lieu aussi de répartir les génisses en deux groupes selon leur grosseur, à défaut de quoi les petites sont chassées des mangeoires, à moins d'y ménager beaucoup d'espace.

\section{PLANS}

Le Service de plans de constructions rurales canadiennes fournit les plans de tous les genres de logements pour les bovins laitiers. Il suffit de les demander aux ministères provinciaux de l'Agriculture.

Le spécialiste régional du service de vulgarisation, section du génie rural, prête volontiers conseils et aide en matière d'aménagement des installations. 


\section{ANNEXES}

Tableau

Titre

Page

A 1 Besoins quotidiens des bovins laitiers en principes nutritifs

82

A 2 Besoins des vaches laitières en période de lactation, en protéine totale, en protéine digestible et en principes nutritifs digestibles totaux (P.N.D.)

A 3 Composition moyenne de certains aliments du bétail ................ 85

A 4 Coût de la tonne de céréales selon le prix de celles-ci au boisseau 88

A 5 Poids étalon au boisseau de certains aliments du bétail et nombre de boisseaux de ceux-ci à la tonne

A 6 Poids moyen de certains aliments du bétail …............................ 89

A 7 Capacité, exprimée en tonnes, des silos selon leur hauteur ....... 90

A 8 Capacité requise pour le stockage des aliments du bétail ........... 90

A 9 Table de calcul de la période de gestation de la vache .............. 91

A 10 Croissance normale des bovins laitiers (femelles) en poids et en hauteur

A 11 Poids estimatif des bovins d'après le périmètre de la poitrine au niveau du coeur

A 12 Fiche individuelle des bovins du troupeau ............................... 94

A 13 Méthode d'estimation de la valeur génétique des vaches

Les données relatives à la composition des aliments du bétail sont adaptées de la publication $\mathrm{n}^{\circ} 659$ du Conseil national des recherches et des tables de Morrison, Feeds and Feeding, $22^{\mathrm{e}}$ édition. 


\section{TABleau A 1. Besoins quotidiens des bovins laitiers en principes nutritifs ${ }^{1}$}

\begin{tabular}{|c|c|c|c|c|c|c|c|}
\hline $\begin{array}{l}\text { Poids } \\
\text { corporel } \\
\text { (lb) }\end{array}$ & $\begin{array}{l}\text { Gain } \\
\text { quotidien } \\
\text { (lb) }\end{array}$ & $\begin{array}{l}\text { Protéine } \\
\text { (lb) }\end{array}$ & $\begin{array}{c}\text { Protéine } \\
\text { digestible } \\
\text { (lb) }\end{array}$ & $\begin{array}{l}\text { P.N.D. } \\
\text { (lb) }\end{array}$ & $\begin{array}{l}\text { Ca } \\
(\mathrm{g})\end{array}$ & $\begin{array}{l}\mathbf{P} \\
(\mathrm{g})\end{array}$ & $\begin{array}{c}\text { Carotèn } \\
(\mathrm{mg})\end{array}$ \\
\hline \multicolumn{8}{|c|}{ Génisses de remplacement - ration de croissance } \\
\hline 50 & 0.6 & 0.18 & 0.16 & 1.0 & 2 & 2 & 2 \\
\hline 100 & 1.1 & 0.40 & 0.36 & 2.0 & 4 & 3 & 5 \\
\hline 150 & 1.2 & 0.68 & 0.48 & 3.0 & 8 & 6 & 8 \\
\hline 200 & 1.4 & 0.86 & 0.56 & 4.0 & 10 & 8 & 10 \\
\hline 400 & 1.5 & 1.04 & 0.76 & 6.5 & 13 & 12 & 20 \\
\hline 600 & 1.3 & 1.32 & 0.82 & 8.5 & 14 & 13 & 30 \\
\hline 800 & 1.2 & 1.48 & 0.90 & 9.5 & 16 & 15 & 39 \\
\hline 1000 & 1.0 & 1.60 & 0.96 & 10.6 & 16 & 15 & 48 \\
\hline 1200 & 0.7 & 1.69 & 1.02 & 11.0 & 16 & 15 & 58 \\
\hline \multicolumn{8}{|c|}{ Vaches adultes, ration d'entretien } \\
\hline 800 & & 0.83 & 0.50 & 6.0 & 10 & 10 & 40 \\
\hline 1000 & & 1.00 & 0.60 & 7.0 & 12 & 12 & 48 \\
\hline 1200 & & 1.17 & 0.70 & 8.2 & 15 & 15 & 58 \\
\hline 1400 & & 1.34 & 0.80 & 9.2 & 17 & 17 & 69 \\
\hline 1600 & & 1.52 & 0.90 & 10.2 & 20 & 20 & 80 \\
\hline
\end{tabular}

Ration des vaches reproductrices - s'ajoute à la ration d'entretien durant les 2 ou 3 derniers mois de la gestation

\begin{tabular}{rrrrrrr}
\hline 800 & 0.80 & 0.48 & 4.8 & 10 & 8 & 22 \\
1200 & 1.00 & 0.60 & 6.6 & 13 & 11 & 30 \\
1600 & 1.25 & 0.72 & 8.0 & 16 & 14 & 38 \\
\hline
\end{tabular}

Vaches en lactation - ration de production à ajouter, selon le cas, à la ration de croissance ou à la ration d'entretien pour chaque livre de lait

\begin{tabular}{lrlllll}
\hline Vaches pro- & mg 3\% & 0.078 & 0.050 & 0.36 & 1.3 & 0.9 \\
duisant plus & $4 \%$ & 0.088 & 0.056 & 0.42 & 1.3 & 0.9 \\
de 75 lb de & $5 \%$ & 0.098 & 0.062 & 0.48 & 1.3 & 0.9 \\
lait par jour & $6 \%$ & 0.108 & 0.070 & 0.54 & 1.3 & 0.9 \\
\hline $\begin{array}{l}\text { Vaches pro- } \\
\text { duisant de } 45\end{array}$ & $3 \%$ & 0.070 & 0.045 & 0.32 & 1.1 & 0.8 \\
à 75 lb de & $5 \%$ & 0.078 & 0.051 & 0.37 & 1.1 & 0.8 \\
lait par jour & $6 \%$ & 0.086 & 0.056 & 0.42 & 1.1 & 0.8 \\
\hline $\begin{array}{l}\text { Vaches pro- } \\
\text { duisant moins }\end{array}$ & $3 \%$ & 0.094 & 0.060 & 0.47 & 1.1 & 0.8 \\
de 45 lb de & $5 \%$ & 0.070 & 0.040 & 0.28 & 1.0 & 0.7 \\
lait par jour & $6 \%$ & 0.078 & 0.050 & 0.33 & 1.0 & 0.7 \\
\hline
\end{tabular}

Veaux d'abattage - ration de croissance

\begin{tabular}{rrrrrrrr}
\hline 100 & 1.5 & 0.54 & 0.48 & 2.8 & 5 & 4 & 5 \\
150 & 2.0 & 0.80 & 0.72 & 4.6 & 8 & 6 & 8 \\
200 & 2.4 & 1.20 & 0.90 & 6.0 & 9 & 8 & 10 \\
250 & 2.5 & 1.24 & 0.93 & 6.2 & 11 & 10 & 13 \\
300 & 2.6 & 1.28 & 0.96 & 6.4 & 12 & 11 & 16 \\
\hline
\end{tabular}




\section{TABleau A 1 (suite)}

\begin{tabular}{|c|c|c|c|c|c|c|c|}
\hline $\begin{array}{l}\text { Poids } \\
\text { corporel } \\
\text { (lb) }\end{array}$ & $\begin{array}{l}\text { Gain } \\
\text { quotidien } \\
\text { (lb) }\end{array}$ & $\begin{array}{l}\text { Protéine } \\
\text { (lb) }\end{array}$ & $\begin{array}{l}\text { Protéine } \\
\text { digestible } \\
\text { (lb) }\end{array}$ & $\underset{\text { (lb) }}{\text { P.N.D. }}$ & $\begin{array}{l}\mathbf{C a} \\
(\mathbf{g})\end{array}$ & $\underset{(\mathbf{g})}{\mathbf{P}}$ & $\begin{array}{c}\text { Carotène } \\
(\mathrm{mg})\end{array}$ \\
\hline \multicolumn{8}{|c|}{$\begin{array}{l}\text { Veaux laitiers mâles, ration de croissance - jusqu'au poids corporel de } \\
400 \mathrm{lb} \text {, utiliser la table propre aux génisses en croissance }\end{array}$} \\
\hline 400 & 2.2 & 1.22 & 0.85 & 7.0 & 14 & 13 & 21 \\
\hline 800 & 2.0 & 1.60 & 1.10 & 11.0 & 17 & 15 & 40 \\
\hline 1200 & 1.7 & 1.90 & 1.20 & 13.0 & 18 & 17 & 58 \\
\hline 1600 & 1.3 & 2.20 & 1.40 & 15.0 & 20 & 19 & 78 \\
\hline 2000 & 一 & 2.40 & 1.50 & 17.0 & 22 & 20 & 95 \\
\hline \multicolumn{8}{|c|}{ Taureaux reproducteurs adultes - ration d'entretien } \\
\hline 1200 & & 1.55 & 1.03 & 10.3 & 12 & 12 & 60 \\
\hline 1600 & & 1.77 & 1.18 & 12.8 & 16 & 16 & 80 \\
\hline 2000 & & 2.11 & 1.41 & 15.4 & 20 & 20 & 95 \\
\hline 2400 & & 2.44 & 1.63 & 18.5 & 24 & 24 & 117 \\
\hline
\end{tabular}

1 Adaptation de la publication 1349, sur les besoins des bovins laitiers en principes nutritifs, Conseil national de recherches. 


\section{TABleAu A 2. Besoins des vaches laitières en période de lactation, en protéine totale, en protéine digestible et en principes nutritifs totaux (P.N.D.)}

(Besoins additionnels des animaux en croissance ou à l'entretien)

\begin{tabular}{|c|c|c|c|c|c|c|c|c|}
\hline \multirow{2}{*}{\multicolumn{2}{|c|}{$\begin{array}{l}\text { Production } \\
\text { laitière } \\
\text { (lb) }\end{array}$}} & \multicolumn{7}{|c|}{ Matière grasse $(\%)$} \\
\hline & & 3.0 & 3.5 & 4.0 & 4.5 & 5.0 & 5.5 & 6.0 \\
\hline \multirow[t]{3}{*}{1.0} & Protéine totale & 0.062 & 0.066 & 0.070 & 0.074 & 0.078 & 0.082 & $\overline{0.086}$ \\
\hline & Protéine digestible & 0.040 & 0.043 & 0.046 & 0.048 & 0.050 & 0.053 & 0.056 \\
\hline & P.N.D & 0.280 & 0.305 & 0.330 & 0.355 & 0.380 & 0.405 & 0.430 \\
\hline \multirow{3}{*}{10} & Protéine totale & 0.62 & 0.66 & 0.70 & 0.74 & 0.78 & 0.82 & 0.86 \\
\hline & Protéine digestible & 0.40 & 0.43 & 0.46 & 0.48 & 0.50 & 0.53 & 0.56 \\
\hline & P.N.D. & 2.80 & 3.05 & 3.30 & 3.55 & 3.80 & 4.05 & 4.30 \\
\hline \multirow{3}{*}{20} & Protéine totale & 1.24 & 1.32 & 1.40 & 1.48 & 1.56 & 1.64 & 1.72 \\
\hline & Protéine digestible & 0.80 & 0.86 & 0.92 & 0.96 & 1.00 & 1.06 & 1.12 \\
\hline & P.N.D. & 5.60 & 6.10 & 6.60 & 7.10 & 7.60 & 8.10 & 8.60 \\
\hline \multirow{3}{*}{30} & Protéine totale & 1.86 & 1.98 & 2.10 & 2.22 & 2.34 & 2.46 & 2.58 \\
\hline & Protéine digestible & 1.20 & 1.29 & 1.38 & 1.44 & 1.50 & 1.59 & 1.68 \\
\hline & P.N.D. & 8.40 & 9.15 & 9.90 & 10.65 & 11.40 & 12.15 & 12.90 \\
\hline \multirow{3}{*}{40} & Protéine totale & 2.48 & 2.64 & 2.80 & 2.96 & 3.12 & 3.28 & 3.44 \\
\hline & Protéine digestible & 1.60 & 1.72 & 1.84 & 1.92 & 2.00 & 2.12 & 2.24 \\
\hline & P.N.D. & 11.20 & 12.20 & 13.20 & 14.20 & 15.20 & 16.20 & 17.20 \\
\hline \multirow{3}{*}{50} & Protéine totale & 3.50 & 3.70 & 3.90 & 4.10 & 4.30 & 4.50 & 4.70 \\
\hline & Protéine digestible & 2.25 & 2.40 & 2.55 & 2.68 & 2.80 & 2.90 & 3.00 \\
\hline & P.N.D. & 16.00 & 17.25 & 18.50 & 19.75 & 21.00 & 22.25 & 23.50 \\
\hline \multirow{3}{*}{60} & Protéine totale & 4.20 & 4.44 & 4.68 & 4.92 & 5.16 & 5.40 & 5.64 \\
\hline & Protéine digestible & 2.70 & 2.88 & 3.06 & 3.21 & 3.36 & 3.48 & 3.60 \\
\hline & P.N.D. & 19.20 & 20.70 & 22.20 & 23.70 & 25.20 & 26.70 & 28.20 \\
\hline \multirow{3}{*}{70} & Protéine totale & 4.90 & 5.18 & 5.46 & 5.74 & 6.02 & 6.30 & 6.58 \\
\hline & Protéine digestible & 3.15 & 3.36 & 3.57 & 3.74 & 3.92 & 4.06 & 4.20 \\
\hline & P.N.D. & 22.40 & 24.15 & 25.90 & 27.65 & 29.40 & 31.15 & 32.90 \\
\hline \multirow{3}{*}{80} & Protéine totale & 6.24 & 6.64 & 7.04 & 7.44 & 7.84 & & \\
\hline & Protéine digestible & 4.00 & 4.24 & 4.48 & 4.72 & 4.96 & & \\
\hline & P.N.D. & 28.80 & 31.20 & 33.60 & 36.00 & 38.40 & & \\
\hline \multirow{3}{*}{90} & Protéine totale & 7.02 & 7.47 & 7.92 & & & & \\
\hline & Protéine digestible & 4.50 & 4.82 & 5.14 & & & & \\
\hline & P.N.D. & 32.40 & 35.10 & 37.80 & & & & \\
\hline
\end{tabular}

Adaptation des données de la publication 1349, sur les besoins des bovins laitiers er. principes nutritifs, Conseil national de recherches.

Les chiffres de ce tableau sont établis d'après les besoins des vaches en production, tableau A1.

Mode d'emploi du tableau: repérer dans la colonne de gauche la production laitière en livres, puis horizontalement la colonne correspondant à la richesse du lait en matière grasse. Exemple: une vache produisant $50 \mathrm{lb}$ de lait à $4 \%$ de matière grasse exigerait, pour maintenir son rendement, $3.9 \mathrm{lb}$ de protéine totale, ou $2.55 \mathrm{lb}$ de protéine digestible, et $18.5 \mathrm{lb}$ de P.N.D. 


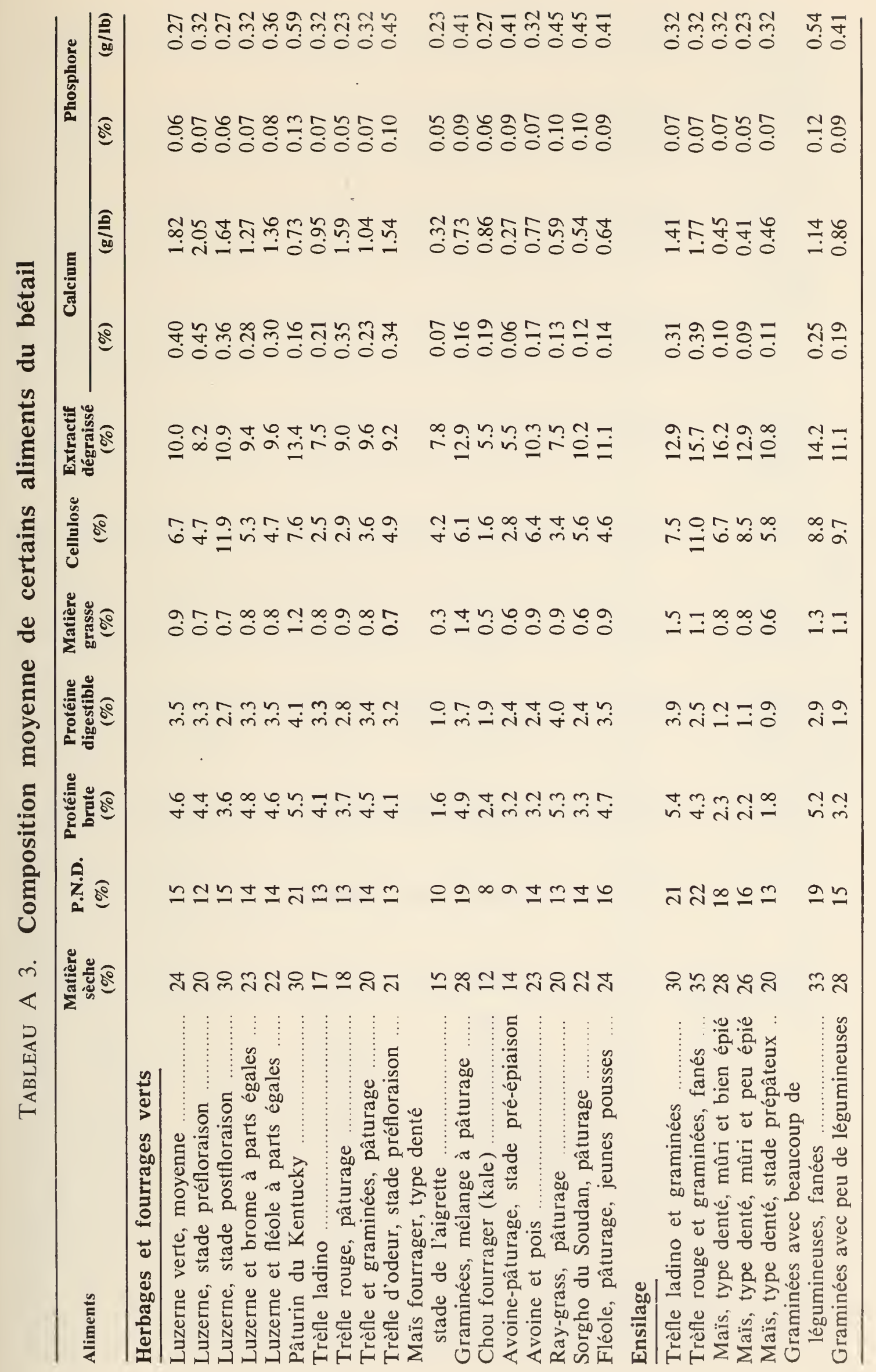




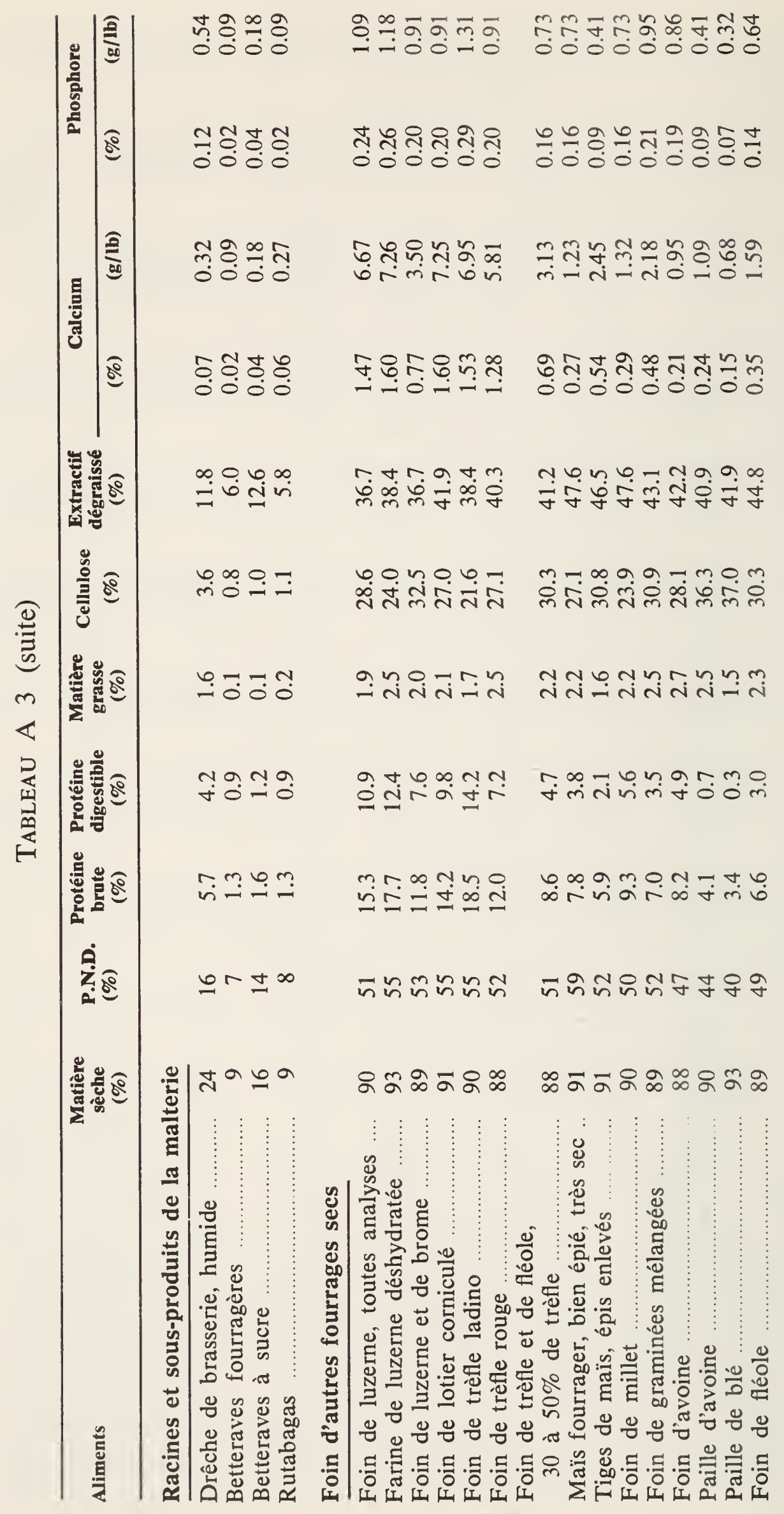




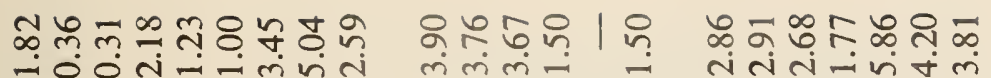

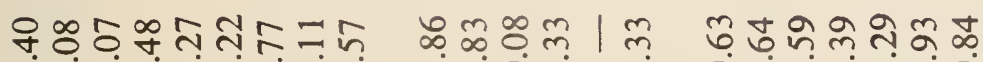

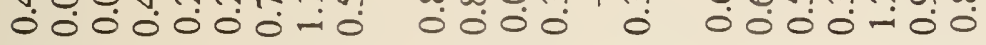

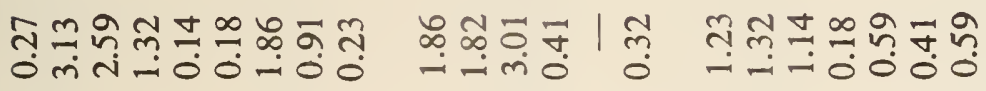

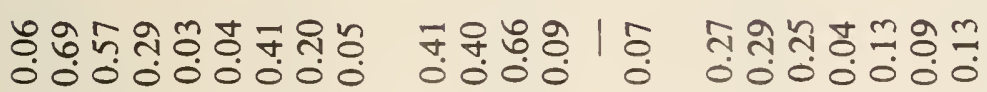

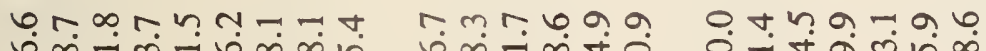

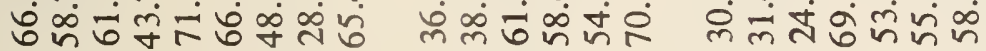

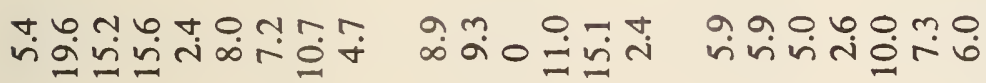

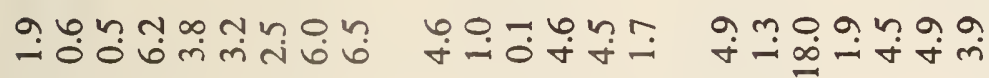

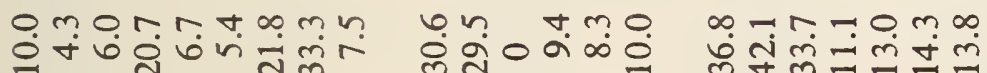

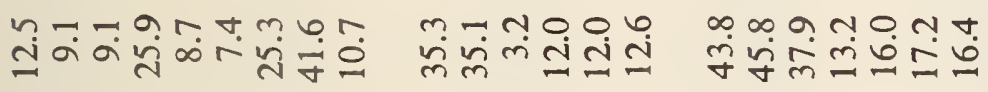

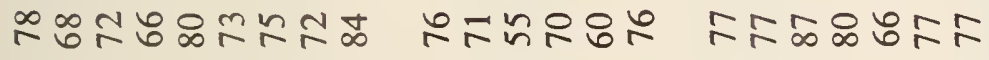

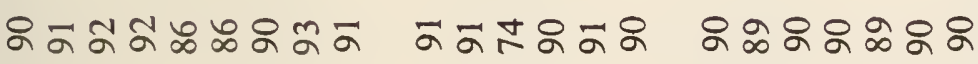

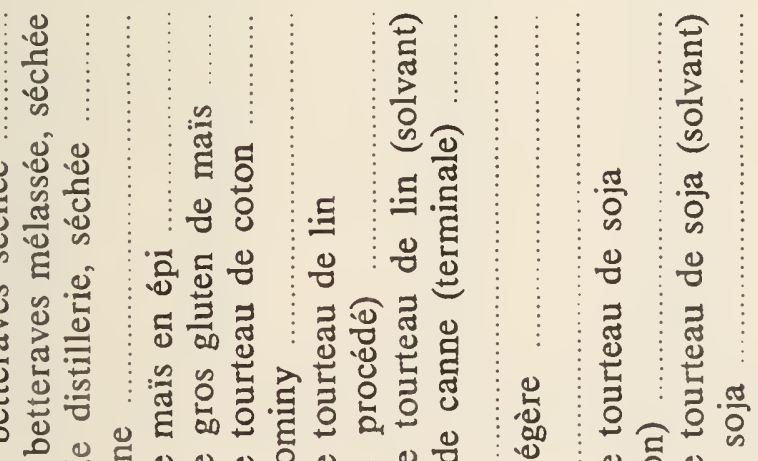

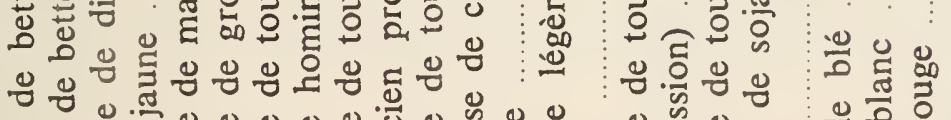

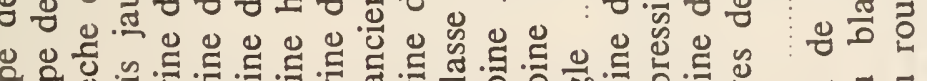

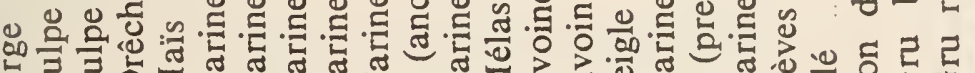

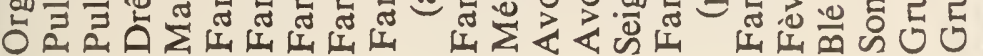


Tableau A 4. Coût de la tonne de céréales, selon le prix de celles-ci au boisseau

\begin{tabular}{|c|c|c|c|c|c|}
\hline Poids au boisseau & $\begin{array}{c}\text { Avoine } \\
34 \text { lb } \\
\end{array}$ & $\begin{array}{c}\text { Orge } \\
48 \mathrm{lb} \\
\end{array}$ & $\begin{array}{c}\text { Maïs, seigle } \\
56 \mathrm{lb} \\
\end{array}$ & $\begin{array}{l}\text { Blé } \\
60 \mathrm{lb} \\
\end{array}$ & $\begin{array}{c}\text { Maïs en épi* } \\
70 \text { lb }\end{array}$ \\
\hline Prix au boisseau & \multicolumn{5}{|c|}{ Coût de la tonne - en dollars } \\
\hline .30 & 17.65 & 12.50 & 10.71 & 10.00 & 8.57 \\
\hline .35 & 20.58 & 14.59 & 12.50 & 11.67 & 10.00 \\
\hline .40 & 23.53 & 16.67 & 14.29 & 13.33 & 11.43 \\
\hline .45 & 26.47 & 18.75 & 16.07 & 15.00 & 12.86 \\
\hline .50 & 29.41 & 20.83 & 17.86 & 16.67 & 14.28 \\
\hline .55 & 32.35 & 22.92 & 19.64 & 18.33 & 15.71 \\
\hline .60 & 35.29 & 25.00 & 21.43 & 20.00 & 17.14 \\
\hline .65 & 38.23 & 27.08 & 23.21 & 21.67 & 18.57 \\
\hline .70 & 41.17 & 29.17 & 25.00 & 23.33 & 20.00 \\
\hline .75 & 44.12 & 31.25 & 26.79 & 25.00 & 21.43 \\
\hline .80 & 47.05 & 33.33 & 28.57 & 26.67 & 22.86 \\
\hline .85 & 49.99 & 35.42 & 30.36 & 28.33 & 24.28 \\
\hline .90 & 52.94 & 37.50 & 32.14 & 30.00 & 25.71 \\
\hline .95 & 55.88 & 39.58 & 33.93 & 31.67 & 27.14 \\
\hline 1.00 & 58.82 & 41.67 & 35.71 & 33.33 & 28.57 \\
\hline 1.05 & 61.76 & 43.75 & 37.50 & 35.00 & 30.00 \\
\hline 1.10 & 64.70 & 45.83 & 39.29 & 36.67 & 31.43 \\
\hline 1.15 & 67.64 & 47.92 & 41.07 & 38.33 & 32.86 \\
\hline 1.20 & 70.58 & 50.00 & 42.86 & 40.00 & 34.28 \\
\hline 1.25 & 73.52 & 52.08 & 44.64 & 41.67 & 35.71 \\
\hline 1.30 & 76.47 & 54.17 & 46.43 & 43.33 & 37.14 \\
\hline 1.35 & 79.41 & 56.25 & 48.21 & 45.00 & 38.57 \\
\hline 1.40 & 82.34 & 58.33 & 50.00 & 46.67 & 40.00 \\
\hline 1.45 & 85.29 & 60.42 & 51.79 & 48.33 & 41.33 \\
\hline 1.50 & 88.23 & 62.50 & 53.57 & 50.00 & 42.86 \\
\hline 1.55 & 91.17 & 64.58 & 55.36 & 51.67 & 44.28 \\
\hline 1.60 & 94.11 & 66.67 & 57.14 & 53.33 & 45.71 \\
\hline 1.65 & 97.05 & 68.75 & 58.93 & 55.00 & 47.14 \\
\hline 1.70 & 99.99 & 70.83 & 60.71 & 56.67 & 48.57 \\
\hline 1.75 & 102.93 & 72.92 & 62.50 & 58.33 & 50.00 \\
\hline 1.80 & 105.87 & 75.00 & 64.29 & 60.00 & 51.43 \\
\hline 1.85 & 108.82 & 77.08 & 66.07 & 61.67 & 52.86 \\
\hline 1.90 & 111.75 & 79.17 & 67.86 & 63.33 & 54.28 \\
\hline 1.95 & 114.70 & 81.25 & 69.64 & 65.00 & 55.71 \\
\hline 2.00 & 117.64 & 83.33 & 71.43 & 66.67 & 57.14 \\
\hline 2.05 & 120.58 & 85.42 & 73.21 & 68.33 & 58.57 \\
\hline 2.10 & 123.52 & 87.50 & 75.00 & 70.00 & 60.00 \\
\hline 2.15 & 126.46 & 89.58 & 76.79 & 71.67 & 61.43 \\
\hline 2.20 & 129.40 & 91.67 & 78.57 & 73.33 & 62.86 \\
\hline 2.25 & 132.34 & 93.75 & 80.36 & 75.00 & 64.28 \\
\hline 2.30 & 135.28 & 95.83 & 82.14 & 76.67 & 65.71 \\
\hline 2.35 & 138.23 & 97.92 & 83.93 & 78.33 & 67.14 \\
\hline 2.40 & 141.16 & 100.00 & 85.71 & 80.00 & 68.57 \\
\hline 2.45 & 144.10 & 102.08 & 87.50 & 81.67 & 70.00 \\
\hline 2.50 & 147.05 & 104.17 & 89.29 & 83.33 & 71.42 \\
\hline \multicolumn{6}{|c|}{ Table de calcul du coût en augmentation de moins de 5 cents } \\
\hline .01 & .58 & .42 & .36 & .33 & .28 \\
\hline .02 & 1.17 & .83 & .71 & .67 & .57 \\
\hline .03 & 1.76 & 1.25 & 1.07 & 1.00 & .86 \\
\hline .04 & 2.35 & 1.67 & 1.43 & 1.33 & 1.14 \\
\hline .05 & 2.94 & 2.08 & 1.79 & 1.67 & 1.43 \\
\hline
\end{tabular}

* Volume équivalent à un boisseau de maïs grain à $15 \%$ d'humidité. 
Tableau A 5. Poids étalon au boisseau de certains aliments du bétail et nombre de boisseaux de ceux-ci à la tonne

\begin{tabular}{|c|c|c|c|}
\hline & & $\begin{array}{c}\text { Poids au } \\
\text { boisseau } \\
\text { (lb) }\end{array}$ & $\begin{array}{l}\text { Boisseaux } \\
\text { à la tonne }\end{array}$ \\
\hline Orge (grains entiers) & & 48 & 41.67 \\
\hline Haricots (secs) & & 60 & 33.33 \\
\hline Betteraves ......... & & 60 & 33.33 \\
\hline Son $\ldots \ldots \ldots . . .$. & & 20 & 100.00 \\
\hline Sarrasin & & 48 & 41.67 \\
\hline Carottes & ....... & 50 & 40.00 \\
\hline Maïs-grain & & 56 & 35.71 \\
\hline Maīs en épi & . & 70 & 28.57 \\
\hline Semoule de maîs & ............. & 50 & 40.00 \\
\hline Graine de lin & . & 56 & 35.71 \\
\hline Millet-grain & .................. & 50 & 40.00 \\
\hline Avoine $\ldots \ldots .$. & ............ & 34 & 58.82 \\
\hline 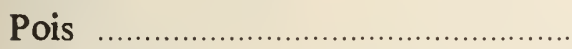 & 年 & 60 & 33.33 \\
\hline Pois chiche .......... & & 56 & 35.71 \\
\hline Pommes de terre & & 60 & 33.33 \\
\hline Rutabagas $\ldots \ldots \ldots \ldots$ & & 56 & 35.71 \\
\hline Seigle $\quad \ldots . . .$. & & 56 & 35.71 \\
\hline Blé .... & & 60 & 33.33 \\
\hline Sel, baril & $280 \mathrm{lb}$ & - & - \\
\hline Mélasse, tonneau de 52 gallons & environ $624 \mathrm{lb}$ & - & - \\
\hline Mélasse, gallon & environ $12 \mathrm{lb}$ & - & - \\
\hline
\end{tabular}

Tableau A 6. Poids moyen de certains aliments du bétail

\begin{tabular}{|c|c|c|}
\hline & $\begin{array}{c}\text { Poids la } \\
\text { pinte } \\
\text { (lb) }\end{array}$ & $\begin{array}{c}\text { Volume } \\
\text { la livre } \\
\text { (pinte) }\end{array}$ \\
\hline Maïs, grains entiers & 2.0 & 0.5 \\
\hline Semoule de maïs ... & 1.8 & 0.6 \\
\hline Maĩs en épi ........... & 1.7 & 0.6 \\
\hline Fin gluten de maîs & 2.0 & 0.5 \\
\hline Gros gluten de maîs & 1.6 & 0.7 \\
\hline Blé, grains entiers ..... & 2.3 & 0.4 \\
\hline Blé broyé ............... & 2.0 & 0.5 \\
\hline Son de blé ................. & 0.6 & 1.7 \\
\hline Gru blanc (courant) & 1.0 & 1.1 \\
\hline Avoine entière & 1.2 & 0.8 \\
\hline Avoine broyée & 0.8 & 1.2 \\
\hline Seigle entiér .... & 2.0 & 0.5 \\
\hline Seigle broyé & 1.8 & 0.6 \\
\hline Son de seigle & 1.0 & 1.1 \\
\hline Fines recoupes de seigle & 1.8 & 0.5 \\
\hline Orge entière & 1.8 & 0.6 \\
\hline Orge broyée & 1.3 & 0.8 \\
\hline Sarrasin ........ & 1.7 & 0.6 \\
\hline Fèves de soja ..... & 2.2 & 0.5 \\
\hline Farine de luzerne & 0.7 & 1.4 \\
\hline Mélasse ....... & 3.6 & 0.3 \\
\hline Farine de tourteau de lin (expeller ou pression) & 1.3 & 0.8 \\
\hline Farine de tourteau de lin (solvant) & 1.1 & 0.9 \\
\hline Farine de tourteau de coton .......... & 1.8 & 0.6 \\
\hline Farine de tourteau de soja (solvant) & 1.6 & 0.7 \\
\hline
\end{tabular}


Table de la capacité estimative des silos de ferme, en tonnes d'ensilage de toutes espèces ordinaires 1

\begin{tabular}{ccccccr}
\hline $\begin{array}{c}\text { Hauteur } \\
\text { en pieds }\end{array}$ & $\mathbf{1 4}$ & $\mathbf{1 6}$ & $\mathbf{1 8}$ & $\mathbf{2 0}$ & $\mathbf{2 4}$ & $\mathbf{3 0}$ \\
\hline 20 & 54 & 70 & 89 & 110 & 158 & 248 \\
25 & 73 & 96 & 121 & 150 & 216 & 337 \\
30 & 96 & 125 & 158 & 195 & 280 & 440 \\
35 & 119 & 156 & 197 & 244 & 350 & 550 \\
40 & 145 & 189 & 239 & 295 & 423 & 663 \\
45 & 171 & 224 & 283 & 350 & 503 & 788 \\
50 & 200 & 261 & 330 & 407 & 583 & 913 \\
55 & 230 & 301 & 380 & 468 & 673 & 1,060 \\
60 & 260 & 341 & 430 & 529 & 760 & 1,190 \\
\hline
\end{tabular}

$1 \mathrm{Ne}$ comprend pas l'ensilage de foin mi-fané.

TABleaU A 8. Capacité requise pour le stockage des aliments du bétail

Maïs en épi

Céréales secondaires

Foin long

Foin haché

Foin pressé

Paille pressée

Paille en vrac

Ensilage de maïs

Ensilage de foin

Ensilage de foin mi-fané
$21 / 2$ pieds cubes par boisseau

$11 / 4$ pieds cubes par boisseau

500 pieds cubes par tonne 250-375 pieds cubes par tonne 100-250 pieds cubes par tonne 250-300 pieds cubes par tonne 1,000 pieds cubes par tonne 40-55 pieds cubes par tonne 35-50 pieds cubes par tonne 50-70 pieds cubes par tonne 


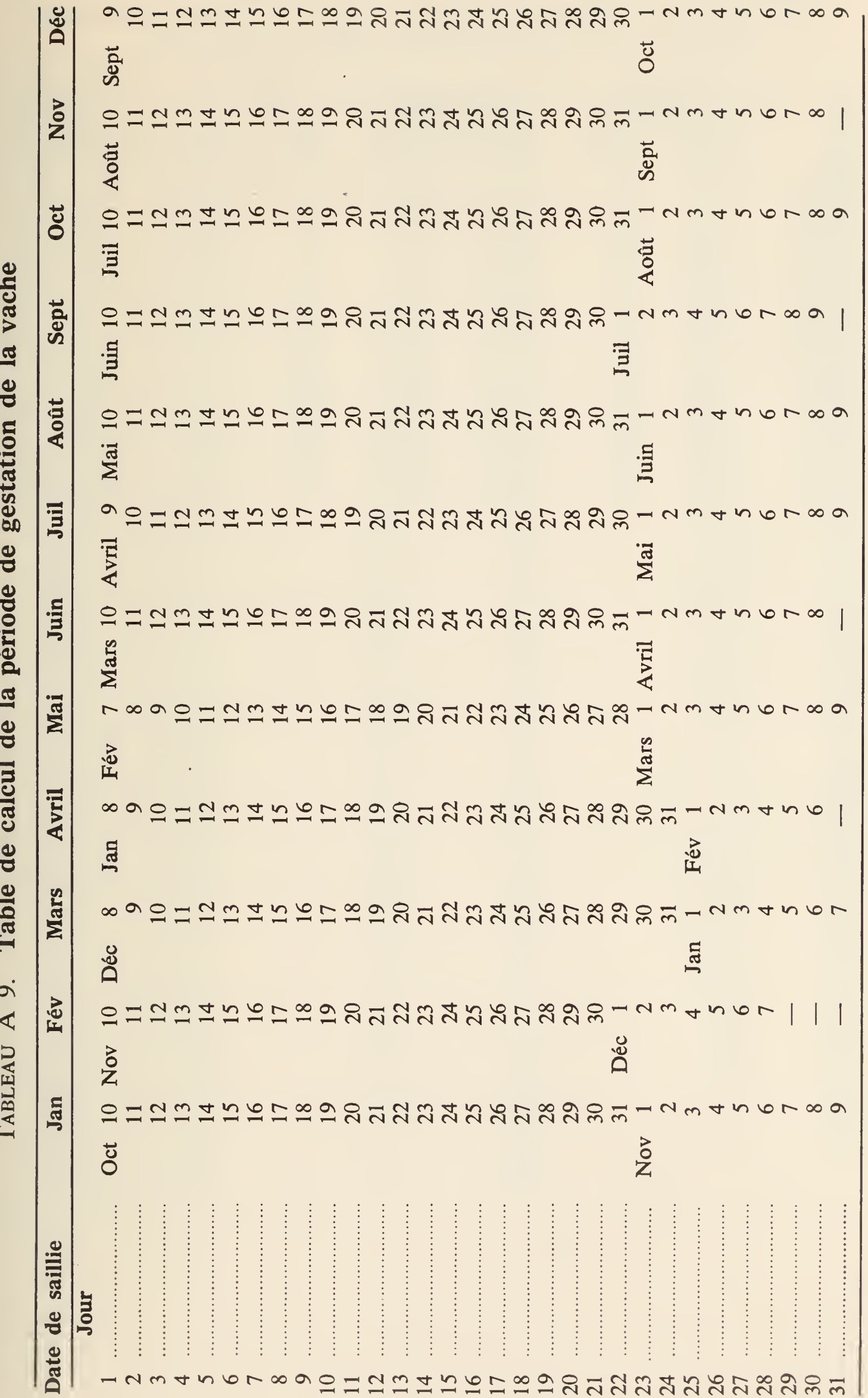


TABleau A 10. Croissance normale des bovins laitiers (femelles) en poids et en hauteur

\begin{tabular}{|c|c|c|c|c|c|c|c|c|}
\hline \multirow[b]{2}{*}{ Age } & \multicolumn{2}{|c|}{ Ayrshire } & \multicolumn{2}{|c|}{ Guernsey } & \multicolumn{2}{|c|}{ Holstein } & \multicolumn{2}{|c|}{ Jersey } \\
\hline & $\begin{array}{l}\text { Poids } \\
\text { (lb) }\end{array}$ & $\begin{array}{c}\text { Hauteur } \\
\text { (po) }\end{array}$ & $\begin{array}{l}\text { Poids } \\
\text { (lb) }\end{array}$ & $\begin{array}{l}\text { Hauteur } \\
\text { (po) }\end{array}$ & $\begin{array}{l}\text { Poids } \\
\text { (lb) }\end{array}$ & $\begin{array}{c}\text { Hauteur } \\
\text { (po) }\end{array}$ & $\begin{array}{c}\text { Poids } \\
\text { (lb) }\end{array}$ & $\begin{array}{c}\text { Hauteur } \\
\text { (po) }\end{array}$ \\
\hline 1 mois & 89 & 28.6 & 77 & 28.2 & 112 & 30.6 & 67 & 27.0 \\
\hline 2 mois & 119 & 30.2 & 102 & 29.8 & 148 & 32.3 & 90 & 28.9 \\
\hline 4 mois & 198 & 34.0 & 173 & 33.5 & 243 & 36.2 & 158 & 32.6 \\
\hline 6 mois & 293 & 37.2 & 260 & 36.9 & 355 & 39.7 & 243 & 36.2 \\
\hline 8 mois & 389 & 39.9 & 350 & 39.9 & 462 & 42.3 & 324 & 39.0 \\
\hline 10 mois & 469 & 41.7 & 427 & 41.7 & 552 & 44.4 & 393 & 40.9 \\
\hline 12 mois & 538 & 43.2 & 490 & 43.3 & 632 & 46.0 & 450 & 42.2 \\
\hline 18 mois & 725 & 46.5 & 663 & 46.4 & 845 & 49.3 & 601 & 45.2 \\
\hline 24 mois & 902 & 48.3 & 818 & 48.0 & 1,069 & 51.7 & 733 & 46.9 \\
\hline 3 ans & 968 & 48.7 & 901 & 49.9 & 1,165 & 53.0 & 855 & 48.2 \\
\hline 4 ans & 1,035 & 50.2 & 990 & 50.4 & 1,232 & 53.3 & 897 & 48.5 \\
\hline 5 ans & 1,080 & 50.4 & 1,055 & 50.6 & 1,330 & 53.6 & 937 & 49.0 \\
\hline 6 ans & 1,132 & 49.1 & 1,093 & 49.7 & 1,317 & 53.7 & 973 & 48.4 \\
\hline
\end{tabular}


Tableau A 11. Poids estimatif des bovins d'après le périmètre de la poitrine au niveau du coeur

\begin{tabular}{|c|c|c|c|c|c|}
\hline $\begin{array}{l}\text { Périmètre } \\
\text { de la poitrine } \\
\text { (po) }\end{array}$ & $\begin{array}{l}\text { Poids } \\
\text { (lb) }\end{array}$ & $\begin{array}{l}\text { Périmètre } \\
\text { de la poitrine } \\
\text { (po) }\end{array}$ & $\begin{array}{c}\text { Poids } \\
\text { (lb) }\end{array}$ & $\begin{array}{l}\text { Périmètre } \\
\text { de la poitrine } \\
\text { (po) }\end{array}$ & $\begin{array}{l}\text { Poids } \\
\text { (lb) }\end{array}$ \\
\hline 30.0 & 100 & 51.0 & 414 & 72.0 & 1,064 \\
\hline 30.5 & 103 & 51.5 & 424 & 72.5 & 1,085 \\
\hline 31.0 & 107 & 52.0 & 434 & 73.0 & 1,104 \\
\hline 31.5 & 112 & 52.5 & 445 & 73.5 & 1,126 \\
\hline 32.0 & 117 & 53.0 & 456 & 74.0 & 1,146 \\
\hline 32.5 & 121 & 53.5 & 467 & 74.5 & 1,169 \\
\hline 33.0 & 127 & 54.0 & 476 & 75.0 & 1,191 \\
\hline 33.5 & 131 & 54.5 & 495 & 75.5 & 1,213 \\
\hline 34.0 & 137 & 55.0 & 510 & 76.0 & 1,236 \\
\hline 34.5 & 141 & 55.5 & 521 & 76.5 & 1,263 \\
\hline 35.0 & 146 & 56.0 & 534 & 77.0 & 1,285 \\
\hline 35.5 & 152 & 56.5 & 545 & 77.5 & 1,308 \\
\hline 36.0 & 157 & 57.0 & 562 & 78.0 & 1,331 \\
\hline 36.5 & 162 & 57.5 & 577 & 78.5 & 1,354 \\
\hline 37.0 & 167 & 58.0 & 590 & 79.0 & 1,377 \\
\hline 37.5 & 173 & 58.5 & 605 & 79.5 & 1,400 \\
\hline 38.0 & 179 & 59.0 & 616 & -80.0 & 1,423 \\
\hline 38.5 & 186 & 59.5 & 629 & 80.5 & 1,446 \\
\hline 39.0 & 193 & 60.0 & 647 & 81.0 & 1,469 \\
\hline 39.5 & 199 & 60.5 & 668 & 81.5 & 1,492 \\
\hline 40.0 & 206 & 61.0 & 684 & 82.0 & 1,515 \\
\hline 40.5 & 214 & 61.5 & 700 & 82.5 & 1,538 \\
\hline 41.0 & 223 & 62.0 & 716 & 83.0 & 1,561 \\
\hline 41.5 & 229 & 62.5 & 732 & 83.5 & 1,584 \\
\hline 42.0 & 239 & 63.0 & 748 & 84.0 & 1,607 \\
\hline 42.5 & 247 & 63.5 & 762 & 84.5 & 1,629 \\
\hline 43.0 & 255 & 64.0 & 778 & 85.0 & 1,650 \\
\hline 43.5 & 270 & 64.5 & 790 & 85.5 & 1,673 \\
\hline 44.0 & 283 & 65.0 & 815 & 86.0 & 1,692 \\
\hline 44.5 & 293 & 65.5 & 828 & 86.5 & 1,718 \\
\hline 45.0 & 298 & 66.0 & 848 & 87.0 & 1,741 \\
\hline 45.5 & 307 & 66.5 & 866 & 87.5 & 1,764 \\
\hline 46.0 & 315 & 67.0 & 883 & 88.0 & 1,788 \\
\hline 46.5 & 323 & 67.5 & 891 & 88.5 & 1,812 \\
\hline 47.0 & 334 & 68.0 & 904 & 89.0 & 1,833 \\
\hline 47.5 & 344 & 68.5 & 923 & 89.5 & 1,857 \\
\hline 48.0 & 354 & 69.0 & 942 & 90.0 & 1,831 \\
\hline 48.5 & 364 & 69.5 & 962 & 90.5 & 1,905 \\
\hline 49.0 & 374 & 70.0 & 982 & 91.0 & 1,929 \\
\hline 49.5 & 384 & 70.5 & 1,002 & 91.5 & 1,952 \\
\hline 50.0 & 394 & 71.0 & 1,022 & 92.0 & 1,975 \\
\hline 50.5 & 404 & 71.5 & 1,043 & & \\
\hline
\end{tabular}




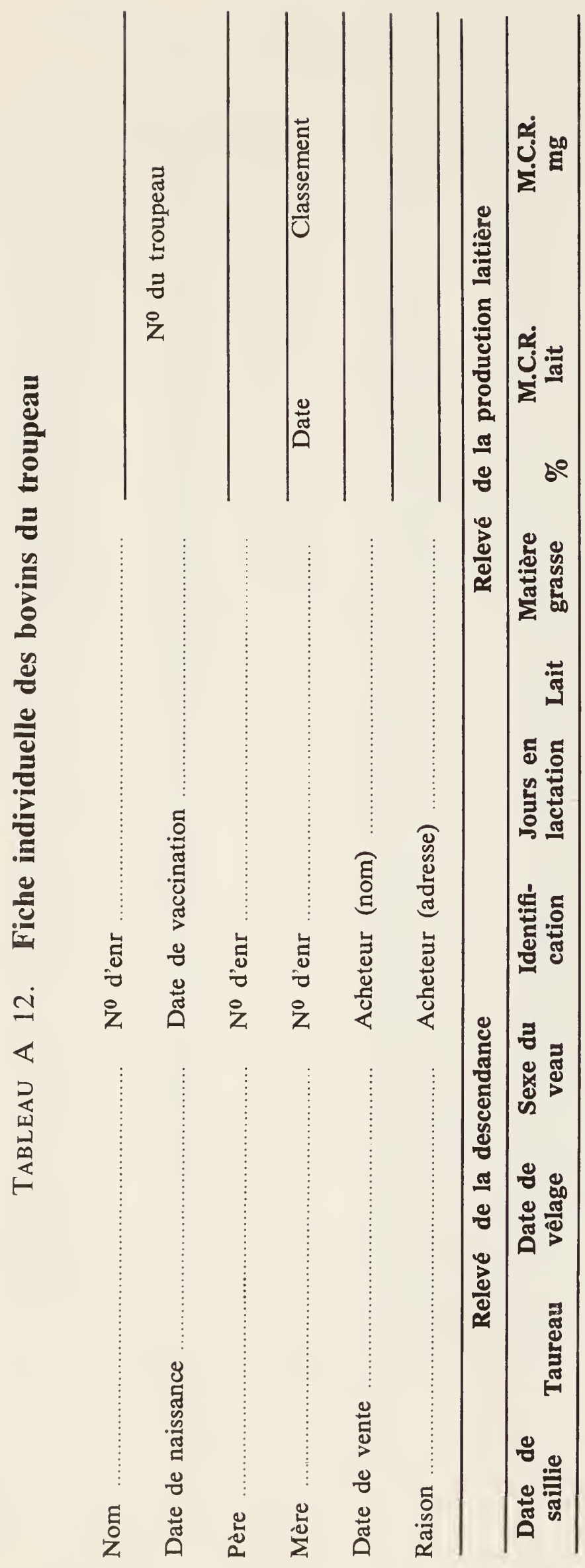




\section{TABleau A 13. Méthode d'estimation de la valeur génétique des vaches, compte tenu de chacun de ses relevés}

La valeur génétique offre le moyen le plus exact de comparer les vaches qui ont un nombre variable de relevés. La méthode sert à comparer le rendement laitier des vaches.

\section{Méthode}

1. Etablir pour chaque vache un tableau indiquant l'année de chaque vêlage, le chiffre de la M.C.R. pour le lait, au regard du chiffre de la M.C.R. du troupeau, également pour le lait, pour l'année en cause. (Voir le tableau A13a.)

2. Soustraire le chiffre de la M.C.R. (lait) du troupeau, du chiffre de la M.C.R. (lait) de la vache, pour établir l'écart en plus ou en moins entre chaque relevé de la vache en cause et la M.C.R. (lait) du troupeau.

3. Etablir l'écart moyen de chaque vache (soit pour chaque vache, la somme des écarts divisée par le nombre d'écarts ou de, relevés de la vache en cause).

4. Multiplier l'écart moyen par le facteur approprié, compte tenu du nombre de relevés de chaque vache (voir le tableau A13b). Exemple:-En se référant au tableau A13a, la vache $n^{\circ} 1$ a quatre relevés. Dans son cas, le facteur approprié est .40. En multipliant l'écart moyen -5 de la M.C.R. par le facteur .40 , la valeur génétique de la vache $n^{\circ} 1$ s'établit à -2 . A noter que le facteur s'accroît avec le nombre de relevés. La raison de l'accroissement est que pour estimer la valeur génétique d'une vache, cinq relevés sont plus fiables que deux.

Le principal avantage des données sur la valeur génétique des vache réside dans le fait que l'on peut comparer correctement à cet égard des vaches dont le nombre de relevés et l'âge diffèrent. En vue du rendement laitier on sélectionne les vaches dont l'écart positif est le plus élevé et on réforme celles dont l'écart négatif est aussi le plus grand.

\section{TABLEAU A 13a. Estimation de la valeur génétique d'une vache}

\begin{tabular}{lccccc}
\hline $\begin{array}{l}\text { Vache } \\
\text { No }\end{array}$ & $\begin{array}{c}\text { Année } \\
\text { de vêlage }\end{array}$ & $\begin{array}{c}\text { M.C.R. } \\
\text { lait }\end{array}$ & $\begin{array}{c}\text { Ecart de la } \\
\text { moyenne du } \\
\text { troupeau } \\
\text { (M.C.R.) }\end{array}$ & $\begin{array}{c}\text { Ecart } \\
\text { moyen }\end{array}$ & $\begin{array}{c}\text { Valeur } \\
\text { génétique } \\
\text { (M.C.R.) }\end{array}$ \\
\hline 1 & 1959 & 133 & +1 & & \\
& 1961 & 118 & -14 & & -2 \\
\hline 2 & 1962 & 139 & -1 & -25 & +7.9 \\
\hline 3 & 1963 & 159 & -6 & -25 & -8.7 \\
\hline 9 & 1960 & 157 & +25 & +25 & +7 \\
\hline
\end{tabular}


Tableau A $13 b$.

\section{Nombre de relevés \\ établissant l'écart}

moyen

\begin{tabular}{ll}
\hline 1 & .25 \\
2 & .33 \\
3 & .375 \\
4 & .40 \\
5 & .42 \\
6 ou plus & .43 \\
\hline
\end{tabular}

\section{FACTEURS DE CONVERSION VERS LE SYSTĖME MÉTRIQUE}

Unités ımpériales

MESURES DELONGUEUR

pouce

pred

verge

mille

MESURES DE SURFACE pouce carré

pied carré

acre

MESURES DE VOLUME

pouce cube

pied cube

verge cube

once liquide

chopıne

pinte

gallon

boisseau

MESURES DE POIDS

once

livre

tonne courte $(2000 \mathrm{lb})$

Facteur de

conversion

$\times 25$

$\times 30$

$\times 0.9$

$\times 1.6$

$\times 6.5$

$\times 0.09$

$\times 0,40$

$\times 16$

$\times 28$

$\times 0.8$

$\times 28$

$\times 0.57$

$\times 1,1$

$\times 4,5$

$\times 0.36$

$\times 28$

$\times 0.45$

$\times 0.9$

MESURE DE TEMPÉRATURE degré Fahrenhelt

$\mathrm{F}-32 \times 0.56$

(ou ${ }^{\circ} \mathrm{F}-32 \times 5 / 9$ ) degré Celsius $\left({ }^{\circ} \mathrm{C}\right.$ )

MESURE DE PRESSION

livre au pouce carré

$\times 6,9$

MESURE DE PUISSANCE

horsepower

$\times 746$

$\times 0.75$

MESURES DE VITESSE

pied à la seconde

mille à l'heure

MESURES AGRAIRESE

boısseau à l'acre

gallon à l'acre

pınte à l'acre

chopıne à l'acre

once liquide à l'acre

tonne à l'acre

lıvre à l'acre

once à l'acre

plants à l acre $\times 0.30$

$\times 1.6$

$\times 0.90$

$\times 11,23$

$\times 2.8$

$\times 1,4$

$\times 70$

$\times 2,24$

$\times 1,12$

$\times 70$

$\times 2,47$
Résultat en

millimètre $(\mathrm{mm})$

centimètre $(\mathrm{cm})$

mètre (m)

kilomètre $(\mathrm{km})$

centimètre carré $\left(\mathrm{cm}^{2}\right)$

mètre carré $\left(\mathrm{m}^{2}\right)$

hectare (ha)

centimètre cube $\left(\mathrm{cm}^{3}\right)$

décimètre cube $\left(\mathrm{dm}^{3}\right)$

mètre cube $\left(\mathrm{m}^{3}\right)$

millilitre $(\mathrm{m} \ell)$

litre (l)

litre $(\ell)$

litre (k)

hectolitre (hi)

gramme (g)

kilogramme (kg)

tonne $(t)$

kilopascal (kPa)

watt (W)

kilowatt (kW)

mètre à la scconde $(\mathrm{m} / \mathrm{s})$

kilomètre à l'heure $(\mathrm{km} / \mathrm{h})$

hectolitre à l'hectare (h $\ell /$ ha)

litre à l'hectare ( $\ell / h a)$

litre à l'hectare ( $i / h a)$

litre à l'hectare ( $k / h a)$

millilitre à l'hectare $(\mathrm{m} \ell / \mathrm{ha}$

tonne à l'hectare (t/ha)

kilogramme à l'hectare (kg/ha)

gramme à l'hectare (g/ha)

plants à l'hectare (plants/ha)

Exemples 2 milles $\times 1,6=32 \mathrm{~km}, 15$ bois $/ \mathrm{ac} \times 090=13,5 \mathrm{hf}$ ha

-Le horsepower est une unité différente du cheval-vapeur

Le sıgne décımal est une virgule 
39073001800707

$$
630.4 C 212 \text { P1439 1972fer C.I }
$$

CANADA: MINISTERE AGRICULTURE 'PRODUCTION' LAITIERE AU 
Edifice Sir John Carling Building 930 Carling Avenue

Ottawa, Ontario

K1A OC7

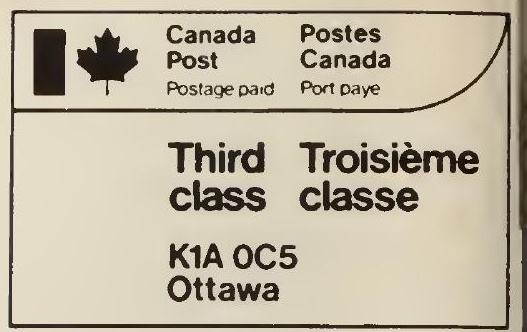

IF UNDELIVERED, RETURN TO SENDER

EN CAS DE NON-LIVRAISON, RETOURNER Ȧ L'EXPÉDITEUR 